\title{
Paradigms on Indigenous Language Revitalisation: The case of te reo Māori in Aotearoa New Zealand and Mapudungun in Chile
}

\author{
by \\ Carina Gallegos
}

\begin{abstract}
A thesis submitted to Victoria University of Wellington
In partial fulfilment of the Master of Development Studies Degree
\end{abstract}

Victoria University of Wellington 2007 
Para, por y gracias a Alfred.

Iñche Poyeyu.

Kei te aroha au i a koe. 


\begin{abstract}
The existence of systems of indigenous knowledge depend greatly on the existence of indigenous languages. Processes of language revitalisation seek to uphold indigenous knowledge by restoring endangered indigenous languages. Historical processes of colonisation and globalisation in Chile and Aotearoa New Zealand have impacted and threatened each country's indigenous language. This dissertation describes language revitalisation processes of te reo Māori in Aotearoa New Zealand and Mapudungun in Chile in order to further understand the implications of language on effectively revitalising indigenous culture and knowledge. The research and analysis presented implements comparative methodology through the use of case studies, direct observations, primary and secondary data sources. In an effort to evaluate and compare outcomes of indigenous language revitalisation schemes of te reo Māori in Aotearoa New Zealand and Mapudungun in Chile, this thesis focuses on case studies in the context of how education programmes in each country approach indigenous language revitalisation.
\end{abstract}




\section{Acknowledgements}

I would like to thank the following people, who have, in one way or another, helped me throughout the process of this research:

Warwick Murray for his supervision and guidance; Peter Adds for his insights and advice; Iosua Esera and his team at Petone Central School for their time, great generosity and assistance; Arturo Hernández and Alejandro Herrera in Temuco, for their time and guidance with fieldwork and interviews; and Joanna Spratt, whose ongoing support and friendship contributed greatly in making this possible.

Above all, I would like to thank Alfred Boyd, the driving force behind my efforts, and María Fernanda Gallegos, my continuous sunshine. There are not enough words in any language to thank you both for your undeviating encouragement and support. You have been the sources of inspiration and motivation behind every step of this process. 


\section{Contents}

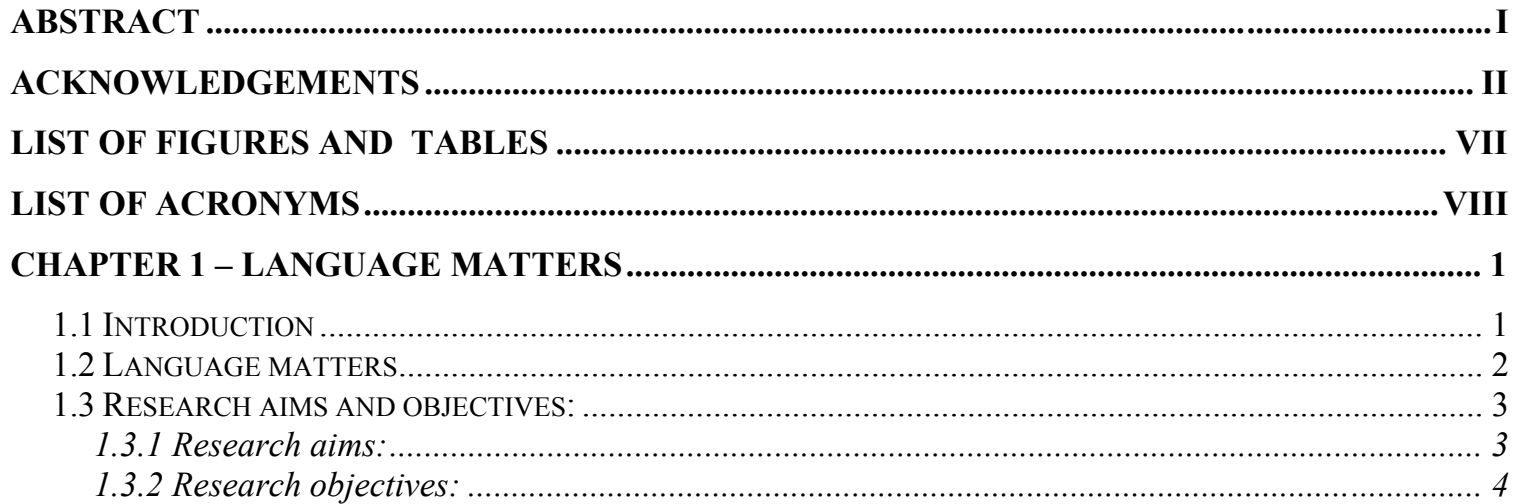

CHAPTER 2 - RESEARCH EPISTEMOLOGY AND METHODOLOGY ........................................... 5

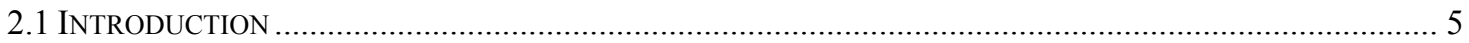

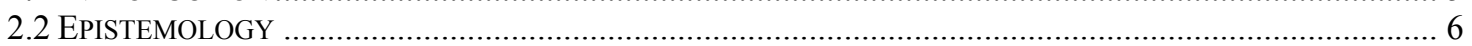

2.3 CHOICE OF SETTING AND PREMISE

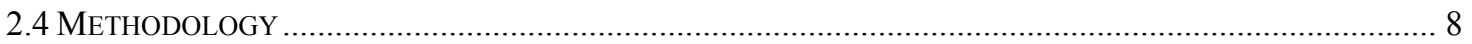

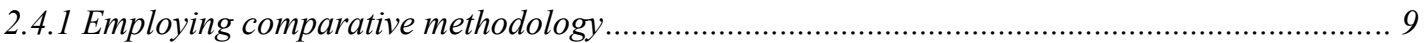

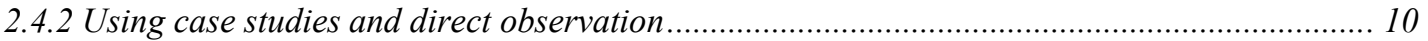

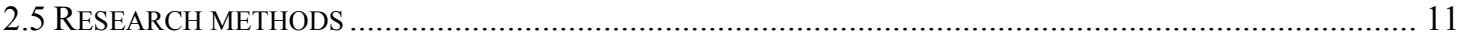

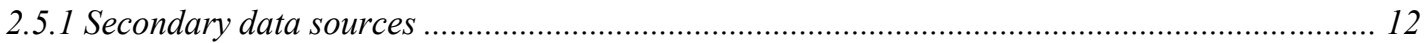

2.5.2 Primary data sources, workshops and case studies ................................................................ 12

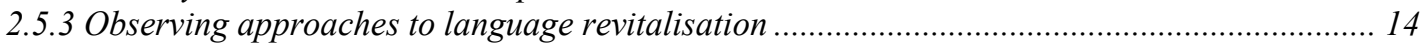

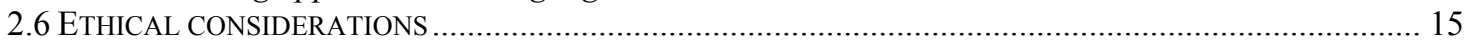

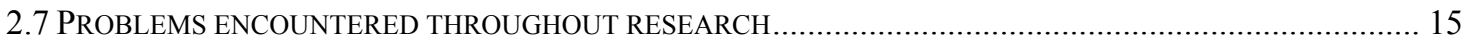

CHAPTER 3 - INDIGENOUS PEOPLES OF THE WORLD.................................................................. 18

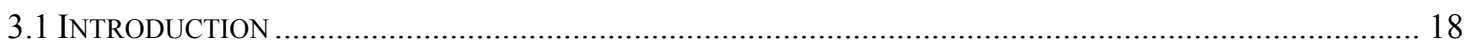

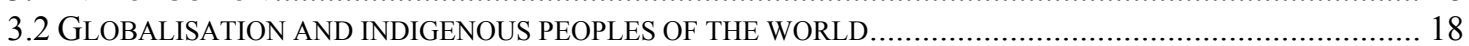

3.3 The United NATIONS' ROLE: UNESCO AND WORKING GROUP OF INDIGENOUS PEOPLES ................ 19

3.4 OMISSION FROM THE UNIVERSAL DECLARATION OF HUMAN RIGHTS ............................................ 19

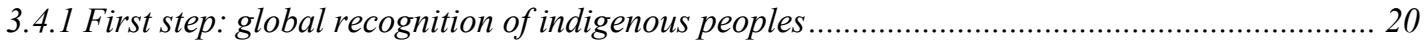

3.4.2 Declaration on the Rights of Indigenous Peoples ................................................................ 21

3.4.3 From singular to plural: Indigenous people and indigenous peoples...................................... 22

3.5 THE MĀORI OF AOTEAROA NEW ZEALAND AND THE MAPUCHE OF CHILE ........................................ 22

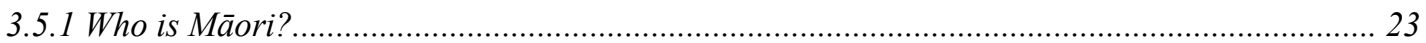

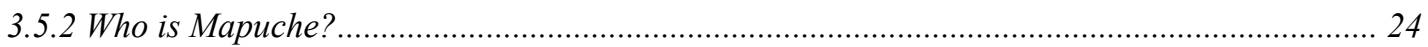

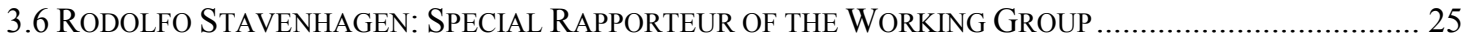

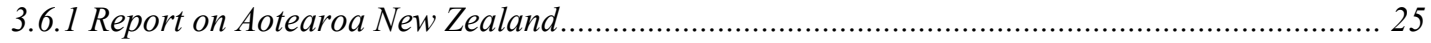

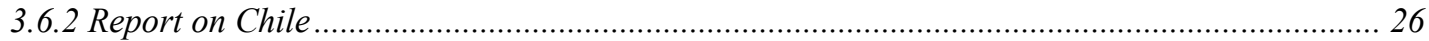

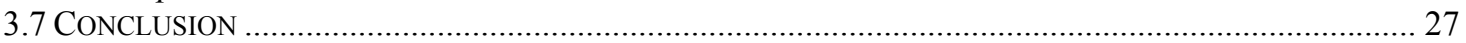

CHAPTER 4 - RELEVANCE OF DEVELOPMENT AND LANGUAGE REVITALISATION....... 28

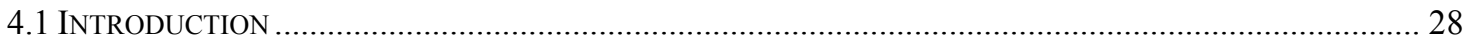

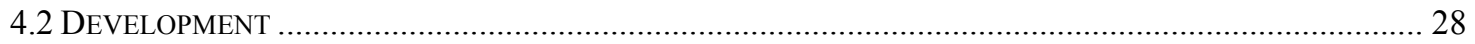

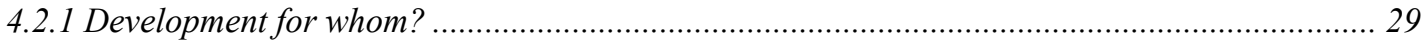

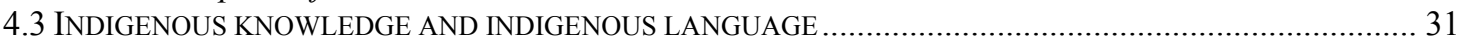

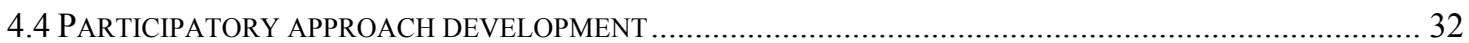

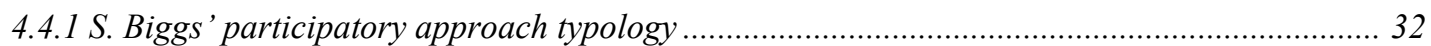

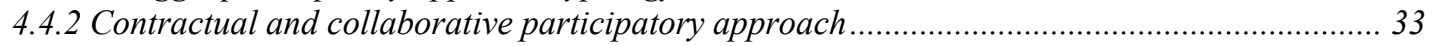

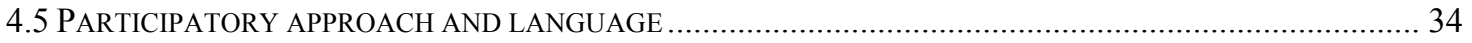

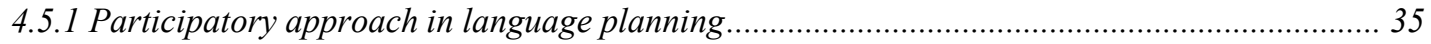

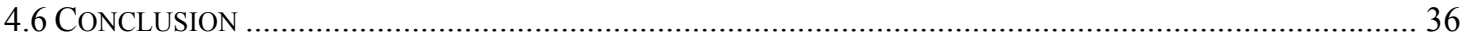


CHAPTER 5 - LANGUAGES' CYCLES OF LIFE AND DEATH .................................................. 37

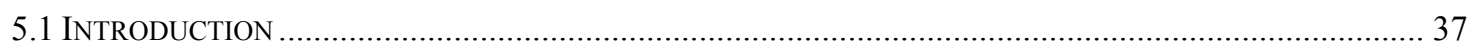

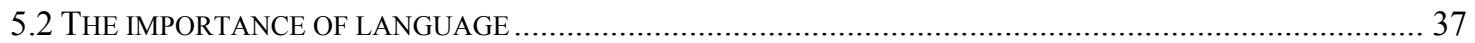

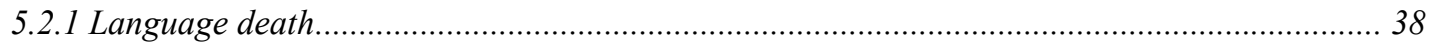

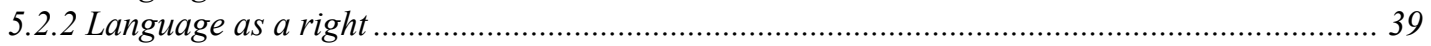

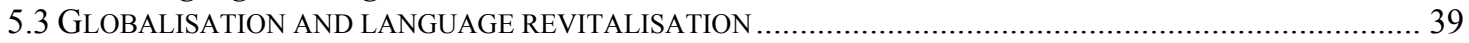

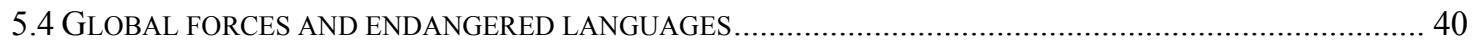

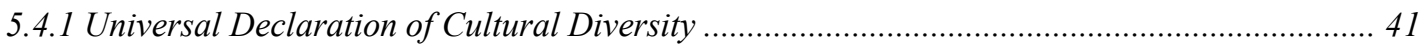

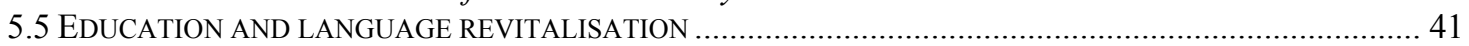

5.5.1 Freire's participatory approach model: the use of language ................................................ 43

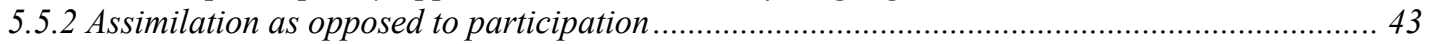

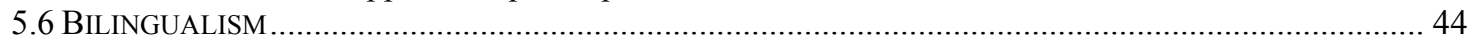

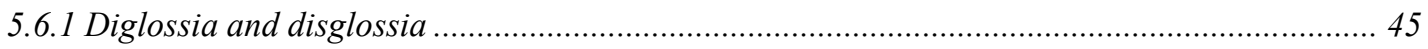

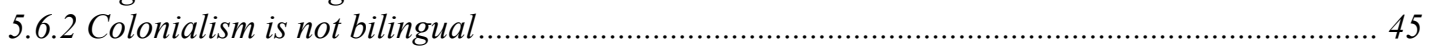

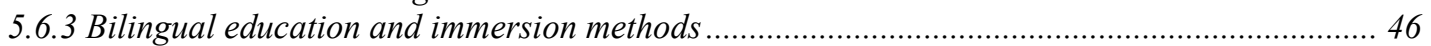

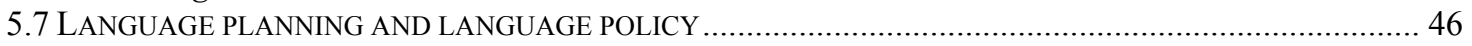

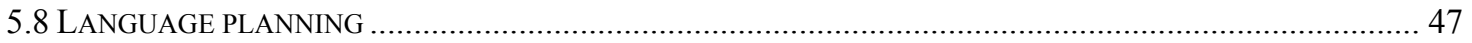

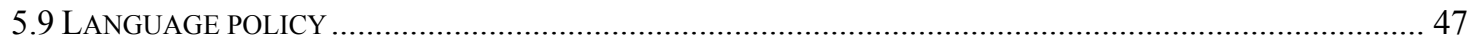

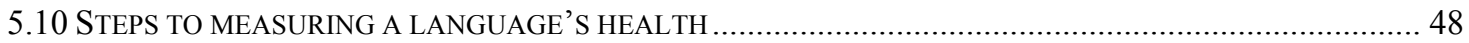

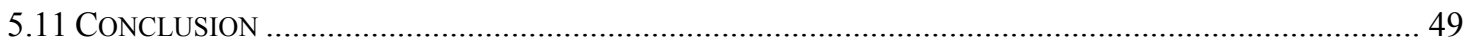

CHAPTER 6 - RIGHT TO TE REO MĀORI WON BY THE PEN.................................................... 51

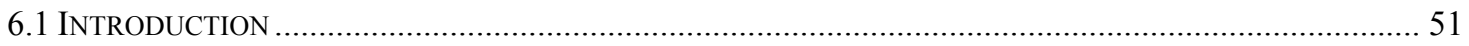

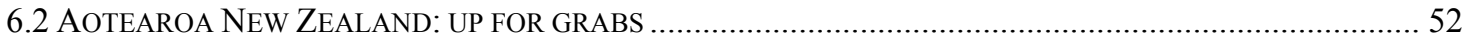

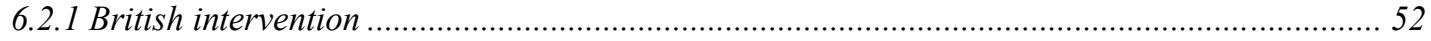

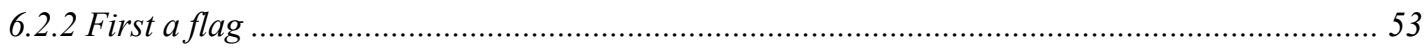

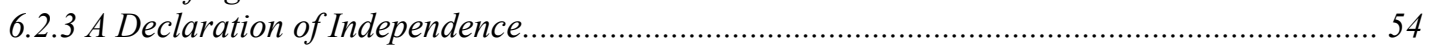

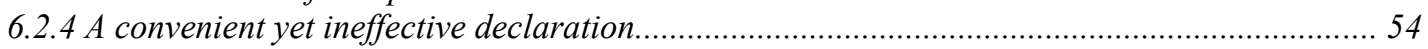

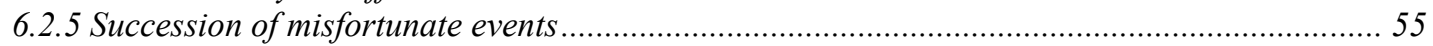

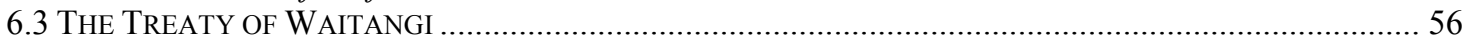

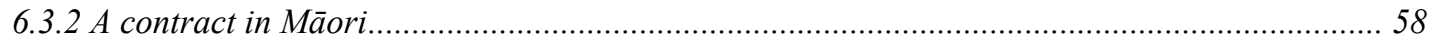

6.4 TE REO MĀORI AND THE TREATY OF WAITANGI: BEFORE AND AFTER …….................................... 58

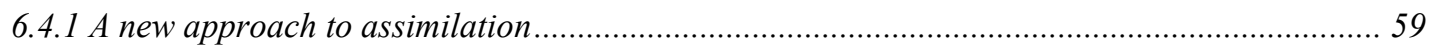

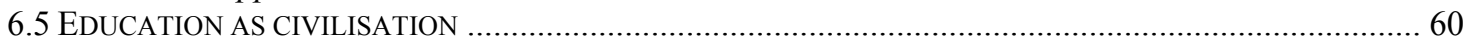

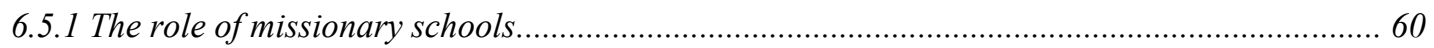

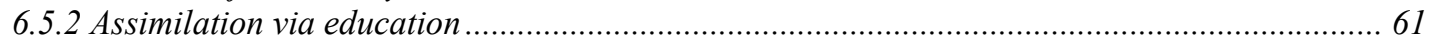

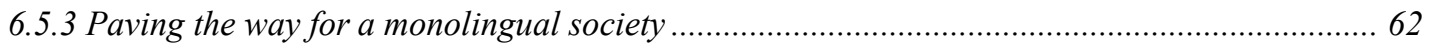

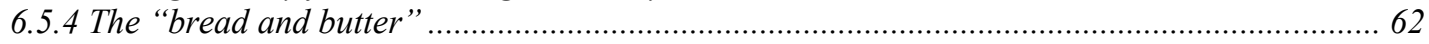

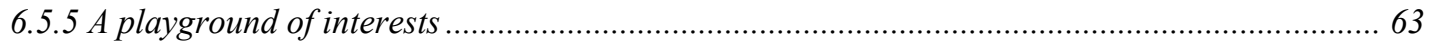

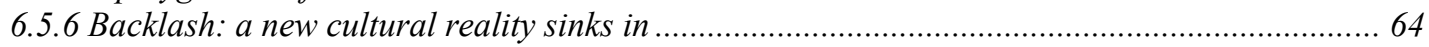

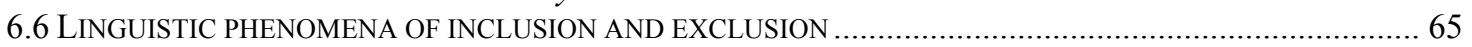

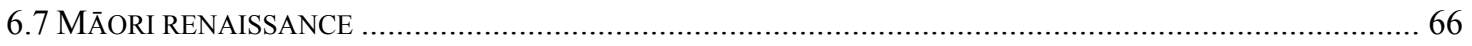

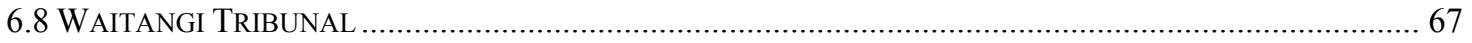

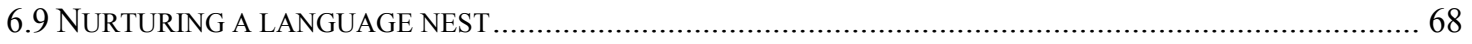

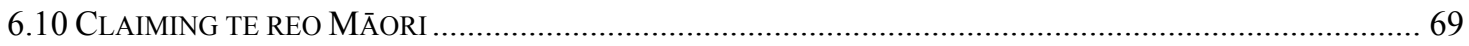

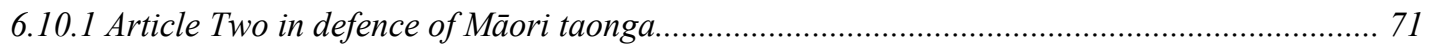

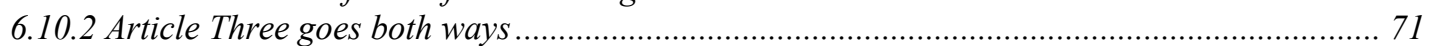

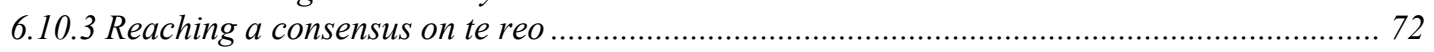

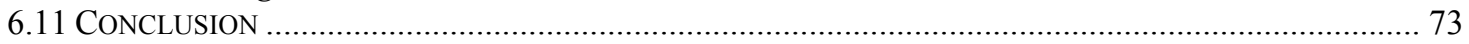

\section{CHAPTER 7 - CASE STUDY: IMMERSION PROGRAMMES AS A TOOL FOR LANGUAGE}

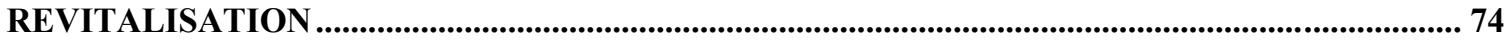

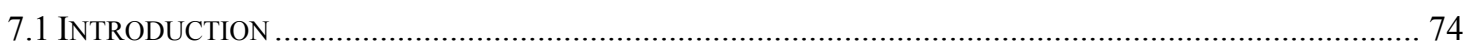

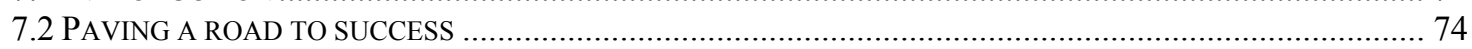

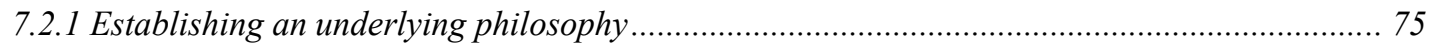

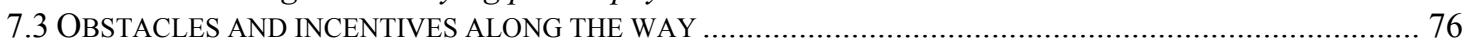

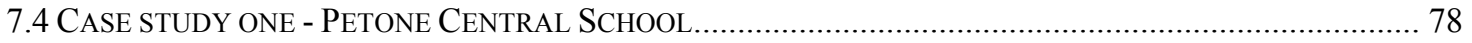




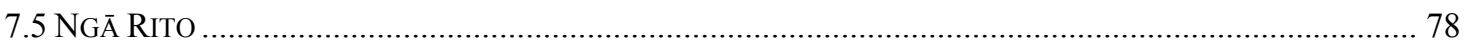

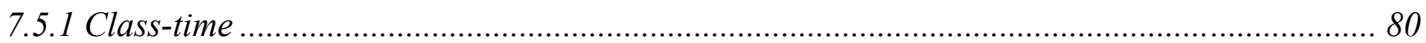

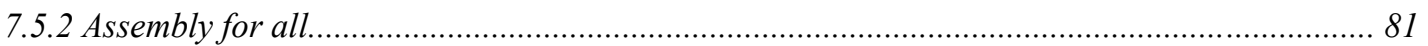

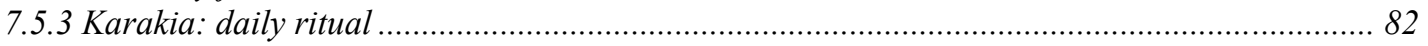

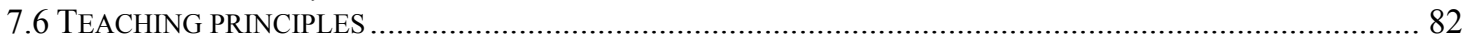

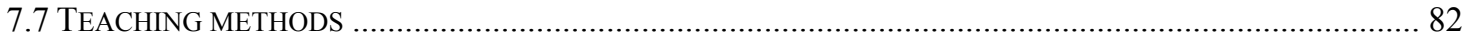

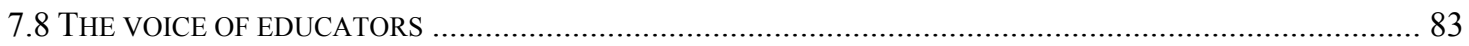

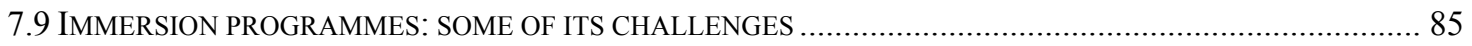

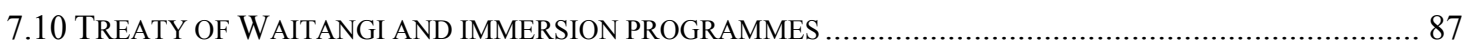

7.11 EQUATION FOR SUCCESS: USE, STATUS, ACQUISITION, AND FUNCTIONALITY OF LANGUAGE.............. 88

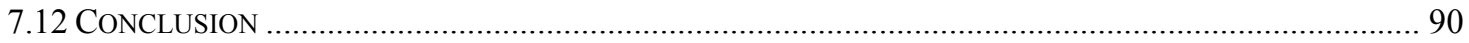

CHAPTER 8 - MAPUCHE: RIGHT TO MAPUDUNGUN WON BY THE SWORD......................... 91

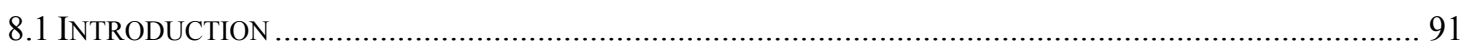

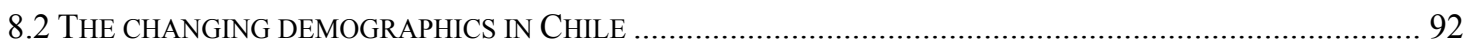

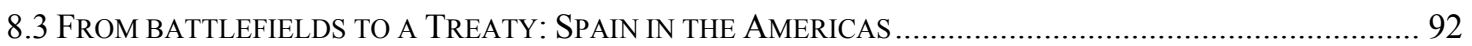

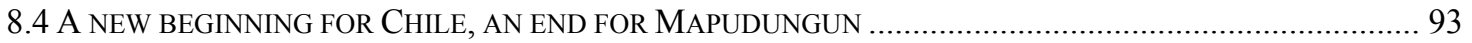

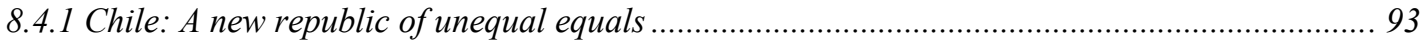

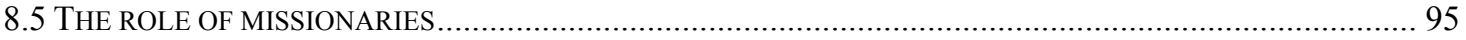

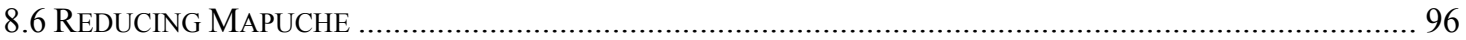

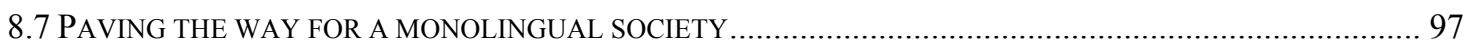

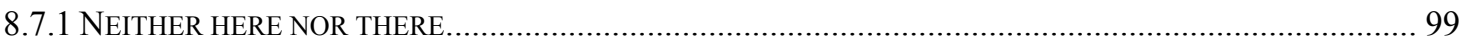

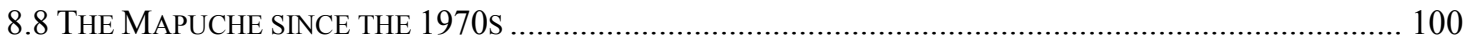

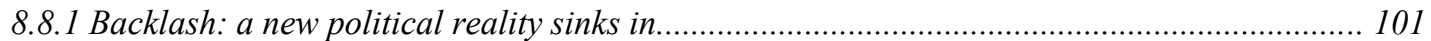

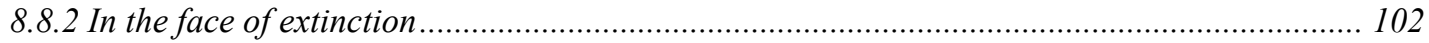

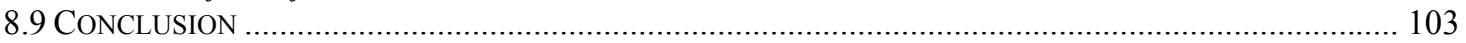

CHAPTER 9 - A NEW BEGINNING, YET A LONG ROAD AHEAD ......................................... 104

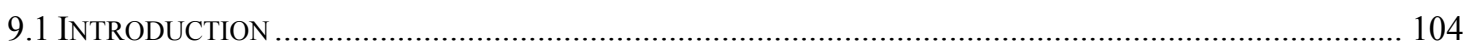

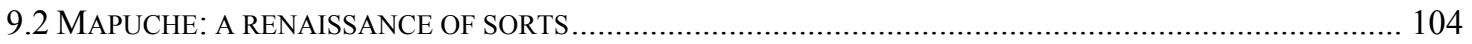

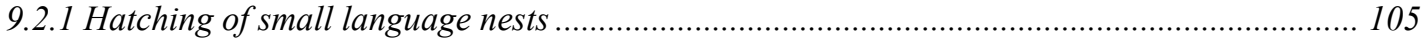

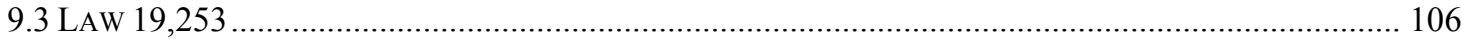

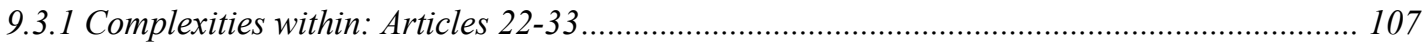

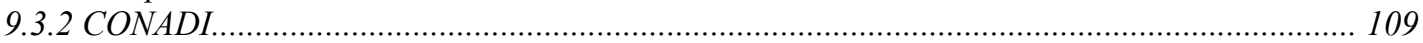

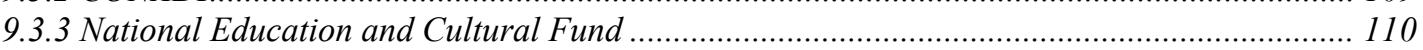

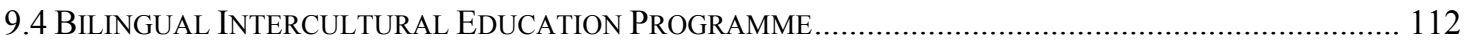

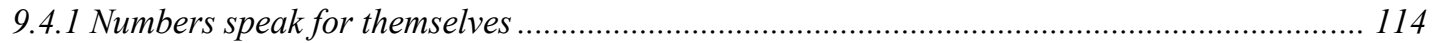

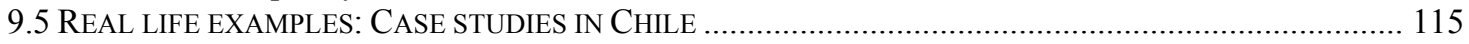

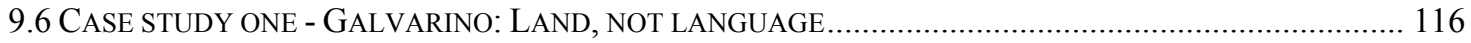

9.7 NURTURING LANGUAGE NESTS: NEW BEGINNINGS AND LESSONS LEARNED .................................... 118

9.7.1 Case study two - Bilingual Intercultural School Trañi-Trañi ............................................ 118

9.7.2 Case study three - Intercultural Technical Secondary School Guacolda............................... 122

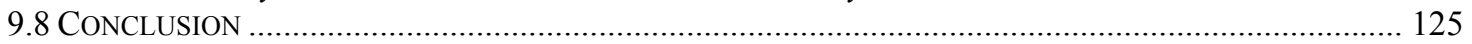

CHAPTER 10 - DRAWING CONCLUSIONS .................................................................................. 126

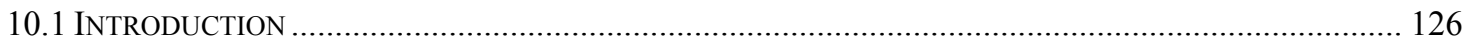

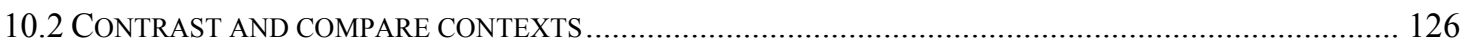

10.3 COMPARING PROCESSES OF COLONIAL LEGACY: NATIONAL MĀORI, TERRITORIAL MAPUCHE .......... 127

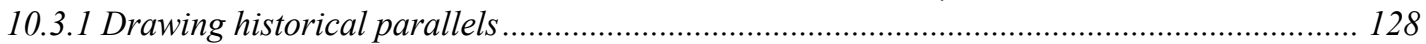

10.3.2 Relations between indigenous and non-indigenous: From settlement to cohesion ................. 129

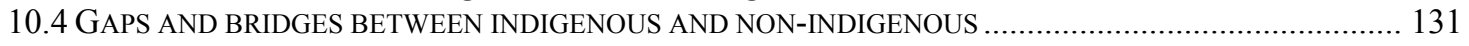

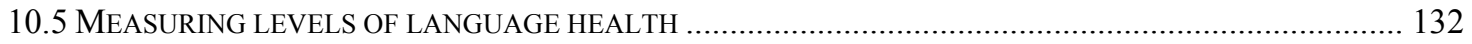

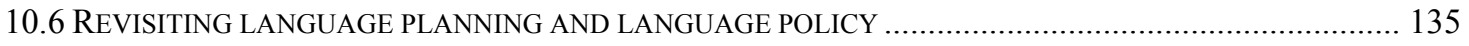

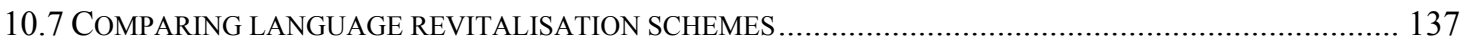

10.7.1 Comparing language revitalisation through education initiatives........................................ 138

10.7.2 Comparing funding schemes for language revitalisation ................................................. 140

10.8 DISPARITIES IN PROCESSES OF INDIGENOUS LANGUAGE PARTICIPATORY APPROACH ...................... 142

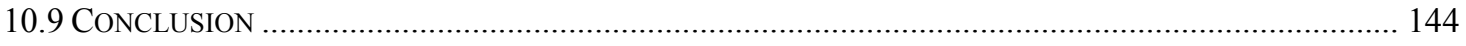




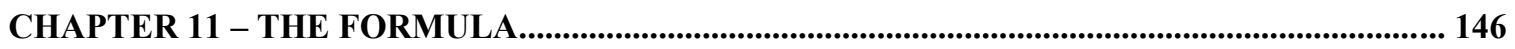

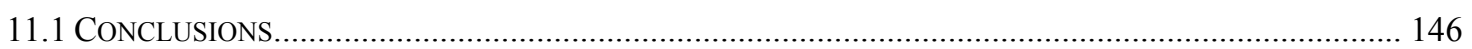

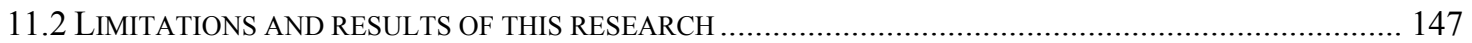

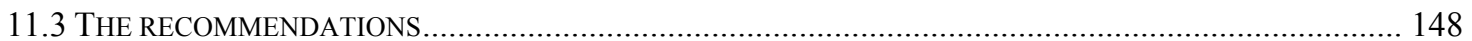

11.4 From LOCAL TO GLOBAL IN AOTEAROA NEW ZEALAND; FROM GLOBAL TO LOCAL IN CHILE ........ 149

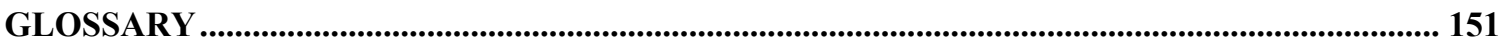

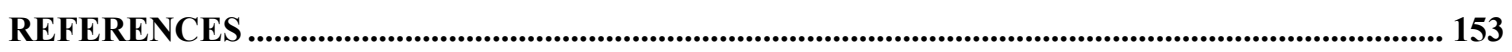

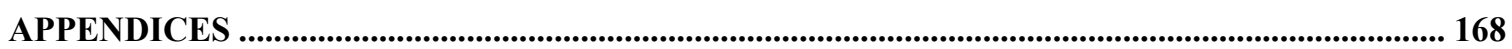

APPENDIX 1- KeY INTERVIEWS IN CHILE AND AOTEAROA NEW ZEALAND .............................................. 169

APPENDIX 2 - LISTING OF CASE STUDIES IN CHILE AND AOTEAROA NEW ZEALAND .............................. 171 APPENDIX 3 - LISTING OF RELEVANT WORKSHOPS, SEMINARS AND CONFERENCES ATTENDED IN CHILE

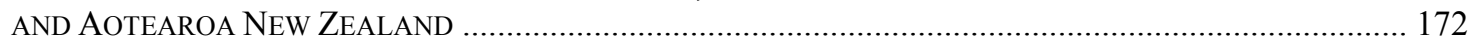




\section{List of Figures and Tables}

Figure 6. 1 Number of funded kura kaupapa Māori (1992 to 2006)................................. 73

Figure 10. 1 Organisational structure for language revitalisation in Aotearoa New

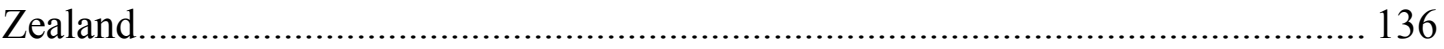

Figure 10. 2 Organisational structure for language revitalisation in Chile..................... 137

Figure 10. 3 Support for Māori Language Revitalisation Initiatives ............................... 140

Table 7. 1 Funding allocated per student according levels of immersion ....................... 77

Table 7. 2 Questions provided to teachers in Petone Central School ............................... 84

Table 10. 1 Human Development Index and GDP per capita of Aotearoa New Zealand

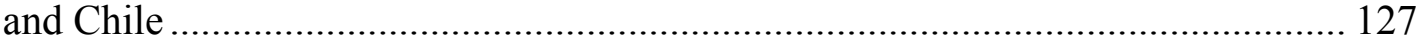

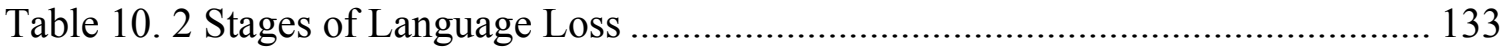




\section{List of acronyms}

CEP

CEPI

CEM

CONADI

ERO

FUNDECAM

FII

MINEDUC

MIDEPLAN

OHCHR

PEIB

RTM

UNESCO

UNHCHR
Centre for Public Studies (Centro de Estúdios Públicos)

Special Commission of Indigenous Peoples (Comisión Especial para los Pueblos Indígenas)

Exterior Mapuche Comittee (Comité Exterior Mapuche)

National Corporation for Indigenous Development (Corporación Nacional de Desarrollo Indígena)

Education Review Office

Foundation for Peasant Development (Fundación de Desarrollo Campesino)

Foundation Indigenous Institute (Fundación Instituto Indígena)

Ministry of Education in Chile (Ministerio de Educación de Chile)

Minister of Planning and Cooperation in Chile (Ministerio de Planificación y Cooperación de Chile)

Office of the United Nations High Commissioner for Human Rights

Bilingual Intercultural Education Programmes (Programa de Educación Intercultural Bilingüe)

Resource Teacher of Māori

United Nations Educational Scientific and Cultural Organisation

United Nations Office of the High Commissioner for Human Rights 


\section{Chapter 1 - Language Matters}

"The sum of human wisdom is not contained in any one language, and no single language is capable of expressing all forms and degrees of human comprehension."

Ezra Pound, 1960

\subsection{Introduction}

Hola. Hello.

As an adult, I instinctively react to either greeting - and feel fortunate I am able to greet people back in either language. Even as a child, I was aware of the advantages and disadvantages of being bilingual: growing up in a Latin American developing countryor in the 'third-world,' a popular misnomer of the eighties and nineties-I realised that opportunities came to those who spoke English, not Spanish. English was a gateway to a better future; Spanish, a limitation which restricted your prospects of a better life. The effort my parents made to ensure and maximise the odds for the professional success and social well-being of their daughters was by providing us with a bilingual education. Hard work was required in order to afford the high cost of attending a bilingual school; it was a privilege for the few. Such hard work has ultimately paid off: being bilingual grants me access to a wealth of knowledge and experiences that I would otherwise not be able to enjoy. And although I hope to be able to offer my children the same opportunity my parents presented me with by learning English, I will undoubtedly and proudly remind them that, regardless of our whereabouts, their mother tongue is Spanish. For there are stories to tell, customs to keep, and values to cherish, that can not be translated but can only be experienced.

Kia ora. Mari mari.

I am unable to respond adequately to either greeting, except with a courteous nod to indicate acknowledgement. The greetings are in te reo Māori and Mapudungun, the indigenous languages of Aotearoa New Zealand's Māori and Chile's Mapuche respectively.

When the Spanish arrived in Chile, and the British arrived in Aotearoa New Zealand, they encountered social systems that functioned and depended on language for the 
transmission of indigenous knowledge from one generation to the next. The wisdom, the stories, the discoveries and findings were-and still are-attached to networks of communication that depend on language. It is within indigenous systems that one can appreciate the power of the human language faculty as a source of knowledge, insight, wisdom and survival (Crystal 2000). Although there are numerous reasons for language death, in the case of indigenous languages, Dorian (1999) asserts that language death is usually a result of a history of political and colonial suppression, social discrimination, and economic deprivation.

The following will use the case studies of te reo Māori and Mapudungun to argue that language is essential to the identity of an individual and to the society to which he or she belongs.

\subsection{Language matters}

A language expresses the realities of people, their communities, and cultures. They indicate one's membership to a particular group; as either an inclusive or exclusive factor (Māori Language Commission n.d.).

Yet despite their significance and value, languages are in trouble. Pagel (1995) estimates that there may have been as many as 600,000 languages spoken in the world, or as few as 31,000. Presently, estimates as to the amount of existing living languages vary between a range of 5,000 to 7,000 (Crystal 2000, p. 11). Therefore, even if we use Pagel's lowest estimate, it becomes evident that in the history of humankind, more languages have died than those which remain. A shrinking minority of languages seem to dominate the majority of the world's population: regardless of the number of existing languages, Crystal (2000, p. 14) and Bernard (1996, p. 142) estimate that just 4 percent of the world's languages are spoken by 96 percent of the population. Reverse the numbers and the estimate appears even more distressing: 96 percent of the world's languages are spoken only by 4 percent of the population. Uniformation, a term used by Fishman (1991) to define lack of language diversity, involves "subjugation of the weak by the strong, of the few by the many" (p. 31). 
This is not a problem that concerns only linguists; it concerns the world as a whole. When a language is lost, it weakens the cultural identity of the group it belonged to, altering the nature of the society of which that group is part of. Language death renders cultural and societal diversity, limits our access to knowledge:

every language reflects a unique world-view and culture complex mirroring the manner in which the speech community has resolved its problems in dealing with the world. With the death of the language [...] an irreplaceable unit of our knowledge and understanding of human thought and world-view has been lost forever. (Wurm 1991, p. 13)

Krauss (1992) predicted that if nothing is done, the coming century will see the death of 90 percent of the world's present languages. If nothing is done. Using the case studies of Māori in Aotearoa New Zealand and of the Mapuche in Chile, this thesis recognises that although language death is real, efforts for language revitalisation do exist. In accord with Crystal (2000) beliefs on the subject of language death, this thesis seeks to argue that language death matters, that we should care, and therefore, take action to prevent the death of vulnerable indigenous languages. Language revitalisation is possible, as will be presented in the case of te reo Māori in Aotearoa New Zealand; the case of Mapudungun in Chile, however, shows the need to increase efforts in preserving the Mapuche indigenous language.

\subsection{Research aims and objectives:}

\subsubsection{Research aims:}

To compare and contrast indigenous language revitalisation processes in Aotearoa New Zealand and Chile in the context of primary education.

The research and analysis will examine and compare government policies in Chile and Aotearoa New Zealand toward the revitalisation of indigenous languages through the use of case studies and by implementing comparative methodology. 


\subsubsection{Research objectives:}

1. To evaluate government strategies in Chile and Aotearoa New Zealand with reference to conservation and revitalisation of indigenous languages by focussing on each country's educational system.

2. To assess and compare indigenous language participatory approach methods used in Chile and Aotearoa New Zealand.

3. To determine how historical processes of colonisation in Chile and Aotearoa New Zealand impacted processes of language erosion.

4. To identify problems encountered by, and/or limitations associated with language revitalisation efforts in Chile and Aotearoa New Zealand.

5. To compare the outcomes of indigenous language revitalisation in the educational systems of Chile and Aotearoa New Zealand.

6. To determine if Chile could use the indigenous language revitalisation schemes implemented by Aotearoa New Zealand as a model from which to take recommendations. 


\section{Chapter 2 - Research epistemology and methodology}

\subsection{Introduction}

Realities are relative; they exist within contexts and are circumstantial. In undertaking the research for this thesis, I became aware and learned of the different realities indigenous peoples face. Mixed methodological approaches that included the study of qualitative, quantitative, secondary and primary data sources, led me to realise that there is no absolute reality, just as there is no absolute truth. Literature reviews exposed me to indigenous peoples on a global scale, whereas primary field research methods introduced me more specifically to the realities of the Māori in Aotearoa New Zealand and of the Mapuche in Chile. Due to the unique historical nature of each country, the social realities each indigenous group experiences are not the same. Nevertheless, there exists a common denominator that connects the Māori to the Mapuche, and to the rest of the indigenous peoples of the world: a desire to conserve their identity and for their heritage to transcend time.

There is a significant difference between simply describing an existing situation and attempting to provide a valid explanation for its existence. For an explanation to be valid and sufficient, it has to expose the arrangement of social relations that justify the existence of certain policies and practices (May 1996). By exposing these underlying social structures, an explanation attempts to justify these policies and practices-in other words, explanations attempt to justify realities. This research process, however, has made me realise the complexity of reality: what it means to whom, the ease with which we find ourselves able to criticise different realities yet the lack of understanding we have of the intricacies involved in the reasoning behind them.

The following chapter will explain the epistemology underlying my research. It will also cover the methodology and research methods employed, as well as some of the difficulties I came across throughout the research process. 


\subsection{Epistemology}

Epistemology is the study of knowledge. It attempts to provide justifications that will ultimately distinguish between true and adequate knowledge from false, inadequate knowledge (Heylighen 1993). Absolute and universal truths however, do not exist in the realm of most social sciences. Perceptions filter realities, and quite often, opinions are labelled as 'facts' when they are, in actuality, just opinions. It is therefore important to provide readers with a clear understanding of the main philosophical belief underlying the author's assumptions and interpretations. The principal values and philosophies of this dissertation reflect a Critical Realist theoretical perspective.

In 1916, American philosopher Roy Wood Sellars introduced the term Critical Realism in an effort to distinguish between direct realism and idealism by stating that the objects of perception are "neither objects themselves nor ideas arid so on in the mind but sets of properties of these objects" (Drake 1920). Critical Realism claims that a 'real world' exists, regardless of one's own personal discernments or insights (Kitchin \& Tate 2000). In the case of social sciences, critical realists argue that social activities are not empirical, but instead, are historically and institutionally determined (Bhaksar 1997). Perception filters in Critical Realism allow the researcher to interpret findings, which account for the subjective elements in this research.

On one hand, there is the Realist theory, which recognises something as real if it is able to bring about visible/material consequences (Bhaksar 1997). It seeks to provide explanations to happenings, to situations, to "uncover the structures of social relations in order to understand why we then have the policies and practices that we do" (May 1997, p. 12). Realists question and explore the reasons behind changes in human relations, in societal interactions (Kitchin \& Tate 2000).

Critical Theory involves the "application of principles or values in order to make judgments for the purpose of bringing about positive change."(Bhaksar 1997) The practical purpose of critical theory is to distinguish itself from traditional theories by seeking human emancipation in order "to liberate human beings from the circumstances that enslave them" (Horkheimer 1982, p. 244). Ultimately, the goal of applying critical 
theory to social sciences is to move away from the notion that it is possible to employ a single unifying theory to a variety of diverse historical situations (Stanford 2005). It seeks to differentiate its aims, methods, theories and forms of explanation from conventional knowledge and understandings. A critical theory is essentially a critique of society as a whole (Penelope 1990).

In employing a Realist and Critical approach, my research in Aotearoa New Zealand and Chile seeks to study and understand why and how historical and social trends affect indigenous peoples, focusing in particular in the loss of indigenous language. The research focuses on efforts for language revitalisation within each country's educational system.

\subsection{Choice of setting and premise}

There exist various parallels between the Aotearoa New Zealand and Chile which make them a valid pair for comparison. A basic starting point is the historic and physical similarities between both countries, which have allowed each to hold similar economic niches in global markets (Murray \& Challies 2004). More important for my research however, is that both share a timeline of historical colonial developments that largely influenced how indigenous peoples are presently perceived by each country's social and political institutions. In both, Aotearoa New Zealand and Chile, colonies of settlement took place: colonisers (in Aotearoa New Zealand, the British; and in the case of Chile, the Spanish and then Chileans) made an attempt to displace indigenous populations through cultural assimilation (McMichael 2000). Such efforts, however, proved to be unsuccessful and the Māori and the Mapuche, along with their languages, managed to survive. This is not to say that such historical developments have yielded similar outcomes in terms of the present status of indigenous people in Aotearoa New Zealand or Chile. Quite the contrary: each country holds unique historical, political and sociological factors that have all contributed to the current widely divergent state of indigenous peoples in Aotearoa New Zealand and Chile.

While there still — and will probably always — exist the need for improving the social and economic status of the Māori, efforts towards creating a bicultural society have been more consistent in Aotearoa New Zealand than in Chile. The Mapuche, on the other 
hand, have continuously faced discrimination and alienation within the Chile's social, political and economic systems, and the mechanisms available for Mapuche to obtain recognition of their indigenous rights, including efforts for revitalisation of Mapudungun, still lack structure, coordination and cohesion.

I chose to study indigenous language revival in Aotearoa New Zealand and in Chile in order to further understand the implications that language has on effectively revitalising indigenous culture and knowledge. The inclusion of te reo Māori in the education curricula of Aotearoa New Zealand, and the official recognition of te reo Māori as a national language, have placed the country's language revival efforts on an almost privileged position by world standards. On the other hand, Chile's efforts to adopt Mapudungun into education curricula or to even promote the use of Mapudungun at a national level have so far show potential for positive results, yet are currently still unsuccessful. Language revival efforts in Aotearoa New Zealand have been in existence for a significant length of time, allowing me to take advantage of the already existing research available on the subject. Efforts in Chile to restore Mapudungun, however, have been much more recent. There exists a potential for Chile to use the strategies Aotearoa New Zealand has implemented in language revitalisation, a motivation that prompted me to attempt to create a link between the countries.

\subsection{Methodology}

Creswell (2003) explains that a methodology does not only refer to a simple set of methods that work as an equation to provide a correct answer, but instead, a methodology refers to the rationale and the philosophical assumptions that underlie a particular study. Building on my epistemological approach, I have employed a comparative methodology technique that utilises a combined recollection of quantitative and qualitative data. Despite the debates surrounding the differences and advantages of qualitative over and quantitative methods, I believe, along the lines of Murray and Overton (2003), that qualitative and quantitative research techniques are not mutually exclusive, but instead, can be used to the advantage of the researcher by complementing each other.

The use of either approach individually would have proved inefficient in my research: in terms of measuring the use of language within indigenous communities, a qualitative 
approach could not have been extended to the wider population with the same extent of certainty of a quantitative analysis. The amount of people able to speak and understand their indigenous language is fundamental in reflecting the level of language endangerment. Nevertheless, qualitative data enabled me to capture the true health status of a language, how well people spoke it, the importance given to language within indigenous communities, the extent to which people feel privileged or condemned by knowing and understanding an indigenous language. Qualitative data allowed me to gain understanding of peoples' perspectives, of the cultural and historical complexities existing and surrounding indigenous peoples. Quantitative data, on the other hand, provided me with percentages, with numbers, with objective and even causal evidence of the increases or decreases of indigenous language speakers over time, dating back to the colonial era.

Overall, I discovered that in the world of social sciences, not everything can be measured in numbers and that it is not possible to interpret situations based solely on numerical values; numbers, however, do provide evidence that allows for valid interpretations. Nevertheless, qualitative research remains essential if we aim to understand what makes our world meaningful for people (Brockington \& Sullivan 2003).

\subsubsection{Employing comparative methodology}

According to Denoon (1983, p. 8) "there is only one analytical method in the social sciences: the comparative method." Although this dissertation doesn't abide by any absolute truths, using a comparative methodology approach proved to be an effective tool by providing a critical and relative evaluation of the status of indigenous peoples. Comparative methodology provides perspective on the difference of the researcher's context by offering insights into what occurs elsewhere and therefore, avoid ethnocentrism. It also deconstructs generalisations and breaks (or in some cases, reenforces) stereotypes by using two different contexts (Havemann 1999). Comparative research allows for the relative evaluation of the performance of systems, agencies, and institutions, and if done properly, the method can help isolate factors that make for success or failure (Havemann 1999). Therefore, one of the main objectives of using comparative approach in discussing indigenous issues is to be able to use contrasting 
evidence to "provide conceptual frameworks to assist with policy analysis, both for predicting outcomes and for advocating reform" (Havemann 1999, p. 9).

Comparative methodology, however, runs the risk of become extremely complex and inefficient if too many factors are involved. This is why it is crucial to select specific units of comparison that are functionally equivalent (Dogan \& Pelassy 1990). In looking at the colonial histories and current state of indigenous language in Aotearoa New Zealand and Chile, "the goal is not to develop invariant hypothesis via comparison of more or less uniform 'cases', but to give substance to a historical process (a whole) though the comparison of its parts" (McMichael 1990, p. 386).

\subsubsection{Using case studies and direct observation}

In order to further understand how language revitalisation methods are approached in Aotearoa New Zealand and Chile, I used a combination of direct observation and case study research methodology. A case study approach is an effective and valuable methodology when a holistic, in-depth investigation is needed (Feagin et al. 1991). Direct observation of case studies proved to be advantageous in that it exposed me as a researcher to the multiple perspectives and complexities surrounding real-life contexts of indigenous peoples and language revitalisation efforts in Aotearoa New Zealand and Chile. Direct observation in case studies enabled me to connect and experience with the some of the realities relevant to indigenous peoples and to efforts of language revitalisation. The case studies made it possible for me to incorporate the voice of relevant groups of actors and observe the interaction between them.

Stake (1995) identified three types of case study approaches, which are not mutually exclusive and may be combined: intrinsic, instrumental and collective. Intrinsic case studies take place when the researcher has an interest in the case. An instrumental case study is used to understand more than what is obvious to the researcher. Collective refers to a group of cases are studies as opposed to limiting results to one case study. The case studies used in Aotearoa New Zealand and Chile are both intrinsic and instrumental, all motivated by my interest in studying language revitalisation and trying to closely understand why language planning methods seemed to prove more beneficial in Aotearoa New Zealand than in Chile. Aotearoa New Zealand is experiencing the results of a 
successful language revitalisation scheme, which allowed me to focus a single-case study in which I was able to observe the benefits of the language revitalisation process. Chile, however, is still in the process of establishing an effective language revitalisation scheme. The complexity of obstacles Chile faces in restoring indigenous language can not be observed in just one case study, which is why I employed a multiple-case study application. A collective approach that included three case studies proved to be more beneficial for my research and my understanding of the complexity of the language revitalisation process in Chile.

\subsection{Research methods}

My research relies on a combination of primary and secondary data, which was collected in Aotearoa New Zealand and Chile between August 2006 and June 2007. My purpose was to achieve an original individual study that connected and was relevant to previous research and to existing disciplinary theories. Primary and secondary sources are not mutually exclusive: primary sources provide information on a "topic upon which subsequent interpretations or studies are based on," (Hairston \& Ruszkiewicz 1996, p. 547) whereas secondary sources offer analysis and an interpretation of information gathered from primary sources.

Secondary and primary data sources both reflected how ideas about the status of indigenous rights are highly contested: at one end, there are those who reject the idea that political and social structures established by colonial powers disempowered and currently discriminate against indigenous communities. This group of people support assimilation and indigenous integration into mainstream societies. At the other end of the spectrum are those who have incessantly fought to liberate indigenous peoples from the structures of colonial domination at political, economic, social, and cultural levels (Maaka \& Fleras 2005). This group seeks the decolonisation of indigenous peoples, of stereotypes, and political and social structures that decimate and threaten the existence of indigenous knowledge. In terms of language revitalisation efforts, it is not very difficult to set one group apart from the others: those who believe indigenous peoples should be integrated into mainstream society oppose language revitalisation efforts, while those who seek recognition and acceptance of the importance of indigenous knowledge, support the restoration of minority indigenous languages. 


\subsubsection{Secondary data sources}

The recollection of secondary data allowed me to gain significant background information before conducting my field research in Chile. The literature review I undertook prior to carrying out the field research consisted of information retrieved from books, official government documents and statistics, articles from the Internet, social science journals, and library databases. The literature review enabled me to examine existing data on the general conditions of Mapuche and Māori communities, such as statistics on poverty status, housing facilities, health and employment levels. This information provided me with insights and suggestions of what some of the existing needs of indigenous communities are and contextualise the current status of Māori and Mapuche. It also allowed me to frame my objectives and aims by narrowing down the scope of alternatives one can focus on when intending to study indigenous issues. The extensive and detailed documentation on language revitalisation supported my objective of using the Aotearoa New Zealand as a model which Chile could follow to make use of successful implementation strategies for language stabilisation.

Due to practical constraints involving lack of time and financial resources that could support my length of stay in Chile, I also relied on secondary data to identify people I wanted to research and to formulate the information I should include in future interviews. Furthermore, due to the subjective and opinionated nature of many texts, the literature review made me realise the importance of having primary data sources confirm (or in some cases rectify) my assumptions.

\subsubsection{Primary data sources, workshops and case studies}

I depended largely on primary sources to confirm the veracity of secondary data. Due to the comparative nature of my research, I aimed to interview people in Chile that would represent contesting views on the importance of language revitalisation, whereas in Aotearoa New Zealand I focused on interviewing people that could provide insights on the success of language revitalisation strategies (see appendix 1 for list of key interviews in Chile and Aotearoa New Zealand).

I discovered I had to rely much more on primary sources while conducting research in Chile: more often than not, texts on Mapuche indigenous issues seemed to be at odds 
with the realities I encountered upon visiting indigenous communities, which led me to have some reservations on the reliability of some secondary sources. Conversely, the extended broad coverage of documentation and secondary sources in Aotearoa New Zealand proved to be more in tune with the on-ground realities I encountered while carrying out my field research.

My research was profoundly affected by the visits I made to schools in Chile and in Aotearoa New Zealand. I initially formulated semi-structured interviews in order to be used with a similar range of people from both countries. After on-ground visits to school grounds in Chile, however, due to the detrimental and unexpected poor conditions I encountered, I had to divert from my original plan of limiting my interviews to school staff. Through the use of semi-structured format, I sought participants for my research elsewhere and had the opportunity to interview government officials, university lecturers, indigenous activists, as well as visit indigenous communities in the rural areas of Chile.

Visits to indigenous communities in Chile were key components of my research; direct observations for the development of three case studies resulted from these visits (see appendix 2 for list of case studies carried out in both countries). All three case studies were held in Temuco, which is located approximately 650 kilometres south of Santiago in Chile's Region IX, Región de la Araucanía. This region holds the largest concentration of Mapuche in Chile.

While in Temuco, I also attended a series of workshops, seminars and conferences on indigenous issues, which included an array of prestigious experts on indigenous issues, ranging from globally renowned figures such as Noam Chomsky, to local Chilean authorities, such as Jorge Pinto Rodríguez (see appendix 3 for list of workshops, seminars and conferences attended in Chile and Aotearoa New Zealand).

These gatherings and events not only provided me with a wealth of knowledge, but also resulted in the emergence of a series of valuable contacts and key participants. These contacts acted as 'gatekeepers' as they recommended other people for me to interview, making arrangements for me and providing me contact information that would have been otherwise unavailable to me (Murray \& Overton 2003). The resulting 'snowball' effect, 
in which I stumbled along more and more interviewees along my research process, proved to be the most effective way of establishing connections with crucial participants (Murray \& Overton 2003). By the time I left Chile, I had interviewed far more people than what I had anticipated in my original framework.

In Aotearoa New Zealand, the most productive experience in terms of obtaining relevant information for my research, came from visiting Petone Central School on several occasions, where I interviewed teachers as well as the school's principle. Observing the learning environment of children who are exposed to te reo was the most indispensable and useful element of my research. Unlike my experience in Chile, here I did not find the need to divert from my original framework nor did I have to alter the anticipated selection of participants.

I also attended a series of seminars, lectures and workshops that helped me further understand Māori on a cultural and historical level. These included presentations by international speakers such as linguist David Crystal, to debates led by national Māori authorities, such as Hon Justice Edward Taihakurei Durie (see appendix 3).

\subsubsection{Observing approaches to language revitalisation}

As mentioned earlier, my experiences visiting school grounds in Aotearoa New Zealand and Chile diverged immensely_ranging from the poor infrastructural conditions of buildings in Chile to the excellence of quality in teaching methods being employed by the school staff and administration in Aotearoa New Zealand. While in Chile, I attended three different indigenous communities in an effort to understand as clearly and fully as possible the conditions in which children where being taught Mapudungun, as well as the living conditions of the Mapuche. I was able to meet with school staff members in two of the three communities: in one instance, I observed a parent-teacher group meeting between Mapuche and the school's principal, while in the other community I had access to a school, I was allowed to sit-in a meeting between the school principle, staff members, and experts on indigenous language revitalisation. In Aotearoa New Zealand, I made four visits to Petone Central School and participated in a series of activities, which included observing students in the classrooms, assemblies, and in other daily teachinglearning environments. 


\subsection{Ethical considerations}

The semi-structured interview guideline I developed was made in accordance with the Human Ethics Policy at Victoria University in Wellington. The guidelines were submitted to Victoria University for approval before any interview took place. All interviews were done in person and participants were provided with an informed consent form, which they proceeded to sign before the interview took place. Also, with the consent of participants, the interview process was recorded in audiotapes. All of the information provided in Aotearoa New Zealand and Chile was made on a voluntary basis; even though participants in the case studies of Chile acceded to me using their opinions as part of my research, I have withheld their names unless I interviewed them directly. The reason being that the direct observations carried out in Chile had not been anticipated and the people participating had not received prior notice of my presence in meetings. Therefore, verbal consent was obtained and privacy regarding the use of their name and identity was requested by some participants.

In interviewing and sharing community life experiences with indigenous peoples in Chile, I became aware of the need to go beyond ethics consent forms and of the researcher's obligation and responsibility in considering the potential effects of research on participants (Scheyvens 2003). Participants in indigenous communities entrusted me with their views, thoughts and opinions. They shared their frustrations and preoccupations, all of which I hope I have used to, in one way or another, eventually empower and benefit them. Although conversations, interviews, and direct observations were all carried out in Spanish, I have employed my experience as a simultaneous interpreter and journalist to be as objective and accurate as possible in carrying out translations for this dissertation.

\subsection{Problems encountered throughout research}

The nature of the problems and disadvantages I experienced while doing my research in Aotearoa New Zealand and in Chile differed to a great extent.

In Aotearoa New Zealand, I did not experience any time constraints, since I currently live in Wellington. My field research experience in Chile however, was limited to only four weeks: one week spent in Santiago and the remaining three spent in Region IX, in 
Temuco. My time in Santiago was not as rewarding as the time spent in Temuco, something I had anticipated due to the large amount of Mapuche living in the Temuco region.

The biggest challenge encountered during my research was travelling within Chile on my own. Because I am Latin American myself, there was no language barrier I had to worry about and I was able to adapt rather rapidly to Chile's customs and lifestyle. Nevertheless, there are inevitable disadvantages of being a young woman travelling by bus to unknown locations during long distances and long periods of times. The Mapuche communities I visited were not easily accessible and required me to hitch rides with strangers. I was lucky in that the goodwill of the people I encountered was genuine; yet I had to keep my guard up and be on the lookout at all times.

I often also found myself overestimating the quality of many of the workshops I attended to in Temuco: in one particular instance, I attended a lecture titled "The Fate of Minority Languages in the World: the case of New Zealand's Māori." The presenter, Lillian González, unaware that there was someone who lived in Aotearoa New Zealand sitting in her audience, began describing events and situations that pertained to the Aborigines in Australia, not to the Māori. ${ }^{1}$

I also anticipated to encounter the problem of what is known as the 'Latin American punctuality' (i.e. expect 15 minutes of delay in any appointment, meeting or date). Due to my background growing up in Costa Rica, I was aware that Costa Ricans excel at the art of never being on time; nevertheless, I was stunned to find Chileans had the ability to surpass Costa Rican unpunctuality. Conferences were cancelled without prior notice; seminars and workshops did not once begin as scheduled; and interviewees were at times more than two hours late for appointments without taking the time to advise me of their delay.

In Aotearoa New Zealand, the greatest and continuous challenge I experienced was cultural alienation and difficulties in gaining continuous access to some of my key informants. I also found myself being stood-up on several occasions by interviewees who

\footnotetext{
${ }^{1}$ Lillian González described how children were taken hostage from their parents and taken to missionary schools to be taught English.
} 
failed to show up for appointments without prior notice. Gaining access to visit school grounds in Aotearoa New Zealand was a bit more problematic than it was in Chile. I was however very fortunate in being referred to a school willing to participate in my research and whose principal, Iosua Esera, has done intensive research on language revitalisation schemes. ${ }^{2} \mathrm{He}$ and his staff kindly welcomed me to Petone Central School's grounds on numerous occasions.

My lack of understanding of both Mapudungun and te reo did not prove to be as problematic as I had anticipated, since all of the participants throughout the research process were fluent in either Spanish or English. Although I never assumed participants to be bilingual, I realised that people from either Mapuche or Māori background believed they were expected to hold their indigenous language as a second language and be fluent in mainstream languages, a fact that reinforces the legacy left behind by colonial powers on attitudes regarding cultural assimilation. Whereas I did encounter plenty of te reo in secondary data sources, I hardly encountered any words in Mapudungun in texts of any kind. I have added footnotes to give immediate translation of indigenous words, and have also included a glossary of words in te reo and Mapudungun used throughout this dissertation in an effort to assist (and inform) the reader.

\footnotetext{
${ }^{2}$ Esera completed a thesis based on an evaluative study of Samoan and English bilingual programmes, highlighting practices that are critical to acquisition of a second language while maintaining a child's first language.
} 


\section{Chapter 3 - Indigenous peoples of the world}

\subsection{Introduction}

The United Nations (UN) estimates that there are roughly 300 million indigenous peoples in the world, a little over 4.5 percent of the world's 6.6 billion population (United Nations Office of the High Commissioner for Human Rights [UNHCHR] 2006a). Since their colonisation, many indigenous peoples have been subjected to continuous human rights violations. It is not until recently that the indigenous peoples were finally successful in attracting the international community's attention to the issues threatening their existence. The UN has the authority to mediate the effects of globalisation on the most vulnerable members of society. By creating the Working Group on Indigenous Peoples and through the United Nations Educational Scientific and Cultural Organisation (UNESCO), and most recently by adopting the Declaration on the Rights of Indigenous Peoples, the UN recognises the existence of these 300 million people.

The following will look at how the UN's Working Group contributes to the protection of indigenous peoples, particularly in the face of globalisation. It will highlight the importance of the Working Group's role as supervisory body on indigenous issues by looking at the reports filed by Rodolfo Stavenhagen, the Special Rapporteur of the Working Group, for the present overall conditions of the Māori of Aotearoa New Zealand and the Mapuche of Chile after he visited each country . This chapter will also establish the considerations used to establish who is considered Māori and Mapuche, and the importance of distinguishing indigenous peoples from mainstream societies.

\subsection{Globalisation and indigenous peoples of the world}

Despite its many definitions, globalisation is a phenomenon of dual nature, an instrument capable of disseminating profits while propagating hardships. The term's amplitude is monumental, and its use has lately become something of a commodity, as people seek to attach more stigmas to its definition, exhausting its meaning and scope. Globalisation identifies mankind's ambition to expand and impose cultural, economic, and political trends at a global scale (Murray 2006; Held et al. 1992). The foundations of globalisation can be traced back to as early as 1492, to the discovery of the Americas and the subsequent waves of colonisation that followed (Murray 2006). Therefore, the struggles 
of indigenous peoples must be situated within a globalising context that can be traced back to colonial times.

For indigenous communities, colonisation and globalisation go hand in hand, signifying the end of an era and the introduction of the ongoing threat to their existence. Both globalisation and colonisation indicate the eradication of indigenous autonomy and the ongoing threat to their cultural identity. Indigenous peoples on a global scale face an ongoing challenge of using globalisation to their advantage, and it is only in recent times that indigenous peoples have been able to effectively do so.

\subsection{The United Nations' role: UNESCO and Working Group of Indigenous Peoples}

By establishing the Working Group of Indigenous Peoples and through UNESCO, the UN seeks to promote interaction between the international community and the concerns of indigenous peoples. The Working Group and UNESCO have served as platforms that condemn human rights violations against indigenous communities and look to protect and preserve indigenous peoples, their knowledge, and cultural values. Both organisations raise awareness of the vulnerability of indigenous groups and provide a shield by unifying indigenous peoples' needs and concerns. Nevertheless, they recognise the uniqueness of each group and endorses their existence. The Working Group's role as a supervisory body and UNESCO's role as advocate for conservation of indigenous heritage, have been of particular importance for the Māori of Aotearoa New Zealand and the Mapuche of Chile. By recognising the importance of indigenity the Working Group and UNESCO work to support and advance the interests of indigenous peoples in the face of globalisation.

\subsection{Omission from the Universal Declaration of Human Rights}

The creation of the Universal Declaration of Human Rights by the United Nations in 1948 did not recognise the indigenous peoples of the world as a separate entity that required special consideration. Indigenous communities worldwide proved to be exceptionally vulnerable as their fundamental human right to equality and freedom from discrimination was repeatedly violated. Not being recognised as equals by government institutions and being subjected to continuous social and political discrimination 
prevented indigenous populations from enjoying the remaining basic rights and freedoms granted by the Declaration to individuals. Hence, it became obvious that the "absence of a mechanism in the Commission on Human Rights with a specific mandate to protect and monitor the respect and enjoyment of the human rights and fundamental freedoms of indigenous peoples" increased the susceptibility to abuse of indigenous communities worldwide (UNHCHR 1997). The evidence of the abuses against indigenous peoples was clear as they became the predominant groups that made up the lowest social strata worldwide. Stripped from their human rights, yet determined to maintain their identity, they became victims of poverty.

\subsubsection{First step: global recognition of indigenous peoples}

The first step the UN took toward recognising the need of indigenous peoples on a global scale came in 1970, when "the Sub-Commission on Prevention of Discrimination and Protection of Minorities recommended that a comprehensive study be made of the problem of discrimination against indigenous populations" (UNHCHR 1997). In 1971, José Martínez-Cobo was appointed Special Rapporteur and assigned the task of preparing a document, titled Study on the Problem of Discrimination against Indigenous Peoples (Nesti 1999, p. IVa). The report's objective has been, ever since, to suggest national and international measures for eliminating such discrimination (UNHCHR 1997). MartínezCobo submitted the report between 1981 and 1984, including in it:

a definition of indigenous peoples, the role of intergovernmental and nongovernmental organisations, the elimination of discrimination, and basic human rights principles, as well as special areas of action in fields such as health, housing, education, language, culture, social and legal institutions, employment, land, political rights, religious rights and practices, and equality in the administration of justice. (UNHCHR 2006b)

The text served to emphasise the need to increase attention given to indigenous peoples. The studies and research provided by Martínez-Cobo, along with the cooperation of nongovernment organisations around the world and the growing number of indigenous groups seeking support from the UN, led the Economic and Social Council to create the Working Group on Indigenous Peoples in 1982 (Nesti 1999). The Working Group works under the Sub-Commission on the Promotion and Protection of Human Rights, and its 
main objective is "the protection of the individual and collective rights of indigenous peoples" (UNHCHR 2006c, p. 3). It is made up of five independent experts (who are already part of the Sub-Commission) and a main supervisor, known as the Special Rapporteur. The Rapporteur is responsible for obtaining first-hand information of events happening in particular locations; data is also submitted by government institutions, nongovernmental organisations, and representatives of indigenous communities, all which provide the Working Group with updates in the developments-or lack of developments - of the world's indigenous sectors.

\subsubsection{Declaration on the Rights of Indigenous Peoples}

The Draft Declaration on the Rights of Indigenous Peoples was completed in 1993. Its aim is to establish rights that are generally taken for granted in dominant and governing societies, yet were (and in many instances, still are) inexistent for most indigenous communities. The Declaration promotes the protection of the "rights of indigenous people and their empowerment to make choices which enable them to retain their cultural identity while participating in political, economic and social life, with full respect for their cultural values, languages, traditions and forms of social organisation" (UNHCHR 1997). It should serve as an instrument that guides and frames the implementation of better practices in favour of the human rights of indigenous peoples (Stavenhagen 2007). Indigenous rights are defined as those collective and inherent entitlements to selfdetermination over customary domains pertaining to identity and cultural values (Maaka \& Fleras 2005, p. 44). "The denial of cultural rights to minorities is as disruptive of the moral fabric of mainstream society as is the denial of civil rights. Civil rights, however, are focused on the individual, while cultural rights must focus on ethnocultural groups" (Fishman 1991, p. 70).

The Human Rights Council adopted the Declaration on 29 June 2006 and recommended its adoption by the UN General Assembly. The request was denied. On 13 September 2007, the UN General Assembly finally adopted the UN Declaration on the Rights of Indigenous Peoples. The Human Rights Council recognised the event as "a triumph for justice and human dignity following more than two decades of negotiations between governments and indigenous peoples' representatives" (Office of the United Nations High Commissioner for Human Rights [OHCHR] 2007). 
The Declaration was adopted by a majority of 144 states voting in favour of the ratification, including Chile. Unfortunately, and paradoxically for purposes of my research, Aotearoa New Zealand one of the four votes that opposed the ratification of the Declaration. Although the draft is not legally binding, it establishes moral standards that most countries feel compelled to meet. It will be interesting to observe how nations that adopted the Declaration will uphold its principles, as well as how the document will impact indigenous peoples on a global scale.

\subsubsection{From singular to plural: Indigenous people and indigenous peoples}

It is important to distinguish between indigenous people and peoples: peoples encompasses the existence of distinct groups of indigenous communities in the world, each denominated as a group of people, in singular, referring to a set of particular characteristics that sets them apart from other groups (UNHCHR 2006a). The umbrellaterm of indigenous peoples comprises those populations in the world that are unable to form part of neighbouring dominant societies due to social, political and economic disparities.

While there is an overwhelming cultural and ethnic diversity among indigenous groups, there exist underlying similarities between the historical and present problems and difficulties these communities face. Such grievances have led indigenous peoples to identify common needs, the most important being their insistence on retaining their separate identity and cultural heritage (UNHCHR 1993). "The study of population is not just concerned with counting people; it is primarily about ensuring that people count" (Pool 1991, p. 11).

\subsection{The Māori of Aotearoa New Zealand and the Mapuche of Chile}

Historical and social constructs complicate the recognition boundaries between ethnic groups, as do biological interpretations of race. Notions of ethnic membership include legal and statistical definitions that complicate categorisation of half-caste indigenous peoples (Pool 1991). The answer to the question of "who is Māori" and "who is Mapuche" is burdened with ambiguity and paradox. 
In an essay studying the demographics of indigenous minority populations, Pool (1986) notes how defining the boundaries of ethnic group membership is one of the more critical conceptual issues in bicultural or multicultural societies. The process becomes more complicated where there are indigenous minorities seeking redress of wrongs originating in the period of colonisation, as is the case of the Māori and the Mapuche.

The arrival of settlers to Aotearoa New Zealand and Chile led to racial fusion between races. The interpenetration and intermarriage between indigenous peoples and colonisers presented the emergence of a new ethnicity, one which could no longer be defined as being $100 \%$ pure blood of either indigenous or coloniser descent.

In terms of amount of indigenous population, the estimated figures between Māori and Mapuche is similar, yet at the same time irrelevant when compare to the overall populations of Aotearoa New Zealand and Chile. Whereas the number of indigenous peoples in each country is strikingly similar, when compared to the overall general population, the comparison becomes disproportionate.

\subsubsection{Who is Māori?}

Prior to the arrival of Europeans, the Māori had no word designated to recognising them as a single group of people. This was due to the fact that they did not have one political social structure that united them under the single title of one people, and they opted to use their tribal names as means of distinction (Walker 1990). Recording evidence of ship journals show that the use of the word Māori to refer to themselves was used since 1801, and it is known that the word Māori was used widespread by the 1830s (King 2003). Yet it was not until the Treaty of Waitangi that the expression 'tangata māori'-meaning ordinary, normal people - was officially coined to designate native Aotearoa New Zealanders. Aotearoa New Zealand recognises te reo Māori as a national official language, along with English and sign language. Te reo ${ }^{3}$ is used to refer to the Māori language.

With the increased influx of settlers the common word of Pākehā was established for the recognition of foreigners. Far from derogatory, the term is derived from pakepakeha,

\footnotetext{
${ }^{3}$ Te reo: language.
} 
which is defined as "imaginary beings resembling men, with fair skins" (Walker 1990, p. 94). The terms Pākehā and Māori are both still currently used to distinguish Europeans from Māori. For the purposes of this paper, however, the term Māori will be used to represent culturally distinct peoples with a shared history, language and tradition whose distinctiveness endows them with privileged entitlements (Maaka \& Fleras 2005) The Māori represent the indigenous peoples of Aotearoa New Zealand.

According to the 2006 Census of Statistics New Zealand, there are an estimated 565,329 people of Māori descent out of Aotearoa New Zealand's total population of 4,184,773. This means that approximately 14 percent of Aotearoa New Zealanders consider themselves Māori.

\subsubsection{Who is Mapuche?}

Mapuche means "people of the land" in Mapundungun, ${ }^{4}$ their official language. Mapu means "land", che means "people"; dungun means "speech"; Mapudungun therefore means "language of the land" (Faron 1986, p. 9). They have historically inhabited the central and southern Chilean regions, as well as parts of south Argentina. The Mapuche however, are not one people. They are a wide-ranging ethnicity composed of an assortment of groups. This paper will use the term Mapuche to refer to these groups, which have been united since colonial times by shared social, religious, and economic structures. More importantly, however, is the shared common linguistic heritage of these groups, which has allowed them to consolidate their identity as Mapuche (Faron 1986; Haughney 2006).

In Chile, the 2002 population census carried out by Chile's Centre for Public Studies (Centro de Estudios Públicos [CEP]), estimated there to be 604,349 Mapuche descendants within Chile's population, also in 2002, of 15,498,930 (Instituto Nacional de Estadísticas 2002) ${ }^{5}$ Hence, only 3 percent of Chileans consider themselves to be Mapuche.

\footnotetext{
${ }^{4}$ Mapudungun: (also referred to as Mapunzungun or Mapuzungun) official language of Mapuche.

${ }^{5}$ Chile's most recent statistics estimate the population has risen to $16,598,074$.
} 
Historically and until the present date, the Chilean Constitution has failed to promote a heterogeneous society by rejecting to recognise the Mapuche as an indigenous entity with unique historical and cultural values. Chile's constitution recognises only one "people"and that is the "Chilean people." Therefore, because the Mapuche are not recognised as "peoples," they had been unable to take advantage of the UN's recognition of indigenous rights. The UN's Declaration of Indigenous Rights applies only to "peoples" that can be defined as distinct from other groups within a state (Stavenhagen 2005). It will be interesting to see if the status of Mapuche changes now that Chile has adopted the Declaration.

\subsection{Rodolfo Stavenhagen: Special Rapporteur of the Working Group}

In 2001, in response to the increasing international regarding the marginalisation and discrimination against indigenous people in the world, the Commission on Human Rights appointed Rodolfo Stavenhagen as the Special Rapporteur on the Human Rights and Fundamental Freedoms of Indigenous People (OHCHR 2007). Stavenhagen visited Chile from 18 to 29 July 2003, and Aotearoa New Zealand from 16 to 25 November 2005 . $^{6}$ Both visits were made at the invitation of the each country's government. It is not the aim of this dissertation to evaluate the effectiveness of the Rapporteur's process and guidelines for evaluating indigenous communities in Chile and Aotearoa New Zealand. Nevertheless, it recognises the importance of effectuating country visits in order to assess the extent to which the protection of indigenous peoples and communities is being met at national levels. The Rapporteur's reports highlights important insights on each country's approach to resolving discrepancies between mainstream societies (including each country's recognition of indigenous rights by political institutions) and indigenous peoples.

\subsubsection{Report on Aotearoa New Zealand}

In his report on Aotearoa New Zealand, Stavenhagen recognised many of the developments and strategies made at a national level to preserve and promote Māori culture. Stavenhagen (2006) praised Aotearoa New Zealand's recognition of Māori as official language, an initiative that has favoured the establishment and development of

\footnotetext{
${ }^{6}$ His mission as Rapporteur also included visits to Guatemala and Philippines in 2002; Mexico in 2003; Colombia and Canada in 2004; and to South Africa in 2005.
} 
Māori schools, with Māori teachers and a Māori curriculum. Nevertheless, the current resources and funding for Māori immersion programmes is considered to be insufficient and inadequate. Stavenhagen recommends that further analysis into the current mainstreaming of education system would allow to better take advantage of the existing cultural possibilities of creating an increasingly pluralistic society (Stavenhagen 2006).

The report's commendations, however, did not come unaccompanied, as Stavenhagen also drew attention to a series of recommendations and observations of the disparities between Māori and Pākehā. While he recognised that the general standard of living of the Māori is at an advantage when compared to that of indigenous peoples in poorer countries, social and human development indicators in the fields of health, housing, income, education and social services show the Māori at an alarming disadvantage when compared to the rest of the country's population (Stavenhagen 2006).

\subsubsection{Report on Chile}

Stavenhagen's (2003) report on Chile reflected the disheartening conditions in which the Mapuche presently find themselves in. The Chilean government's protection and preservation of indigenous cultural heritage, and of the freedoms and rights of the Mapuche was far from nearing satisfactory levels, and after his ten-day tour to Chile in July 2003, Stavenhagen condemned Chile's treatment of the Mapuche. The report submitted by Stavenhagen (2003) indicted the Chilean government's management of the Mapuche, citing the increasing amount of suffering from social and economic marginalisation. Stavenhagen (2003) highlighted how despite Chile's economic growth, the Mapuche continue to experience a far lower quality of life than non-indigenous Chileans. He also noted how Chile's health services systematically discriminates against the Mapuche in terms of access to and quality of medical services.

Furthermore, he emphasised how efforts made by the Ministry of Education to build a bilingual intercultural education programme have not been successful due largely to the lack of trained staff and resources made available by the Chilean government. Stavenhagen (2003) pointed to the failure of Chile's educational system in meeting the Mapuche's demand for the protection, preservation and promotion of their traditional culture and language heritage. The 'Chileanisation' of the Mapuche threatens the already- 
endangered heritage of Mapudungun; real efforts to revitalise Mapudungun require of high-quality, bilingual legal assistance as well as the development of a realistic language planning strategy to revitalise Mapudungun.

\subsection{Conclusion}

This chapter underlines the importance of having an international supervisory body working to prevent and monitor that further abuses against indigenous peoples are not committed. The UN's Working Group fulfils that role as it aims to engage and raise awareness among the international community of how new challenges, such as globalisation, threaten the freedoms and rights of indigenous peoples in the world. This chapter also emphasises how Stavenhagen's observations in both Chile and Aotearoa New Zealand help create cross-cultural benchmarks of progress, or lack thereof, made regarding the protection of indigenous peoples.

Stavenhagen's reports show there is still much room for improvement to be made and for increased government efforts to meet their international human rights obligations. Nevertheless, Stavenhagen's findings also reflect on how it is possible to achieve progress at different levels, particularly in the case of language revitalisation in Aotearoa New Zealand. In his final report to the UN Council of Human Rights (2007), perhaps the recommendation that should resonate the most in the international community is for governments to undertake actions that require the active participation of indigenous peoples. Without active indigenous participation, colonial attitudes toward indigenous peoples will only perpetuate themselves. 


\section{Chapter 4 - Relevance of development and language revitalisation}

\subsection{Introduction}

Death of language hinders development in and of societies. In order to provide adequate evidence to support this claim, the following will look at how language functions as threads of knowledge which contribute to societal advancements.

This chapter explores the core development concepts of this dissertation by presenting a definition for the term 'development.' It will provide an understanding of the importance of indigenous knowledge, and of the types of participatory approach that may be implemented in the context of indigenous language revitalisation. The following argues participatory approach can be effectively used as a tool that can lead to sustainable language revitalisation. In the case of the Māori and the Mapuche, it is the purpose of this dissertation to examine the effectiveness of participatory approach in stabilising indigenous languages.

\subsection{Development}

In order to acknowledge the relation between development and indigenous communities, it is important to state what is meant by development. One of the simplest definitions of development is that provided by Chambers (1997): development means good change. In researching indigenous issues however, one must further and elaborate Chambers' definition of development due to the ambiguity of what the word 'good' entitles. What is good for some, is not necessarily good for others. Therefore, this dissertation understands development to be:

a process of enlarging people's choices'; of enhancing 'participatory democratic processes' and the 'ability of people to have a say in the decisions that shape their lives'; of providing 'human beings with the opportunity to develop their fullest potential' and of enabling the poor, women, and 'free independent peasants' to organise for themselves and work together. Simultaneously, development is defined as the means to 'carry out a nation's development goals' and to promote economic growth, equity and national self-reliance (Cowen \& Shenton 1991, pp. 28-29). 
Adding to the complexity of defining development, is the nature of those involved in the process. Whereas researchers, politicians or even academics may view and label an indigenous community as underdeveloped, the same may be said of them by an indigenous community. Historically, however, it has not been the case that indigenous peoples dictate in any predominant way how mainstream societies should function, nor have many indigenous peoples been able to apply their paradigms of development to colonial powers.

In order to incorporate non-western views and values in development, and in conjunction to Cowen and Shenton's (1991) definition, Sen's understanding of development will also be used as basis for this dissertation. Sen $(1990 ; 1999)$ argues development to be the process of expanding of people's freedom to choose should be achieved with the objective of expanding people's capabilities to attain the kind of life they wish to live. The ultimate outcome of development, according to Sen $(1990 ; 1999)$, is to achieve wellbeing, or a better quality of life, in terms of states of being or doing that individuals or collectives value and their capability of achieving those states or activities. Therefore, people living in societies where there is poverty, unemployment, ill-health, and most importantly, for purposes of examining efforts of indigenous language revitalisation, where there exists cultural discrimination and repression, people have little or no choice about the kind of life they live regardless of their aspirations to something else (Sen 1990). As a result, people experience constraints from living their lives to their fullest due to circumstances beyond their control (Wereta \& Bishop 2004). Development is the process of freeing peoples from such limitations and providing them with the necessary institutional arrangements and with adequate conditions to widen their choices and hence allow them the opportunity to achieve well-being.

\subsubsection{Development for whom?}

History has allowed for development to be characterised by biases of Eurocentrism, positivism, and top-downism, all which result to be disempowering to those sidelined by the process (Escobar 1994; Chambers 1997). It is therefore important to briefly acknowledge that the roots of development lie within the colonial period, with Europe's need of economic expansion, an idea coined by J.A. Hobson in 1902 under the term of imperialism (Giddens 1989, p. 530). Imperialism secured European markets by 
controlling resources acquired through the conquest of colonies; yet imperialism did not constraint itself to economic interests. In order to effectively control colonies abroad, imperial powers thought it necessary to subjugate indigenous populations and impose on them models of Western European societies (Dussel 1995; Giddens 1991).

Dominance during colonial times included not only land tenure and markets, but intellectual and cultural transformations were also suppressed and transformed. The containment of indigenous knowledge - referring to traditions, languages, and ways of life - were necessary in order to avoid any movement that might threaten Europe's economic advancement and hence, risk the collapse of the colonial structure. Based on the Euro-centric model of advancement and betterment, in the need to secure markets and promote economic growth, development became a tool used by the most powerful, pinning minorities and indigenous communities as underdeveloped. In this so-called process of development, the marginalised colonial communities were attributed the role of objects which needed to be instructed on how to better their livelihoods by newly arrived foreigners. Indigenous peoples were reduced to a definition that signalled them as "the descendants of the people who occupied a given territory when it was invaded, conquered, or colonised by a foreign power or population" (Stavenhagen 1996, p. 148).

Even today, indigenous peoples are unable to break away from the stigma of being underdeveloped, according to Western standards. In the name of development, entire indigenous civilisations have been eradicated since colonial times through land expropriation, depletion of natural resources, and eradication of customs and traditions, including annihilation of indigenous languages. Such abuses have, in many cases, led to the extinction of what were once functional societies. Presently, indigenous people existing in at least 70 different countries, all share a common denominator: they have at one point and time in history been at the "losing end of the development process" (Shelton \& Soeftestad 1996, p. 252). Although the international community has done its deed to create mechanisms to protect indigenous peoples, such as the Declaration of Indigenous Rights by the United Nations, centuries of damage have taking their toll, tainting indigenous peoples with distrust and resistance to Western social and economic ideals. 


\subsection{Indigenous knowledge and indigenous language}

"Indigenous knowledge are, in the broadest sense, systems of knowledge that are unique to a particular culture and are passed from generation to generation by members of that society" (Warren 1991, p.1). Indigenous knowledge is embedded in the community and has been developed outside the formal educational system (Grenier 1998). It is closely related to survival and subsistence of indigenous communities, and is transmitted orally from one generation to the next; hence, language is indispensable in transmission hence, language is fundamental in enabling the transmission of indigenous knowledge (Foucault 1969). The knowledge, history and wisdom of entire indigenous societies depend on the existence of language.

Indigenous knowledge is the basis for community-level decision making in areas pertaining to education, natural resource management and other vital economic and social activities (Gorjestani 2000). It is a significant resource with the potential to contribute to the increased efficiency, effectiveness and sustainability of the development process (Gorjestani 2000).

Western social structures fail, more often than not, to recognise the value indigenous knowledge may provide to the advancement of societies (Macedo 1999). Consequently, in many instances, mainstream populations abide by established social norms that do not follow the traditional values and customs of indigenous peoples. In the case of the Māori and the Mapuche, the value of indigenous knowledge can be measured in the success of their pre-colonial social structures which, despite rampant warfare and hostilities between tribes, enabled indigenous communities to establish languages, patterns of land use and political governance that resulted in functional and effective social systems. Retaining the values and legacy of indigenous knowledge is an integral part of indigeneity; without these systems of values and traditions, indigenous peoples dissipate via acculturation into mainstream societies. Language is the key to learning, retaining and diffusing indigenous knowledge (Schaeffer 2003).

Attempts to assimilate indigenous peoples into mainstream populations have been successful in many instances, resulting in the disappearance of entire civilisations. On the 
other hand, there are indigenous groups that have challenged and resisted assimilation, and have effectively succeeded in retaining their traditions and identity; such is the case of the Māori in Aotearoa New Zealand and of the Mapuche in Chile. Both groups, despite having faced a series of adverse circumstances since colonial times, have managed to survive and preserve certain aspects of their indigeneity. Efforts made by the Māori and Mapuche to retain their indigenous knowledge has usually come at the expense of having to forgo certain aspects and customs of their indigeneity; whatever traditions indigenous peoples have been able to preserve have usually been behind closed doors and without the support of predominant social or political systems.

\subsection{Participatory approach development}

Opposed to the 'top-down' approach, S. Biggs (1989) defines participatory approach development as the interaction between local and external actors involved in the implementation or introduction of an innovation process. Participatory approach development functions as a mechanism that can potentially enable local and external parties to reach a consensus that will not place either at a disadvantage. The implementation of participatory methods attempt to actively involve the end users in the construction and design process in order to warrant that the final results of the process will meet the users' needs, that the outcome will be sustainable and effective (Narayan et al. 2001). It should therefore be an interactive and dynamic process between local and exterior stakeholders.

\subsubsection{S. Biggs' participatory approach typology}

In the late 1980s, S. Biggs came up with a typology in order to classify the kinds and levels of participatory approach in development (McDougall \& Braun 2003; Probst et al. 2000). The categories developed by S. Biggs all involve some level of participation in which the local community is able to-in one way or another-provide input on a research or implementation stage of development projects that will directly affect them. S. Biggs' (1989) four ranks of participation are: contractual, consultative, collaborative, and collegiate. Each category has its own set of objectives, research approaches, assumptions, and gives researches and participants alike different roles. Underlying the process however is the core principle that reality is a social construct in which “interpretations are filtered through prevailing cultural values and social, political, 
financial and resource-access contexts" (Conway 2003). This differs from what S. Biggs (1989) denominates a "traditional research process" in that conventional research does not question the paradigms on which reality is built on; participatory approach research, on the other hand, seeks to incorporate different views to reach a consensus between each participant's definition of reality.

S. Biggs' approach to participatory research prompted the emergence of new methodologies that enabled communities at the local level to be part of processes that in many cases dictate their fate. Equally important are Freire's conclusions on the implementation of participatory approach processes in education, which resulted in the emergence of a new methodological approach of development; this will be further discussed in chapter 5 of this dissertation. Participatory approach models replace the notion that view locals as subjects and objects that need to be 'developed' by exterior actors. Different institutions have created different sets of models for participatory approach schemes, most of them running along the same lines: "there can be no development without community involvement" (Freire 1970).

Although processes for participatory approaches of development can not be, in practice, completely compartmentalised, S. Biggs (1989) developed a four-tier framework of participatory approaches that exemplify the range of control that stakeholders may hold in four different case-study scenarios. Such categorisation of participatory approaches is the result of having fieldworkers record their experiences in development projects, who, for the sake of convenience, used certain standards and criteria to classify the approaches to working alongside local communities (Probst et al. 2000). S. Biggs' four types of participation - contractual, collaborative, consultative and collegiate - all share a common denominator: the principle that locals have the right to dictate the degree of involvement of outside fieldworkers (be it scientists, academics, or/and volunteers).

\subsubsection{Contractual and collaborative participatory approach}

In the case of indigenous peoples, it is fundamental to apply principles of either contractual or collaborative participation, particularly during the beginning stages of building a relationship between indigenous communities and outsiders. S. Biggs (1989) defines contractual participation as the process in which one social actor (in this case, the 
indigenous community) holds decision-making power over the decisions taken in establishing an innovation process (in this case, the language revival process), and thus is considered the 'owner' of this process. Those not belonging to the indigenous community may be invited to participate in activities defined by that stakeholder group; "they are (formally or informally) 'contracted' to proved services and support” (S. Biggs 1989) - in this case, to create language planning guidelines that will lead to the implementation of language policies.

This means that linguists, sociolinguists, personnel in government institutions, academics, or researches may be able to assess and survey the status of a language in an indigenous community with the community's consent. Outsiders may be asked by a community to provide choices as to what are the options the community has in terms of creating an effective strategy for language revitalisation, but it is important to remember that it is the community who has the final word on making decisions. An overlap of participatory approaches may happen at this stage: contractual participation may shift to consultative or collaborative participation if communities decide to grant fieldworkers authority in decision-making processes. Regardless of the particular type or method of participatory approach used, what is important is to maintain active levels of local input and involvement within decision-making processes.

\subsection{Participatory approach and language}

The creation of monolingual societies leads to the creation of monocultures, and means that indigenous peoples have to be stripped from their identity and heritage in order to accommodate and facilitate the implementation of Western ideals (Crystal 2000). In the case of Aotearoa New Zealand and Chile, te reo Māori and Mapudungun respectively are the foundations for indigenous development. Māori and Mapuche depend on their indigenous language to establish their social identity and to express, communicate and define the world that surrounds them. The question of who controls or guides the development of the language in a society is where participatory approach should be introduced and implemented. Language should be taught and promoted by its native speakers. Linguistic development in indigenous societies does not limit itself to the teaching of syntactic or to the meaning of particular words, but quite the contrary. Linguistic development includes a transfer of culture and knowledge, and those who take 
the role of mentors, should provide apprentices a full understanding of cultural values (Reyhner 1997). As opposed to 'top-down' approaches in development, community-led language and cultural activities have the ability to renew a group's sense of pride, cultural identity, and self-determination, resulting in successful language revitalisation schemes (Dementi-Leonard \& Gilmore 1999).

Likewise, successful participatory research should highlight the interests of researchers and of participants alike. It is more than likely that interests from both factions will differ in nature; in the case of language and Mapuche and Māori, oral traditions take precedence over written, grammatical structures. Therefore, it is essential for these groups to maintain their spoken language alive; their language is inherent to the existence of many, if not most, of their religious, spiritual, cultural traditions and heritage. Schools and, hence, educators, hold a key role in the preservation and development of indigenous languages.

Effective participatory development in education can lead to bilingual societies. In Chile and Aotearoa New Zealand, governments recognise the theory of the importance of building a bicultural, bilingual society. Nevertheless, placing the theory into practice is where systems fail and, consequently, are unable to establish equitable relationships that are inclusive of indigenous peoples and their languages. The research and observations carried out throughout this thesis allowed me to draw some conclusions as to what are some of the obstacles in language revitalisation efforts. Obstacles as well as achievements of language revitalisation in Chile and Aotearoa New Zealand will be covered later on. What is important to remember and keep in mind is that regardless of the participatory approach method being employed, all efforts to revitalise minority languages should be voluntary and "facilitating and enabling" rather than "compulsory and punitive" (Fishman 1991, p. 82).

\subsubsection{Participatory approach in language planning}

In order to implement participatory method as a development tool in language planning, certain criteria must be taken into consideration. It is not possible to ingrain into people the will to revive or maintain a language from the outside (Skutnabb-Kangas 2000). Krauss (1992) notes how only native speakers of endangered languages hold the power to 
lead successful language revitalisation movements; these movements must therefore be led by indigenous institutions, organisations, academics, and activists. It is therefore crucial for community members and outside fieldworkers to agree on how to approach the preservation and revitalisation of language. The agreement should be reached by a consensus in which stakeholders understand their duties and responsibilities. It is critical for the implementation of participatory to take place during the initial steps of the process of language planning, and to determine what kind of participatory approach will be used.

\subsection{Conclusion}

Because indigenous knowledge does not rely on grammatical syntax, it depends on the diffusion of spoken indigenous knowledge in order to continue to exist. Indigenous peoples are the sole holders of indigenous languages, hence, of indigenous knowledge. Therefore, only they have the necessary faculties to maintain and restore their indigeneity. Used in language planning, participatory approach methods could potentially allow external parties to engage with indigenous peoples in language revitalisation efforts in order to propagate indigenous knowledge. Participatory approach model structures should, in a way, work as a democracy: local communities should be able to freely elect their fate without being subjected to authoritarian decision-making processes that exclude them as main stakeholders. 


\section{Chapter 5 - Languages' cycles of life and death}

"The choice of language and the use to which language is put is central to a peoples' definition of themselves in relation to their natural and social environment; indeed in relation to the entire universe."

Ngugi wa Thiong'o, 1986

\subsection{Introduction}

Over 50\% of the world's 6,000 languages are endangered (UNESCO 2007; Crystal 2000; Skutnabb-Kangas 2000). Yet why does it matter and why should we care? Because languages are not just words; they are powerful tools that evoke meanings and knowledge that goes beyond the lexical and immediate significance of words. They define culture, embody societal values and practices, and transmit systems of knowledge from one generation to the next.

The following will discuss the importance of language and the significance as well as meaning of language death. It will provide understanding of the core linguistic concepts used throughout this research process. Also addressed will be the negative and positive implications of globalisation on language revival efforts by drawing attention to the role UNESCO has played in recognising the importance of protecting indigenous languages.

This chapter reviews the linguistic measures used to determine a language's health and establish the relationship between these measures and the development of indigenous peoples. It will look at what the processes of language planning and language policy entail and how they differ from one another. Finally, the following argues that establishing models based on participatory approach in language planning can lead to successful long-term indigenous language revitalisation. In the case of Aotearoa New Zealand and Chile, the implementation of models of participatory approach (or lack of) will be, further on, examined within the context of each country's education system.

\subsection{The importance of language}

Language is essential to any human society — not only as a means for communication, but as a carrier of history, culture and wisdom. "If you want to destroy a people, you get their language first; get rid of the language and bring in another language, and that brings in 
another world view" (Skutnabb-Kangas 2000, p. 317). Language enables information to transcend time; it is the key to providing explanations on how societies function, on who we are and where we come from, how our culture works, and how we define the world around us. Every existing language epitomises the distinctive cultural wisdom and legacy of a culture and its people.

\subsubsection{Language death}

A language becomes endangered when its speakers cease to use it; language death occurs when speakers stop using it altogether (Crystal 2000, Crawford 1996). Language death is a gradual process triggered by social needs in which a language is replaced by a new language that has higher social and political status (Crystal 2000; Aitchinson 1991). A language becomes endangered when speakers find that its use no longer fulfils their social needs, or when its use alienates speakers from participating or contributing to society. Dorian (1999) states that in cases when people have changed to another language, giving up their own entirely, "it has nearly always been due to a local history of political suppression, social discrimination, or economic deprivation" (p. 31).

The process of language death has several stages which help linguists and society alike determine the language's condition. A language may be safe, endangered, moribund, or extinct (Crystal 2000; Krauss 1992). Kincade (1991) classifies a language as endangered when is it is "spoken by enough people to make survival a possibility, but only in favourable circumstances and with a growth in community support" (p. 160). Wurm (1998) uses three levels to indicate the degree of language endangerment: potentially endangered, endangered, and seriously endangered. A language is potentially endangered when it is at a social and economic disadvantage and beginning to lose child speakers; it is endangered when there are few or no children learning it, and the youngest speakers are young adults; and a language becomes seriously endangered when the youngest good speakers are ages 50 or older (Wurm 1998, p. 192). Languages that surpass the seriously endangered category are said to be moribund. A language becomes moribund when it is no longer being learned as a mother tongue by children, breaking intergenerational transmissions of knowledge as well as language (Krauss 1991). It becomes extinct when it has no speakers left (Crystal 2000; Wurm 1998). 
In order to measure the levels of language loss more precisely, Fishman (1991) developed an eight category scale that shows a language's degree of endangerment. Fishman's Graded Intergenerational Disruption Scale for Threatened Languages (1991) will be introduced in chapter 10 to make reference to levels of language endangerment in Chile and Aotearoa New Zealand.

Death of a language deprives humanity of the opportunity of coming into contact with the knowledge of entire communities and groups. Language loss is not a problem that concerns only linguists; it concerns and involves everyone on a global scale: the decrease in language diversity lowers the pool of knowledge from which we as humans can draw from, therefore leading to the reduction of the adaptational ability of humankind (Bernard 1992). When a language dies, it takes with it entire civilisations, solutions to future problems, explanations to what many consider enigmas. Language death takes us one step closer to the creation of a monolingual society.

\subsubsection{Language as a right}

In the human rights context, linguistic concerns have been continuously neglected, as opposed to economic and social concerns (Eide 1995). The Universal Declaration of Human Rights does not provide a right to language. The Declaration on the Rights of Indigenous Peoples, however, includes the right to indigenous languages in Articles 14, 15 and 17, which could potentially facilitate efforts for indigenous language revitalisation. Relevant to the content of this dissertation are Articles 14 and 15. Article 14 protects indigenous languages by establishing the right to "revitalise, use, develop and transmit [...] languages" (OHCHR 2007). Article 15 promotes the use of indigenous languages in education, stipulating that all indigenous peoples have the right to "establish and control educational systems and institutions providing education in their own languages, in a manner appropriate to their cultural methods of teaching and learning" (OHCHR 2007).

\subsection{Globalisation and language revitalisation}

As discussed earlier, globalisation proves to be a mechanism of dual nature for indigenous peoples: on the one hand, it threatens their existence by imposing cultural assimilation. Although advances in technology have proved efficient in the dissemination 
of information at a global scale, $90 \%$ of the world's languages are still not represented on the internet (UNESCO 2007). This is an example of how language limits the contribution of indigenous peoples to society. As a result, indigenous peoples still find themselves obliged to use mainstream societies' tools (such as learning English, for example) in order to participate in processes of globalisation, or to entice the public's attention to their cause.

On the other hand, globalisation presents indigenous peoples with the option of creating a global network to raise awareness and share information. It can be used as a strategic mechanism in the efforts to recognise the importance of indigenous languages and to foster language revival. Paradoxically, it reminds them that the effectiveness of their efforts and success depends on them having to recur to the use of mainstream language.

\subsection{Global forces and endangered languages}

As a result of globalisation, local, national and global communities are increasingly interdependent. Consequently, localities are much more susceptible to the ripple effects of decisions taken at an international level regarding indigenous issues. As noted in the previous chapter, international organisations play a significant role in coordinating and facilitating cooperation on a global scale by raising awareness of the importance of indigenous issues. In the case of language revitalisation, the role of UNESCO has proved to be crucial in mobilising efforts worldwide to raise awareness of the critical condition of many indigenous languages. Established in 1945 as a specialised agency of the United Nations, the purpose of UNSECO is to:

contribute to peace and security by promoting collaboration among nations through education, science and culture in order to further respect for justice, for the rule of law and for the human rights and fundamental freedoms which are affirmed for the peoples of the world, without distinction of race, sex, language or religion. (UNESCO 1945)

It was during the 1980s that UNESCO addressed, for the first time, language diversity as a crucial element of cultural diversity and recognised the potential implications that loss of indigenous languages would have on the global community. Up until then, the importance and urgency of preserving languages was overshadowed by other cultural 
concerns that were deemed of more importance. Even after UNESCO directed its attention to endangered indigenous languages, the urgency of language revitalisation remained latent until September 2001. It was then that UNESCO finally established an endangered language programme by adopting the Universal Declaration of Cultural Diversity.

\subsubsection{Universal Declaration of Cultural Diversity}

A fundamental point in the development of the Declaration of Cultural Diversity (2001) was the emphasis on participatory models of language preservation, which call for "all those involved to work hand in hand with the endangered language communities towards documentation, maintenance and revitalisation of their language." The Declaration specified that "any work in endangered language communities must be reciprocal and collaborative" (UNESCO 2001). In the past, declarations made by international organisations have proved to be at times elusive, leaving a gap between drafted documents and their actual implementation. This is particularly the case regarding issues on the recognition of rights of indigenous peoples. This is why the role UNESCO plays in safeguarding indigenous languages is vital: by designating and implementing projects on endangered languages, the organisation raises global awareness and has the scope to initiate pressure on governments, at international, national and local levels. The documents and declarations regarding endangered languages that UNESCO has developed, provide indigenous communities with an instrument that serves as evidence that their need to protect their language is legitimate. It is unfortunate that the global community needs the stamp of approval of an international organisation in order to validate a genuine cause - and that such extreme measures of language deterioration had to be reached before international agencies endorsed language revitalisation efforts.

\subsection{Education and language revitalisation}

Fishman (1991) and Crystal (2000) state that the role of schools is fundamental in restoring minority and endangered languages. Education systems reflect the values and aspirations of a nation-state's dominant society (Schaeffer 2003). Incorporating minority languages to education systems promotes the use of endangered languages by elevating the language's status and offering equal opportunity of social, political and economic 
participation to minority languages speakers. "An endangered language will progress if its speakers have a strong presence in the educational system" (Crystal 2000, p. 136).

Languages can not survive as abstractions; restoring indigenous languages requires special planning that includes formal recognition in education systems and incorporation into school curricula. Therefore, schools are focal points that have the potential to promote the development of a child's mother-tongue by teaching it to them at the early stages of their lives. Lennenberg's (1967) 'critical period hypothesis' states that the crucial period of language acquisition is before the age of 12 years. Lenneberg theorised that languages learned after this period could not be learned in a normal and fully functional sense, and suggests incorporating language acquisition into the early stages of a child's life. Incorporating indigenous languages during this stage is not important only in terms of linguistic development and skills, but perhaps even more important is that it gives children the opportunity to adopt and develop social and cultural values related to indigeneity. By integrating these value in the curricula, as well as in the extra-curricular activities, education systems are able to give indigenous language a formal place alongside the dominant language (Crystal 2000).

Governments are responsible for providing a nation's education system with a suitable framework that can adequately incorporate teaching of an indigenous (or minority) language. Skutnabb-Kangas (2000) asserts that what happens in educational institutions is a concretisation of educational state language policies. The author argues that ultimately, it is governments who are responsible for language death, not only for what they do, but more so, for what they fail to do.

In the case of language revitalisation, education is a powerful tool that has the potential of reversing colonial ideals of cultural supremacy, and is a key instrument in promoting of indigenous knowledge. "Education is always an action either for the domestication of people or for their liberation" (Freire p. 99, 1985). Schools can be used to promote the development of bicultural societies by teaching principles that reflect upon the importance of having cultural diversity and of maintaining indigenous legacies alive. 


\subsubsection{Freire's participatory approach model: the use of language}

During the 1970s, Brazilian educator Paulo Freire began advocating participatory approach research in order to attempt the disruption of an oppressive system that only seemed to benefit a privileged elite (Freire 1970). Freire believed that in order for development to take place, it was necessary to recognise the needs of people. According to Freire's observations, this could be achieved through the implementation of participatory approaches that promoted dialogue and bilateral education: on one end, developers should educate themselves of the needs of the people, and on the other, people needed to have access to the skills and necessary means to express their needs. Freire $(1970 ; 1985)$ indicated to the use of language as a tool used by colonisers in schools in order to control indigenous populations.

In order to raise levels of consciousness and awareness within communities of the importance of language revitalisation, and in order for external actors to fully understand the needs of indigenous peoples, there needs to exist more than a two-way dialogue; there needs to be a 'counter-hegemony' process in which indigenous are empowered to take decisions regarding the revitalisation of their own language. Applying Freire's method of participation in education means that local participants are empowered to dictate in their own language, and by using their own systems of knowledge, the language planning strategies that will be implemented, and what language policy to institute. In other words, indigenous peoples should not only be active participants of the process of language restoration, but they should have the choice to own this process. Without indigenous participation, efforts to achieve successful language revitalisation schemes in schools, or even at national levels, are bound to fail. The two cases in point being, in this dissertation, the effects of participatory approach in language revitalisation efforts in both Aotearoa New Zealand and Chile.

\subsubsection{Assimilation as opposed to participation}

When one culture assimilates another, as in the case of colonisers and indigenous peoples, the sequence of events affecting the native language of those being colonised seems to be similar in Aotearoa New Zealand and Chile (Crystal 2000). The first consequence of colonisation on language is the pressure of the homogeniser (or coloniser) to create a dominant language which all must learn (Constantino 1978). In the 
case of Aotearoa New Zealand and Chile, a 'top-down' approach strategy was implemented as laws and trends for social discrimination were introduced by the colonising governments. This enabled the British and Spaniards as colonisers to impose and establish a new system of ideas, causing indigenous communities to break their ties with their native language, and consequently, break their connection to their traditions and cultural heritage. Schooling and education are focal mechanisms in the assimilation of indigenous peoples by colonisers and more recently, by forces of globalisation.

\subsection{Bilingualism}

Linguists tend to disagree over a unanimous definition for bilingualism; for practical terms, this dissertation understands bilingualism to be the ability to communicate (either orally or written) in two languages (Haugen 1953). ${ }^{7}$ The aim of this research is to show how language death is a social phenomena which roots in colonial times and that hinders the development of indigenous peoples. The period of bilingualism in Aotearoa New Zealand was very short-lived, and it will be argued that in Chile it never really existed.

Assimilation does not necessarily prelude bilingualism; bilingualism may be used as a tool that accelerates assimilation. In Aotearoa New Zealand and Chile, a period of bilingualism followed the colonial process of assimilation of Māori and Mapuche respectively. During this period of bilingualism, people learn to speak and understand each other in two different languages while they adjust to the new language which is being imposed and that will eventually become the dominant, if not sole, language of use.

In analysing bilingualism in social sciences, it is necessary to be aware of the wider social and political context surrounding the two languages at stake (Hamers \& Blanc 1989; Cummins 2002). Of particular importance in language revitalisation efforts are a society's views and attitudes toward minority languages, which in the case of Aotearoa New Zealand and Chile, are indigenous languages. Even though it is commonly assumed that 'majority' and 'minority' languages are defined by numerical amounts of speakers,

\footnotetext{
${ }^{7}$ Bilingualism: $b i$ comes from the Latin word for "two", lingual meaning "articulated with the tongue", and the suffix ism describes an action or process. We can therefore deduce that it means to speak two languages, which is indeed how the term is defined in the dictionary (Haugen 1953).
} 
its more important reference is to differences in power, rights and privileges (SkutnabbKangas 2000).

\subsubsection{Diglossia and disglossia}

Bilingualism is replaced by what can be considered to be passive bilingualism, a situation in which elders speak to youngsters in their indigenous language but children respond in the dominant language (be it Spanish in the case of Chile or English in the case of Aotearoa New Zealand). Bilingualism, consequently, is replaced by the phenomenon of diglossia (Hamers \& Blanc 1989). Diglossia is understood to be the coexistence of two different languages, one of which has a higher-status and is regarded as the official means of communications, while the other language is reserved for certain functions, circumstances or domains (Hamers \& Blanc 1989). Although social diglossia allows for the existence of two official languages, it privileges one over the other. Nevertheless, diglossia as a linguistic phenomenon can actually protect the existence of a language by providing it at least circumstances in which it may be used; it curtails its use (hence, its

existence), but it doesn't eradicate it. In most cases, however, younger generations acquire absolute proficiency in the new language, and find if much more useful than their old, native language. Subsequently, feelings of shame of using the indigenous language in public, deter the development of bilingualism, leading to the creation of a monolingual society (Crystal 2000). The result is a condition of disglossia, meaning that a society denies other languages and relegates them to the status of non-tongues (Ogbu 1987).

\subsubsection{Colonialism is not bilingual}

It is clear then that colonisers did not consider bilingualism to be an asset; on the contrary, the existence of two different languages complicated matters for them. "Central to the colonial worldview was the notion of the superiority of the colonial language and the inferiority of indigenous languages" (Mule 1999, p. 227). Presently, the world's linguistic diversity is threatened by globalisation, as indigenous minorities seek to join majority language education programmes in order to decrease levels of social, political and economic marginalisation (Schaeffer 2003).

In the context of colonial times and globalisation, speakers of dominant languages believe in the convenience of monolingualism as a desirable tool that facilitates 
communications (Fishman 1991). Consequently, speakers of endangered languages are given "an either/or choice regarding their language: either to adopt [the dominant] language, or to remain outside the advantages stemming from its mastery in the culture in which the [dominant language is strongest]" (Wurm 1998, p. 193).

\subsubsection{Bilingual education and immersion methods}

Bilingual education, as defined by Andersson and Boyer (1970) is "instruction in two languages and the use of those two languages as mediums of instruction in any part, or all, of the school curriculum" (p. 12). For a programme to be considered bilingual, it must use both languages in teaching students generic curriculum content other than just having the language being taught as a subject on its own (Baker \& Prys-Jones 1998). This dissertation will look upon the results of using immersion programmes in schools in promoting bilingual societies and therefore, in promoting language revitalisation efforts.

Cummins and Swaine (1986) refer to immersion programmes as "the situation in which children from the same linguistic and cultural background who have had [almost] no prior contact with the school language are put together in a classroom setting in which the second language is used as the medium of instruction" (p. 8). The use of the word 'immersion' accurately indicates the nature of the programmes, which is to fully carry out instruction in a foreign or second language, with the intention of not only teaching students how to be fluent in a second language, but to expose them to the cultural values and conditions surrounding the language. Immersion programmes provide students the ability to function in two languages. Ultimately, however, the overall goal of immersion programmes is for students to learn the language within a culturally appropriate context, and learn the significance and relevance of language to preserving cultural practices and traditions. Consequently, students in immersion programmes have the same level proficiency of native speakers and, most importantly, they are able to identify positively with both language groups because they understand the contexts behind each groups (Skutnabb-Kangas 1984).

\subsection{Language planning and language policy}

As it has been noted, languages need speakers; without speakers, a language dies (Crystal 2000). Speakers are therefore empowered with - as well as held responsible for - the 
survival of a language. Crystal (2000) notes that protecting and revitalising a language require proper planning and management among major stakeholders in order to achieve long-term success. Successful language planning strategies lead to the development of sustainable language policies. In other words, the relationship may be seen as one in which the end justifies the means: language planning methods are developed in order to accomplish the institution of language policies.

In the case of revitalisation of indigenous languages, S. Biggs (1989) and Freire (1970; 1985) define participatory approach as a process that requires indigenous people to be as equally involved and engaged as external actors throughout the process of language planning. This will enable the development of a realistic language policy that will address the needs, as expressed by locals, to restore the language.

\subsection{Language planning}

Language planning as defined in Kauplan and Baldauf (1997) is the attempt to modify the linguistic behaviour of a society due to a particular motive. It refers to the conscious effort and deliberate process of implementing decisions to change the behaviour of others regarding the usage, status, acquisition, structure and functional allocation of language. The purpose of language planning strategies is to determine which languages should be used in societies (Trudgill 1983).

\subsection{Language policy}

Language planning is not the same as language policy. Toffleson (1991) defines language policy as the efforts made by governments to implement and make language planning strategies official. In order for language policies to be implemented, a process of language planning must have preceded. After establishing the extent to which a language has been dislocated, steps may be taken to begin overturning language shifts and determine the best strategy that will allow for language revival. This will typically include the development of goals, objectives and strategies in order to change the way a language is used.

In the case of indigenous language revitalisation, language planning should lead to the rehabilitation of indigenous culture and to promote the conservation of indigenous 
knowledge. But if language revival is an endeavour motivated jaded pride in order to reinstate the past, then it will not prove beneficial for the progress and development of indigeneity; language planning and eventual revival should be implemented to potentially provide for the necessities of the future (De Freine 1965).

\subsection{Steps to measuring a language's health}

This dissertation will focus on five key indicators in order to determine the extent to which a language is endangered (in other words, determine the 'health' of a language): its usage, status, acquisition, corpus and awareness (Chomsky 1975; Cooper 1989; Crystal 2000). These areas are interdependent, and in order for language planning strategies to be effective, all areas must be addressed, given equal importance and recognition.

Language usage refers to the frequency with which a language is practiced (Cooper 1989). It also explores the areas or social settings in which people choose to use their language. Is a language reserved for ceremonial or special occasions? Do people feel they can freely use a language without fear of discrimination or rejection of any sort? The threat of language loss initiates when its usage declines in domains where it was once secure, and alarms should go off when the language's usage diminishes in homes and among family members.

Language status refers to the importance and value people place on a language (Cummins 2002). Language status determines the social value given to a language rather its linguistic importance or educational usefulness. It takes into account peoples' attitudes toward a language; while some may feel privileged to speak a particular language, others might feel ashamed due to social prejudices. Governments play an fundamental role in elevating the status of a language by giving it a formal place alongside a the dominant language (Crystal 2000). The first step is therefore, to elevate the status of a language is to make it official and incorporate its use in national education curricula.

Chomsky (1975) defines language acquisition as the development process of language capability in humans. Language acquisition depends largely on peoples' attitudes towards a language: if a language is highly regarded by a community, more people will be keen on learning it. Language acquisition should reflect approximate estimates of the amount 
of people who speak the language and the methods used to teach them how to communicate, either in oral or written form (Chomsky 1975). This area will also determine the different levels of proficiency among speakers.

Language corpus refers to the technical linguistic developments of languages (Van Huyssteen 2003). Due to the lack of terminology in indigenous languages to address modern concepts, ideas and technologies, language corpus engages in the creation of methods that should be implemented in order to develop sources (dictionaries, writing systems) that can adequately represent new concepts. A language can not be left encapsulated in a particular segment of history; it must evolve and adapt to changing notions.

It is challenging, however, to 'modernise' a language when it has been on the verge of extinction; the process of restoration takes time and perhaps even more importantly, it requires resources. A language's corpus is considered healthy when it can adequately describe a community's current lifestyle, and includes words for current concepts and technologies.

Finally, it is necessary to measure the level of critical awareness people have of a language's condition (Amery 2001). Communities need to recognise how critical the situation of their language is. They must also be made aware that they have a choice and the right to revitalise their language. Strategies for language recovery on an oral and written level may then be developed in an attempt to establish a language policy that will help revitalisation efforts.

\subsection{Conclusion}

Language death is not a recent phenomena, but one that dates back to colonial times. By imposing language as the dominant (if not sole) means for communication, colonisers were able to use language as a standard for homogenisation, which consequently helped established and facilitated control over indigenous communities. In the case of Aotearoa New Zealand, the British instituted English as the dominant language to replace te reo Māori; in the case of Chile, the Spaniards enforced the use of Spanish to replace Mapudungun. Reversing the damage made to the development of indigenous 
communities by discontinuing the use of indigenous languages is an imminent challenge. But there are ways to achieve language revitalisation. Using institutions such as UNESCO to raise global awareness levels of the significance of language for indigenous communities and recognising indigenous languages as an inherent human right, may encourage successful language restoration. Furthermore, developing participatory models of language planning schemes in schools can potentially lead to the implementation of successful language policies. Schools have the potential to secure a place for indigenous languages in societies. 


\section{Chapter 6 - Right to te reo Māori won by the pen}

"Whānau ana te tamaiti, mauria atu ka whakamau ki te $\bar{u}$, $\bar{a}$, hei reira tonu ka tīmata te kōrero Māori atu ki a ia"

"When a child is born, take it, put it to the breast, and begin speaking Māori at that point."

Kaumatua Hui, 1980

\subsection{Introduction}

Language revitalisation efforts of te reo in Aotearoa New Zealand have been unique in their success by world standards. Due to Aotearoa New Zealand's particular succession of colonial events, and more specifically, to the signing of the Treaty of Waitangi in 1840, language revitalisation efforts of te reo have been effective and beneficial to the restoration and development of Māori culture, identity and values. The following chapter will argue that upholding the Treaty of Waitangi has helped secure the existence of te reo by establishing the grounds to create partnership between Māori and Pākehā. This partnership led to the foundation of the development of a diverse society in which ideally, both races feel their identity, including language, is respected, protected, and catered for. The objective of this section is to look into the Treaty's dual and incongruous role: first, as an instrument that threatened and endangered Māori existence by revoking Māori sovereignty; and second, as the document that, in all irony, has more recently allowed Māori to defend their heritage and retain much of their identity. The following will highlight the significant events that led to the signing of the Treaty of Waitangi and the impact these had on te reo.

Finally, the chapter will emphasise how British processes of assimilation that sought to eliminate Māori culture, traditions and heritage infringed the Treaty of Waitangi. Particular emphasis will be given to the instrumental role education played in the process of assimilation and the impact colonial administered schools had on diminishing the number of te reo Māori speakers. 


\subsection{Aotearoa New Zealand: up for grabs}

British presence in Aotearoa New Zealand increased in the 1830s as a result of mixed interests on behalf of both, the Crown and the Māori. British missionaries and early New South Wales governors established extensive relations with the Māori prior to the 1830s, encouraging them to seek 'protection' from the British Crown against foreign invaders (Orange 1987). ${ }^{8}$ The effectiveness of creating an image of British Crown as a paternal protector was such that in the face of what was misinterpreted as a French menace, thirteen major northern Māori chiefs agreed to appeal for British protection. Their request was for the King to "become a 'friend and the guardian of these islands', preserving them from foreign threat, $[\ldots]$ and from the misconduct of British subjects" (Orange, p. 12). The petition triggered a sense of British empowerment over Aotearoa New Zealand's Māori, and was, in a way, interpreted as an invitation to intervene in subsequent events.

Crown intervention increased as the misconduct of British subjects in Aotearoa New Zealand intensified. Equally important was the Crown's responsibility "to protect the lives and interests of the growing number of British subjects living in Aotearoa New Zealand" (King 2003, p. 152) as licentious and scandalous behaviour involving alcohol and prostitution escalated, particularly at the Bay of Islands' settlement of Kororareka. Māori made a second appeal to the Crown in an attempt to restore order, which consequently amplified the Crown's sense of authority to get involved in Aotearoa New Zealand.

\subsubsection{British intervention}

As a consequence of the appeals, and particularly due to Britain's increasing concern over maintaining control of trade and intensifying its profits while sustaining a harmonious environment and relationship with Māori, the first step towards annexation was taken.

Britain acknowledged its interest in securing a permanent relationship with Aotearoa New Zealand in 1832, by appointing James Busby as first British Resident in Aotearoa New Zealand. Busby's arrival was arranged so that it appeared that his appointment was

\footnotetext{
${ }^{8}$ Most specifically, against French invasion.
} 
a response to Māori appeals to the Crown, which in turn appeared to recognise the Māori as equals by granting them the same levels of protection as it was provided its citizens (Orange 1987).

\subsubsection{First a flag}

Expectations ran high with Busby's arrival. Both the British and the Māori were led to believe that Busby's presence signified "a promise of protection to life and property" (Orange 1987, p. 15). Busby however did not have any British naval, military or civil support and he could only verbally adjudicate cases and act as mediator (King 2003; Orange 1987).

Busby believed that by encouraging Māori nationalism, and creating one Māori identity, he would be able to promote a collective form of government and unity among tribe leaders. The first step he took into attempting to consolidate Māori sovereignty over Aotearoa New Zealand - and his first official act — was the selection of a Aotearoa New Zealand flag. The decision came as a consequence of the confiscation and impounding of Aotearoa New Zealand ships in 1830 due to the absence of an accredited national flag that acted as register.

In 1834, Busby proceeded by convening a meeting with twenty-five Māori chiefs in front of his residence at Waitangi to select one of three flags presented to them in order to represent their country (Walker 1990). Busby's strategy was to ask Māori for their 'participation' in helping him understand their needs in order to establish a system that could fulfil these needs and work under their mandate; in essence, a method of participatory approach (Orange 1987; Walker 1990).

To many, the cohesive affair represented advances in humanitarian and participatory approaches of colonisation methods, departing from the previous history of ruthless, brutal assimilation techniques in the Americas, Asia and Africa (Walker 1990). On the other hand, the event portrayed a new method of colonisation: one which involved carefully manoeuvring relations with indigenous peoples in order to protect colonisers' economic interests at stake. Symbolically, once the flag was chosen, a feast followed in which Europeans were presented with an elegant lunch, while Māori chiefs were given "a 
cauldron of cold porridge, which they were obliged to eat with their fingers" (King 2003, p. 154).

\subsubsection{A Declaration of Independence}

On 10 October 1835, Busby received a communication that Frenchman Charles Baron de Thierry was proclaiming himself sovereign chief of Aotearoa New Zealand (Saunders 1896). Busby immediately called a meeting of thirty-four northern chiefs with the intention of having them sign a Declaration of Independence in order to block Thierry's claims (Orange 1987). Such Declaration consisted of three articles, and was drafted and translated by Busby and Reverend Henry Williams without Māori input (Walker 1999). On 28 October 1835, the chiefs signed the Declaration under the designation of United Tribes of New Zealand, asking King William "to be the parent of their infant state [...] its Protector from all attempts upon its independence" (Orange 1987, p. 21), also using the document to thank him for acknowledging the Māori flag.

\subsubsection{A convenient yet ineffective declaration}

The Declaration became a key instrument in British dominance over Aotearoa New Zealand. The fourth and final article of the document declared His Majesty to be the parent of the infant State of Aotearoa New Zealand and to "become its Protector from all attempts upon its independence" (Orange 1987, p. 21). Therefore, while on the surface the Declaration might have appeared to grant Māori autonomy and complete authority, the reality was that it reinforced the Crown's role as saviour by offering to provide 'protection' and safeguard Aotearoa New Zealand. In effect, the Crown acknowledged the Declaration bearing in mind that the "independence of the country under the protection of the British Government would be the most effectual mode of making the country a dependency of the British empire in everything but the name" (Orange 1987, p. 22).

The Declaration however did hold important twofold significance: it effectively constituted Aotearoa New Zealand as a single sovereign state under complete Māori rule, separate from the British Empire (Moon 2002). Secondly, and almost consequently, it presented an accurate translation of the concept of sovereignty, which explains why the chiefs may have conceded to signing it in the first place. By associating "sovereignty and 
kingship with the concept of the mana whenua ${ }^{9}$ of a chief [...] sovereignty was declared to reside with the collective authority of the chiefs of the confederation" (Walker 1999, p. 112). Their mana ${ }^{10}$ was not being threatened in any way - on the contrary, as far as the chiefs were concerned, the fourth article affirmed the existence of their mana by extending protection from the British Crown. It comes to show that Busby and head missionary Henry Williams, ${ }^{11}$ who both drafted and translated the articles of the Declaration, had a clear understanding of the Māori significance of mana and sovereignty. This becomes particularly important later on, with the drafting of the Treaty of Waitangi.

\subsubsection{Succession of misfortunate events}

In 1837 the Crown felt its control over Aotearoa New Zealand threatened by the New Zealand Company's interest in acquiring vast amounts of land for private interest. If Aotearoa New Zealand was in fact an independent country, then land acquisition by contract with the Māori was reasonable. Profits of colonisation, however, were intended to benefit the Crown, not the New Zealand Company. The Crown realised the immigration to Aotearoa New Zealand was spiralling out of control, and that this meant that Aotearoa New Zealand was being colonised in a subtle, informal way by the private interests of British subjects willing to buy the country (Ward 1999).

The Crown's ability to intervene was restricted by amends that had been made to British colonisation strategies of previous years, with the establishment of the 1837 Report of the Aborigines Committee of the House of Commons, condemning further exploitation of Aborigines and setting new guidelines for future colonies (Sorrenson 1991). The Report provided indigenous people with a certain degree of protection against abuses by colonisers and represented an attempt to make colonisation efforts more humanitarian. The Report also signified an important obstacle that the British would have to overcome: in order to legally establish their settlers in Aotearoa New Zealand territory, they needed the consent of Aotearoa New Zealand's indigenous peoples.

\footnotetext{
${ }^{9}$ Mana whenua: territorial rights, power from the land - power associated with possession and occupation of tribal land.

${ }^{10}$ Mana: prestige, authority, control, power, influence, status, spiritual power, charisma - mana is a supernatural force in a person, place or object.

${ }^{11}$ Missionary leader in Aotearoa of the Church Missionary Society.
} 
On 14 January 1840, Aotearoa New Zealand was declared a colony of New South Wales (Walker 1990). Captain William Hobson was sworn in as Lieutenant-Governor of New South Wales with the purpose of obtaining surrender of Māori sovereignty to the British Crown (Walker 1990). His appointment is fundamental in that it reflects the shift of Britain's stance from a 'no-colonisation' position to one supporting and promoting direct intervention, colonisation and cultural assimilation (Adams 1977).

\subsection{The Treaty of Waitangi}

On 3 February, the Treaty of Waitangi was drafted. Hobson, with the help of his secretary James Freeman and Busby, created the treaty document, which was comprised of a preamble, three articles, and an amended postscript. It is worth noting that neither of the three men involved in the creation of the Treaty of Waitangi were lawyers, nor did they have any kind of legislative skills or training. One hundred invitations were sent to chiefs to adjourn on 5 February in Waitangi (Orange 1987).

Chiefs were not expected to understand English; therefore, the English version of the treaty had to be translated to Māori in order for the chiefs to understand and sign the agreement. On 4 February, one night before the meeting at Waitangi, Hobson assigned missionary Henry Williams and his son Edward the task of translating the English version of the treaty to Māori. Documentation at the time yield no indication of Māori assistance in the translation process (Carleton 1877). The Treaty of Waitangi's translation, therefore, does not use indigenous Māori, but instead, uses the Māori missionaries understood (Ross 1972).

Perhaps the most challenging task for Williams was the translation of concepts in the English treaty that did not exist for Māori and therefore lacked a term or definition. Thus, the comparison between the English and Māori versions of the Treaty of Waitangi ${ }^{12}$ reflect crucial discrepancies, as in the case of the translation of the term of sovereignty. Sovereignty was translated by Williams as kāwanatanga, an invented word derived from $k \bar{a} w a n a$, itself a transliteration of 'governor,' used previously by missionaries to depict to the Māori the Biblical character of Pontius Pilate. Käwanatanga, however, was being

\footnotetext{
${ }^{12}$ There are five English versions of the Treaty.
} 
used to translate two terms that had hugely different implications: territorial sovereign authority and government. Therefore, when the Treaty of Waitangi transferred "all rights and powers of Sovereignty" over to the Crown in Article One of the English text, Māori chiefs could have easily presumed they were giving up governing, but not territorial sovereignty (Maaka \& Fleras 2005). They could not have, however, presumed they were giving up the rights to te reo. Had Williams incorporated or linked the concept of kāwanatanga to the mana whenua of a chief, like it had been previously done in the Declaration of Independence, then perhaps the Māori could have understood the real implications of signing the Treaty. But the use of kāwanatanga to convey both 'sovereign authority' and 'government' was devious. It made the Treaty of Waitangi a saleable option that would secure the signature of Māori chiefs; it was not, however, an accurate nor precise interpretation of the Crown's interests.

Article Two of the Māori language version guaranteed te tino rangatiratanga ${ }^{13}$ over land, resources, properties and taonga katoa ${ }^{14}$. Such vague notion of what these treasures encompassed triggered future conflicts over the debate of whether language was considered a taonga. ${ }^{15}$

Finally, Article Three presented Māori with the "all rights and privileges of British subjects." It granted citizenship rights to Māori, while tacitly and consequently tying them to British law and jurisprudence. This included establishing English as Aotearoa New Zealand's dominant language, as well as the introduction of British models of systems of education.

On 6 of February 1940, Hobson assured Māori present at Waitangi that the treaty offered the Crown protection that Māori had often asked for (Orange 1987). After long hours of debate, forty-three chiefs signed the treaty. Over 500 Māori chiefs signed the document as it was taken around the country during the following eight months (King 2003). Opposition to the treaty was overcome by the notion that the treaty was asking little of

\footnotetext{
${ }^{13}$ Te tino rangatiratanga: unqualified chieftainship; self-determination.

${ }^{14}$ Taonga katoa: all other treasured possessions.

${ }^{15}$ Tikanga: treasure.
} 
Māori, but offering them much (Orange 1987). The stage for future race relations between Pākehā and Māori had been set.

\subsubsection{A contract in Māori}

The Treaty of Waitangi represents a political compact. Maaka and Fleras (2005) define political compact as "more than a simple contract between parties; it constitutes a solemn pact that establishes a binding covenant between two fundamentally autonomous political communities, with controlling interest over both joint and exclusive jurisdiction" (p. 108). In other words, the Treaty established a foundation for the creation of a partnership between the Crown and the Māori. It sought to reaffirm cooperation between both parties, instituting them as constitutional partners that "were expected to act in good faith toward the other, while the Crown assumed a fiduciary obligation to protect and respect Māori” (Henderson \& Bellamy 2002; Maaka \& Fleras 2005, p. 108).

Whatever the English version of the Treaty of Waitangi specified, was of no relevance to the Māori, for the contract to which they complied was in Māori. Imprecise translation and the obscurity of the meanings conveyed by the use of certain terms, concealed the Crown's real intentions of using the Treaty as a tool that would secure colonisation efforts. The Treaty of Waitangi served the British as an instrument for achieving legitimate control over Aotearoa New Zealand, effectively terminating the constitutional autonomy of Māori by inaugurating an era of colonial governance (M. Durie 1998).

\subsection{Te reo Māori and the Treaty of Waitangi: before and after}

The period following the Treaty of Waitangi should have, in theory, been one of partnership. As far as customs and traditional values were concerned, it had so far been the norm for English settlers or officials living in these communities to learn te reo Māori in order to successfully establish communication links with Māori and accomplish their goals of creating economic or social ties (Benton 1991). Māori hardly saw the need to learn English; after all, at the time of the Treaty, Māori still outnumbered settlers thirty to one (Walker 1990). Conflicting data makes it hard to accurately estimate the number of 
Māori in 1840; according to Pool's estimates (1991) the numbers range from 70,000 to $90,000 .^{16}$

By the end of the $1840 \mathrm{~s}$, it is estimated that approximately 2,000 Europeans were living in Aotearoa New Zealand (Consedine \& Consedine 2001; King 2003). But with the surge of thousands of British settlers, Māori became a minority. Estimates from demographic analysis show that Māori population in the 1830s ranged from 70,000 to 90,000, which meant that Māori outnumbered Pākehā 40:1 (Pool 1991), and between 1831 and 1881, it is estimated that English settlers increased by 50,000 percent (King 2003). By the end of the nineteenth century, the Māori population comprised only a mere five percent of the total population of Aotearoa New Zealand (Benton 1991). The need to learn English increased and Māori found themselves with no choice but to speak English in order to be able to cope with the new world that was coming into being. Consequently, the use of te reo weakened under rising pressures for assimilation. The Treaty of Waitangi heightened the menace of cultural homogeneity with the permeation of European culture.

\subsubsection{A new approach to assimilation}

British processes of cultural assimilation seeking to eliminate te reo Māori infringed Articles Two and Three of the Treaty of Waitangi. Particular emphasis will be given to the instrumental role education played in the process of assimilation and the effectiveness schools had on diminishing the number of te reo Māori speakers.

Due to the Treaty of Waitangi, the process of assimilation following the initial colonisation of Māori in Aotearoa New Zealand was never fully accomplished. Article Three of the Treaty of Waitangi explicitly places Māori subjects under the immediate responsibility of the Crown, and hence, provides them with the same benefits enjoyed by British citizens.

The Māori saw Aotearoa New Zealand as their country. The Declaration of Independence, the selection of a flag to represent a Māori Aotearoa New Zealand, and the Treaty of Waitangi achieved a level of empowerment of national identity for the Māori.

${ }^{16}$ Conversely, explorer Johann Dieffenbach estimated there were approximately 114,690 Māori at the time (Pool 1991). 
These events reinforced the Māori sense of self-determination, and empowered them to build a strong sense of cultural identity. More importantly, these events demonstrated that Māori were able to partake in the decision-making processes of Aotearoa New Zealand, which would prove to be fundamental in future race relations between Māori and Pākehā.

\subsection{Education as civilisation}

Perhaps the most important means of incorporating Māori into British social structures was education. Education had been a critical point of Lord Normanby's instructions to Hobson in addressing race relations. In his guidelines for securing Māori-Crown relations Normanby stated that "civilisation of the Māori was to be promoted by 'the establishment of schools for the education of the aborigines in the elements of literature', but with the condition that, 'until they can be brought within the pale of civilised life, and trained to the adoption of its habits, they must be carefully defended in the observance of their own customs, so far as these are compatible with the universal maxims of humanity and morals" (Barrington \& Beaglehole 1974, p. 36). But which of these customs were to be defended? Hobson made an attempt to retain some of Māori cultural autonomy, of preserving Māori interests and welfare. His intentions materialised in 1841 with the appointment of missionary George Clarke as Protector of Aborigines (Barrington \& Beaglehole 1974). The Protector of Aborigines' task was to monitor Treaty compliance, and the appointment was seen as "an admirable, humanitarian shift in colonial policy" (Orange 1987, p. 93). Clarke however, who had twenty-three years of experience in Aotearoa New Zealand, was quick to realise that in order to fulfil the Treaty's promise to treat Māori as British subjects, Māori would not be able to retain any kind of cultural autonomy, including the use of te reo. Assimilation, the process of absorbing rather than merely incorporating Māori into British social structures, was inevitable and included a the establishment of a monolingual society.

\subsubsection{The role of missionary schools}

Missionary schools played an important role in safeguarding te reo. The earliest missionary school in Aotearoa New Zealand dates back to 1816. Mission schools did all the teaching in Māori, and it took a considerable amount of effort for missionaries to not only learn the language, but to devise a writing system for it. The advantage of using te reo to promote the Gospel as opposed to attempting to teach natives English was that it 
was difficult enough to attempt to draw the interest of communities to new spiritual ideas, let alone try to implement these new ideas in a foreign language.

Ironically, however, while the missionaries' intention to convert Māori to Christianity was a direct attempt cultural invasion, the use of te reo Māori by missionaries to achieve their goal proved effective in partially safeguarding the language. The survival of te reo Māori is probably a direct result of the advances of the missionaries in developing and establishing a Māori writing system.

\subsubsection{Assimilation via education}

The Crown criticised the use of Māori language in missionary schools as early as 1832: if Māori were expected to make any progress in Western knowledge and Western ways, then the Crown argued they had to be taught English (Biggs 1968). Nonetheless, missionaries abstained from modifying schools' policies, and adapted the British school curriculum, which included reading, writing, arithmetic and catechism, to Māori language. The signing of the Treaty of Waitangi, however, gave way to British colonial expansion and provided a much greater challenge for colonisers and missionaries alike: "the challenge of providing a system of formal education for the indigenous people of the country they were occupying and whose culture they believed was much inferior to their own" (Barrington \& Beaglehole 1974, p. vii).

Māori who did not speak or understand English found themselves increasingly excluded from the growing communities of British settlers. Settlers became more reluctant of learning to speak Māori, as the need to communicate with Māori in order to maintain a functioning society came to be almost completely unnecessary. Missionaries began reconsidering and debating about the effectiveness of their method of teaching Māori solely in te reo Māori. "To benefit them effectually and to make a permanent impression on them they must be intimately brought into contact with European manners and customs which must be done from early years" (Ross 1966). The decision to begin teaching in English was taken before there was any legal requirement to do so or any financial advantage. This marked a tacit acceptance by the missionaries of the inevitability of assimilation (Barrington \& Beaglehole 1974). Furthermore, shifting to the English language in the classroom marked the beginning of "an extended period of 
bilingualism, increasingly unidirectional - the pressure on Māori to learn English became much greater, while that on the colonisers to learn or use Māori lessened correspondingly" (Benton 1991, p. 14).

\subsubsection{Paving the way for a monolingual society}

In 1847, the Education Ordinance was established by Governor George Grey. Instead of creating a national education system, the Ordinance sought to restructure missionary schools. It stipulated a set of principles that was to be followed in every school in Aotearoa New Zealand and, although Grey's initial proposal was to apply the Ordinance stipulations solely to the Māori, it was agreed that the provisions were to be applied to Pākehā as well. Of the four principles stated by the Ordinance, the obligation for English to be the language of instruction was the one to have the greatest impact in the development of Māori social networks. It was obvious to Grey that in order to accelerate the assimilation of Māori to the habits and usages of the European, Māori children had to be taught how to read, write and speak in what he called 'proper' English (Walker 1990). To Grey, the use for te reo Māori was fruitless in terms of economic or social advancement (Walker 1990).

Schools became key social components that established-as they currently do - the grounds for development of race relations and interaction, and of race acceptance or rejection. Maaka and Fleras (2005) point out how "education and schooling were promulgated as especially effective tools in accelerating the absorption of Māori into the prevailing social, political and cultural order” (p. 113). School inspectors began describing Māori as "another obstacle in the way of civilisation" and in 1867, the Native School system was established, directing that English should be the preferred language of instruction (B. Biggs 1968).

\subsubsection{The "bread and butter"}

Largely outnumbered by then, Māori realised that in order to for them to secure economic success and survival in the Pākehā-dominated society, they had no choice but to learn English (Biggs 1968). Māori saw schooling in English as the means that would allow them to take advantage of the benefits Pākehā society could offer them. Whereas colonial authorities sought to use education and schooling as an effective tool that would hasten 
the absorption of Māori into British society, the Māori held different views: learning English would improve their lives by providing them with the opportunity to participate in the new formed society.

Years later, in 1986, Māori Sir James Henare would testify and recall how this trend was extended into the 1900's, when he was taught that "English is the bread-and-butter language"; in order for Māori to earn their "bread and butter," they "must speak English" (Wai-11 1986, p. 9). Therefore, Māori regarded education in English as their opportunity for advancement. Learning English became the key for understanding and mastering the Pākehā world, and it became crucial in securing their empowerment and hence, the protection of their rangatiratanga. ${ }^{17}$

\subsubsection{A playground of interests}

Interestingly, Maaka and Fleras (2005) analyse how the dynamics of kāwanatanga and rangatiratanga were present in the school system. As mentioned earlier, in order for Māori to secure their rangatiratanga, they could not risk being subjugated by the Pākehā, which is why Māori sought to use schools as a tool that would facilitate their way into the Pākehā-constructed society. Paradoxically, this was achieved only by enforcing Pākehā $k \bar{a}$ wanatanga. Schools became breeding centres for British ideals, incubators that promoted the Crown's goals of assimilation. Control and governance lay ultimately in the hands of Pākehā, who sought to effectively control Māori by dissolving it into British mainstream ways, to replace Māori knowledge and customs with British traditions and principles. Therefore, encouraging Māori children to attend schools did yield positive results in terms of increasing the integration of Māori to Pākehā norms - or in other words, schools proved to be efficient in speeding the process of assimilation. Yet the repercussions this had on te reo were almost fatal.

At the time, Māori preoccupation with land loss outweighed their concern for losing their cultural identity. For Māori, the idea of having their language extinguish was absurd. Their language had, after all, flourished without need of schools prior to British arrival. The thought of reverting to old-ways in which Māori was spoken in households and in everyday affairs did not appear to be illogical. On the contrary, it seemed only natural to

\footnotetext{
${ }^{17}$ Rangatiratanga: self-determination.
} 
restrict the use of English to formal education and dealings with Pākehā (Benton 1991). But while Māori sought to "enhance life chances through Native Schools, colonial authorities were hoping to control and curtail opportunities through European models of schools" (Harker \& McConnochie 1985, p. 79). By 1871, the Native Schools Amendment Act decreed schools to teach in English (B. Biggs 1968). This signalled the beginning "of the policy of prohibiting the use of Māori in schools, with the aim of replacing Māori by English as the language not only of the school but of all situations. Māori language became the "enemy"” that prevented Māori from becoming fully civilised (B. Biggs 1968, p. 74). The Education Department explicitly discouraged teachers from learning to speak Māori, arguing that it would only reduce their efficiency as teachers of English. It was a declaration of war by the Education Department on te reo Māori.

The assimilation process which the British had initially attempted to subtly implement became obvious and straightforward once they outright denied te reo Māori a place in society, going as far as banning the use of the language in school grounds. The understated methods of absorbing Māori into the mainstream new society were displaced by the clear imposition of British methods employed in the education system. Education became the principal colonial instrument that sought to affirm Crown control over Māori. The exclusion and denying of Māori language from society emphasised the commitment of eliminating Māori as Māori, a tyrannical yet non-violent technique of cultural invasion that contradicted the principle of co-existence that had supposedly been set by the Treaty of Waitangi.

It is extremely difficult to feel threatened by what one doesn't consider is possible. Māori had never experienced life without te reo Māori. As far as they could recollect, there had been no Māori life without te reo Māori. The threat of their language becoming extinct was, therefore, inconceivable. Language transmits culture: te reo was, and still is, the vehicle that allows for Māori ceremonial, social and many political customs to take place.

\subsubsection{Backlash: a new cultural reality sinks in}

Schooling of the Māori contributed significantly to the securing of Pākehā economic and political dominance in the nineteenth century and to the maintenance of that dominance throughout much of the twentieth century (Simon 1998). By the early 1900s, Māori 
language was officially banned from the school curriculum. Teachers were urged to encourage children to talk in English even in times of recess in the playground, and parents were pressured by school administrators to speak to discourage their children to speak Māori at home. (Barrington \& Beaglehole 1974; Wai-11 1986). Schooling successfully assimilated Māori into Pākehā norms and practices; it also proved to be successful in subverting Māori culture. Māori intentions of strengthening their rangatiratanga by promoting English education backfired. The preservation of the treasures of Māori culture began to be threatened as Māori children felt their cultural pride and self-respect of being Māori to be discouraged and weakened by the education

system. Whereas initially English had been thought of as a foreign language, the opposite came to be the reality: English became the dominant language, and Māori the limited vernacular. Efforts to suppress and eradicate Māori culture became even more evident in the eventual neglect of young children to learn Māori or their refusal to speak the language in public.

\subsection{Linguistic phenomena of inclusion and exclusion}

Māori experienced linguistic security until the Treaty of Waitangi was signed. As the Pākehā pushed te reo Māori out of everyday activities, and then more aggressively and formally out of the education system, a state of linguistic diglossia developed (see chapter 5). Māori continued to use te reo within their communities and households, as well as for the practice of their religious and political ceremonies, enabling them to conserve the existence of their language. This constant (if albeit restrained) use of te reo Māori prevented the development of a linguistic disglossia.

In the case of Māori and English, English became the dominant language, used in formal education. With the increase of migration in the late nineteenth century however, it became the central, governing language. Te reo Māori was reserved for Māori family or cultural affairs, eroding as well as minimising its use. Soon after, however, the diglossia developed to a disglossia, as intolerance for te reo Māori increased among Pākehā. The diminishing number of Māori, led to diminishing number of native speakers. The Second World War, however, led to significant changes for Māori society, as more Māori migrated to urban centres due to the increase of work availability in cities. Before the 1940s, 75 percent of Māori lived in rural areas; by 1960, nearly 60 percent of Māori had 
moved to urban centres (New Zealand Ministry for Culture and Heritage 2006). These urbanisation trends led to the erosion of Māori cultural heritage and dissipated the attempts of re-establishing the language among younger generations. Most families in urban settings stopped speaking to their children in te reo for fear of being discriminated against, and Māori children were raised as English speakers (Māori Language Commission n.d.). Consequently, Māori culture and identity was corroded to a point were the initial idea of creating a bicultural society vanished. The monolingual society led to the acceleration of a monoculture.

\subsection{Māori renaissance}

Māori renaissance is usually linked to the flourishing of Māori expression in arts and literature during the 1970s (Williams 1998). Nevertheless, the movement can not be separated from the underlying political and historical contexts which inspired it. The combination of interests in promoting Māori cultural rights led to a renewed interest in the restoration of te reo; all practices and sacred traditions were carried out in te reo, so therefore, it was fundamental to keep the language alive. In it, Māori held their identity and heritage; it was irreplaceable.

By 1973, a national survey by New Zealand Centre for Educational Research showed that only about 20 percent of Māori as fluent Māori speakers, and that most were elderly or beyond childbearing years, and by 1985, it is estimated that only 12 percent of the Māori population spoke te reo (Māori Language Commission n.d.). The social and political relegation of te reo and Māori cultural values within the urban setting caused a vacuum in the development of Māori professionals and academics dedicated to teaching te reo. Hence, the decrease in use of te reo, jeopardised the identity of Māori indigeneity.

Te reo native speakers for whom the te reo language was a natural medium of speech used in daily life realised their number was diminishing at alarming rates (Williams 1998; Royal 2007). This erosion of te reo meant the erosion and endangerment of transmitting and practicing Māori cultural values and knowledge. Māori considered te reo to be one of the intangible taonga which had been guaranteed protection by the Treaty of Waitangi. As a result, demands for government commitment to supporting the language increased (Williams 1998; Research New Zealand 2007). What distinguished the period of Māori 
renaissance from other movements was the coalition of people's interests: arts merged with politics and activists under one overarching aim, which was to restore Māori indigeneity.

The experience of a Māori renaissance gained momentum and a reactionary movement to the loss of Māori identity emerged in the late 1970s as Māori protests over the breaches to the Treaty of Waitangi escalated (Royal 2007; King 2003). Central to the reassertion of Māori identity was an emphasis on te reo. Violation of the Treaty principles on behalf of the British led to Māori protesters to seek ratification. A surge of Māori activists jointly protested the breaches of the Treaty of Waitangi, which they argued had resulted in monoculture power and control of Pākehā over Māori. Protests included the alarming deterioration of te reo Māori and consequently, in 1975, the Rowling Labour Government established the Waitangi Tribunal under the Treaty of Waitangi Act 1975. The Tribunal was created to "make recommendations on claims relating to the practical application of the principles of the Treaty and, for that purpose, to determine its meaning and effect and whether certain matters are inconsistent with those principles" (Orange 1987, p. 246). The most important role of the Tribunal was - and still is - to observe the Treaty of Waitangi by providing Māori with a legal process for Māori Treaty claims to be investigated. The intention was for the Tribunal to contribute to the resolution of Treaty claims and therefore achieve the reconciliation between Māori and Pākehā on unresolved issues dealing with breaches of the Treaty of Waitangi.

\subsection{Waitangi Tribunal}

The Tribunal is a permanent commission of inquiry responsible for making recommendations on claims brought by Māori relating to actions or omissions of the Crown that breach the promises made in the Treaty of Waitangi (Waitangi Tribunal 2007).

Before 1985, the Tribunal had no power or authority to make recommendations to the government regarding matters arising before its 1975 founding legislation (Orange 1987). By 1985, however, after years of Māori vehement protests over the breaches to the Treaty of Waitangi, the Tribunal's powers were made retrospective to 1840 (King 2003). By that time, it became clear that the Māori renaissance movement had been successful in 
restoring tribal activity throughout the country, and as religious and traditional ceremonies were reinstated, the need for the use of te reo augmented. Furthermore, with the success of kōhanga reo and kura kaupapa, it became evident that there was a demand for te reo in Aotearoa New Zealand; it was just a matter of receiving recognition of te reo at a national level in order to secure the supply of the language's existing demand. Without official recognition, te reo was still an endangered language.

The Tribunal was therefore fundamental in the recognition of te reo Māori as an official language in Aotearoa New Zealand. Since its foundation, the Tribunal has been the focus of Māori claims to the Crown and is the vehicle that has allowed for major settlements to take place. It abides to both, the English and the Māori texts of the Treaty of Waitangi. It is important to recognise, however, that the Tribunal is not a court and can not settle claims. Nevertheless, it holds the power to influence public opinion as well as government decisions, and to raise public awareness on issues concerning breaches to the Treaty of Waitangi. The Tribunal has worked as a mechanism that has continuously invigorated the fight for Māori rights, and one that enabled the claim for the revitalisation of te reo to be heard by Aotearoa New Zealand's government.

The total membership of the Tribunal shows a balanced and equal representation of Māori and Pākehā. Having equal representation in membership reflects the efforts by both Māori and Pākehā to work in partnership "to create a future for two peoples as one nation" rather than working separately or even against each other (Waitangi Tribunal 2007).

\subsection{Nurturing a language nest}

The progress for the restoration of te reo Māori gained strength in 1981 with the Te Kōhanga Reo movement. Te Kōhanga Reo literally translates to 'language nest,' a name that indicates the principle behind efforts to restore Māori heritage: a place specially structured to serve as a safe haven for the embryonic stages of te reo. Māori of all ages should have the right to express their values in te reo, beginning from the earliest stages of their development, Māori children should have the right to grow in an environment that nurtured the practice of customs in te reo (Te Kōhanga Reo 2003). Te Kōhanga Reo 
movement also reflected the desire of Māori to retain and foster Māori knowledge, which could only be accurately transmitted in te reo Māori (Black et al. 2003).

Te reo embodies all aspects of Māori cultural values and heritage. Māori communities realised the limitation of intergenerational teaching of te reo, as those who were fluent in te reo and who held in-depth Māori knowledge were mostly elders over the age of 50 (Te Kōhanga Reo 2003). If these elder generations did not teach younger generations their knowledge, then not only would they take their knowledge to their grave, but inevitably, the language would die out with them as well. The solution lay in the children; in order to stop the alarming decline of te reo speakers, children would be taught from an early age of the importance of expressing Māori knowledge and values in te reo. Children became "the investment for the future of the language" (Te Kōhanga Reo 2003).

The fundamental policy of Te Kōhanga Reo became to "impart traditional Māori values and knowledge to pre-schoolers using Māori as the only language of instruction” (Māori Language Commission n.d.). The movement led to the establishment of kōhanga reo programmes. These were the first total immersion programmes that would allow children from birth to 6 years of age to be raised with Māori as the language of communication in an environment that fostered Māori culture and values.

The opening of the first kōhanga reo in $1982^{18}$ marked an important milestone: it demonstrated the determination behind restoring Māori heritage at a national level, emphasising the preservation of te reo as an intrinsic Māori value (Te Kōhanga Reo 2003). The establishment of the kōhanga reo led to the eventual establishment in 1984 of kura kaupapa, which extended kindergarten immersion programmes to children from ages 3 to 14. The development of this network of immersion programmes became key to language revitalisation efforts by stopping the decline in number of te reo speakers.

\subsection{Claiming te reo Māori}

Despite the success of Te Kōhanga Reo movement in initiating a renewed interest in the importance of language revitalisation efforts, requests for the implementation of a legislation which recognised the status of te reo in Aotearoa New Zealand had been

\footnotetext{
18 The first kōhanga reo was located in Pukeatu, near Wellington.
} 
unsuccessful. With the establishment of the Waitangi Tribunal, however, in 1985, the Māori Language Board of Wellington ${ }^{19}$ and Huirangi Waikerepuru, chairman of the Board, were able to set forth a claim that reflected the ongoing concern of the decline of te reo Māori. Te Reo Māori claim, referred to as Wai-11, asked the Waitangi Tribunal to recommend the reinstitution of te reo Māori by recognising it as an official language throughout Aotearoa New Zealand and for all purposes (Wai-11 1986). Claimants asked for the enabling of its use as right in parliament, the courts, government departments, local authorities and public bodies, including schools (Wai-11 1986).

Although the claim's nature was quite simple - the national recognition of te reo as an official language of Aotearoa New Zealand-its political and social implications were not. Unlike other claims involving fisheries and land issues, that had limited impact on the rest of the country, the claim of te reo would affect everybody in Aotearoa New Zealand. It also signified millions of dollars in translation of official documents, in the establishment of Māori media communications services, and most importantly, the sourcing for the redevelopment of education acts and systems (Wai-11 1986).

The claimants presented evidence to support their argument: if te reo died, Māori history, culture, heritage and knowledge would die with it. The testimony of experiences from Māori women, men, teachers, academics, along with the knowledge of demographers and proven statistics, verified how the decline of te reo in schools and in society as a whole would eventually lead to cultural genocide, resulting in the disappearance of Māori as a distinct and unique group of people. Furthermore, the claimants argued that Article Two and Three of the Treaty of Waitangi made it the Crown's duty to protect te reo Māori. "The treaty was directed to ensuring a place for two peoples in [Aotearoa New Zealand]; in the Māori perspective, the place of the language in the life of the nation is indicative of the place of the people" (Wai-11 1986, p. 21). Failing to protect te reo was a breach to the promise made in the Treaty of Waitangi. Evidence and arguments presented throughout the hearing made it clear to the Tribunal that by the Treaty, the Crown had promised to recognise and protect the language and that such promise had not been kept.

\footnotetext{
${ }^{19}$ The Maori Language Board of Wellington (Nga Kaishakapumau I te reo) was a legal society, therefore, the Board did not have the right to make a claim to the Tribunal since only Māori are legally entitled to make claims. Huirangi Waikerepuru, however, was Māori and could therefore rightfully make a claim to the Tribunal.
} 


\subsubsection{Article Two in defence of Māori taonga}

Article Two of the Treaty of Waitangi guarantees and confirms - depending on which English version is taken into consideration - the protection for "all the people in Aotearoa New Zealand in the unqualified exercise of their chieftainship over their lands, villages and all their treasures" (Maaka \& Fleras 2005, p.109). The Māori version concerns itself with the phrase "O ratou taonga katoa" which can best be translated as "all their valued customs and possessions" (Wai-11 1986, p. 20). The taonga-or treasures, valued customs, or possessions - refer to both, the tangible and intangible, to the physical as well as the spiritual. This broadens the responsibility of the Crown to guarantee protection for more than just objects of tangible and material value, including te reo. Te reo Māori presented the embodiment of all spiritual and mental concepts of Māori people, and as such, language was and still is an inherent component for the subsistence of Māori (Wai11 1986). Te reo Māori is therefore considered a valuable possession, an irreplaceable treasure. Furthermore, the use of the word guarantee entails the Crown with the obligation to take active steps within its power as guarantor. It is the Crown's duty under the Treaty of Waitangi to act on behalf of the Māori people if their possession of the taonga is in any way threatened or disturbed (Wai-11 1986). By guaranteeing protection, the Crown has the responsibility to adhere to the legal entitlements of setting forth affirmative action rather than passive permissiveness.

\subsubsection{Article Three goes both ways}

While in 1841 Clarke $^{20}$ had noted that Article Three of the Treaty, which promised to treat Māori as British subjects, would lead to the assimilation of Māori to British ways, the contrary proved to be applicable as well. British citizenship provides the right to access to education; in the case of Māori, therefore, the Crown is obliged to provide Māori with an education that is appropriate and accessible, and that does not threaten Māori cultural taonga (Tapine \& Waiti 1997). Hence the dual nature of Article Three in terms of preservation of Māori cultural values: while it can be manipulated to emphasise the need for assimilation, it may also be understood to grant Māori the same rights to exercise their own cultural practices and establishes the grounds for Māori to reclaim their human right to language. Paradoxically, the Treaty of Waitangi, allowed for the

${ }^{20}$ As mentioned earlier, missionary George Clarke was Protector of Aborigines in 1841. 
creation of a bicultural society in which both Māori and Pākehā can equally participate so long as they adhere to British law. Both provisions made it possible for the Waitangi Tribunal to issue a claim requesting the restoration of te reo Māori.

\subsubsection{Reaching a consensus on te reo}

After four weeks of listening to arguments and testimony on behalf of the claimants, on 29 April 1986, the Tribunal recognised te reo Māori as a taonga, as stated by Article Two of the Treaty. It acknowledged language to be an essential part of Māori culture and one that should be regarded as a "valued possession" (Wai-11 1986). It recommended that "an understanding of Māori language and culture was necessary not only to develop the full personal development of Māori children but also to assist the Pākehā to fully appreciate the history, achievements and character of Maori society" (Wai-11 1986, p. 47). The Tribunal however, did not recommend for te reo Maori to be a compulsory subject in schools, stating that "we [the Tribunal] think it more profitable to promote the language than to impose it" (Wai-11, p. 47). Nevertheless, the steady increase of kura kaupapa through the country due to the increasing attendance of children, was evidence of the need and desire to include te reo in school curricula and the Education Act 1986 recognised kura kaupapa as state schools (New Zealand Ministry of Education 2007).

The Tribunal's findings and recommendations led to the enactment of the Māori language Bill, which became the Māori Language Act 1987 (Māori Language Commission n.d.). Although the Act did not implement all of the Tribunal's recommendations, it declared Māori as an official language of Aotearoa New Zealand, and established the Māori Language Commission as a regulatory body that could establish language policies, providing assistance in the revitalisation of te reo Māori at a national level. This mechanism ensured a place for te reo in Aotearoa New Zealand; one example is the steady increasing number of funded kura kaupapa throughout the years (See Figure 6.1). 
Figure 6. 1 Number of funded kura kaupapa Māori (1992 to 2006)

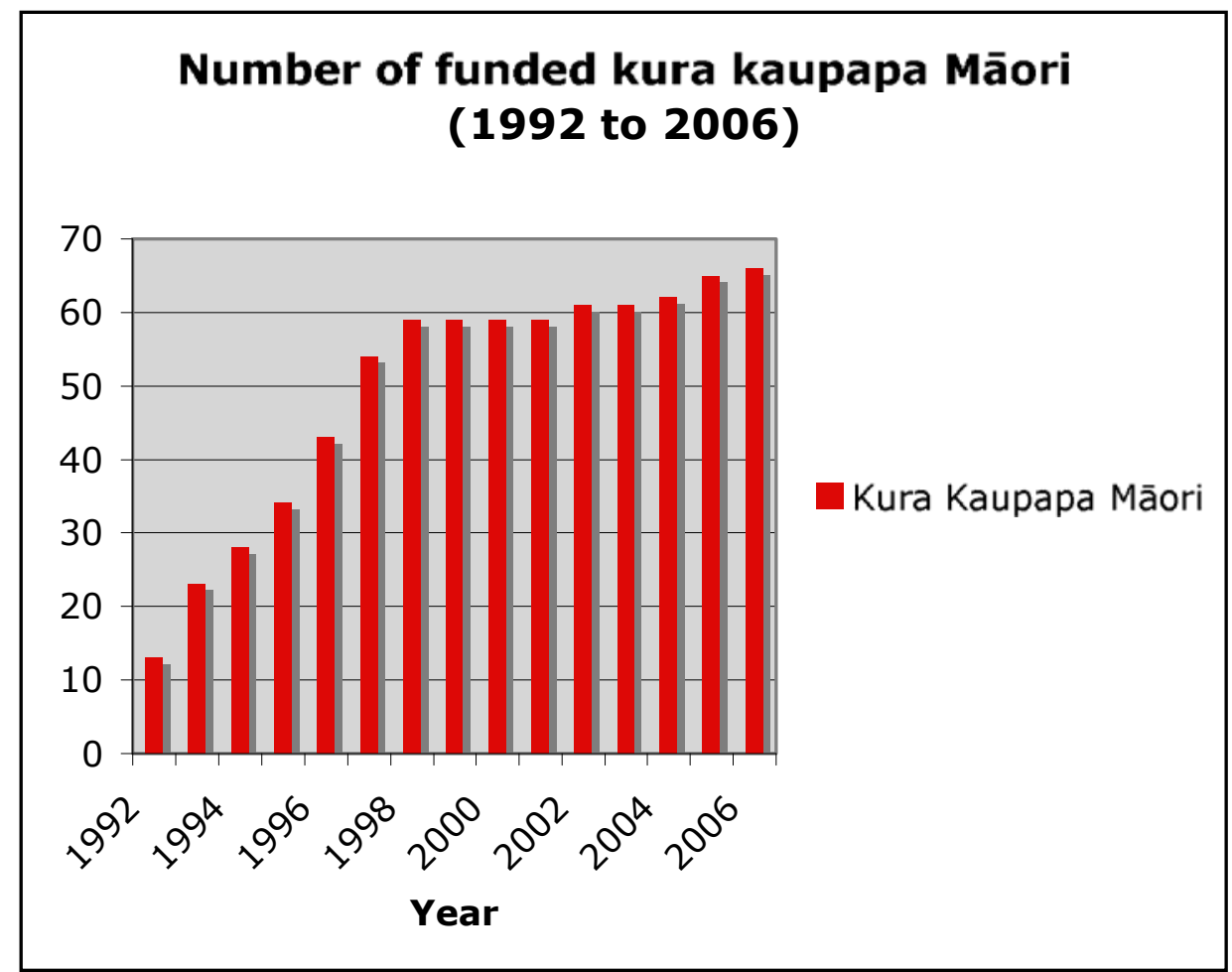

Source: Education Counts. (2006). Māori Medium Education, Ministry of Education.

\subsection{Conclusion}

In Aotearoa New Zealand, it was the power of words - not the might of weapons or disease - what ultimately proved to be the biggest threat for the sustainability of Māori in Aotearoa New Zealand. Historical events that led to the signing of the Treaty of Waitangi established the grounds for the development of Māori self-determination, which drove them to assert their right to use te reo and solicit the creation of mechanisms that would enable them to claim breaches made to the Treaty by Crown. As a result of Wai11, recognition of te reo as Aotearoa New Zealand's official language, alongside English, secured language revitalisation efforts for Māori. 


\section{Chapter 7 - Case study: Immersion programmes as a tool for language revitalisation}

\subsection{Introduction}

The implementation of full-immersion approaches instituted by the system of kura established the commitment of Māori to reassert their tino rangatiratanga and maintain Māori knowledge alive by protecting and revitalising te reo. The contract signed by Māori and Pākehā in the Treaty of Waitangi, in either the English or Māori version, allowed for the restoration of te reo. The sequence of historical events outlined so far demonstrates that without the Treaty of Waitangi, Māori would have not been able to issue claim Wai-11.

The following will now describe direct observations of a case study. Immersion programmes like the one observed in Petone Central School have been successfully implemented in Aotearoa New Zealand, leading to increasing numbers of te reo and successful language revitalisation. Māori participation in the design and implementation of immersion programmes is and has been fundamental in order to achieve language revitalisation at a national level.

\subsection{Paving a road to success}

By the end of 1987, the Māori Language Commission statistics show that there were 522 kōhanga reo centres established in the country, and an enrolment that exceeded 11,000 children (Māori Language Commission n.d.). Kōhanga reo were established "by Māori for Māori" with very little or no financial assistance from the Ministry of Education (Te Kōhanga Reo 2003). Therefore, kura kaupapa Māori functioned as private schools, which allowed them to develop their own systems of administration, their own curriculum and ways of teaching that were consistent with Māori values (New Zealand Ministry of Education 2007). Yet this also meant, however, that kura kaupapa depended on the efforts of the Māori community to subsist: on one hand, the community had to cover the expenses and supply the necessary resources for the schools to function. On the other hand, and perhaps even more importantly, was the fact that the community had to be held 
accountable for establishing a sustainable environment that would make the efforts of the kura kaupapa meaningful. This down-top approach reflected the ability and conviction of Māori to set foundations for a revolutionised system of education that broke schemes of assimilation through education. Furthermore, it established the grounds for the development of Māori-medium schools and triggered the officiating of te reo Māori as a national language in years to follow.

\subsubsection{Establishing an underlying philosophy}

In order to promote levels of consistency among the different kura kaupapa and to maintain a degree of quality in education, the Education Act 1989 called for kura kaupapa to operate under a the Te Aho Matua philosophy. ${ }^{21}$ Te Aho Matua was defined by the Act as a "statement that sets out an approach to teaching and learning" (Education Act 1989, 155A) and was established as the underlining philosophy of kura kaupapa. Te Aho Matua calls for the incorporation of the knowledge, skills, attitudes, and values of Māori society within school curricula; while it is compulsory for Māori immersion programmes to abide by Te Aho Matua, the same is not required of mainstream schools (New Zealand Ministry of Education 2007).

An integral part of Te Aho Matua is the principle of Ako. ${ }^{22}$ Bishop (2005) defines Ako as the process of learning as well as teaching, emphasising how the principle refers to knowledge acquisition as well as to the processing and imparting of knowledge. The principle of Ako in education abides by the idea that understanding and knowing the cultural context surrounding the education setting is a key component in achieving effective teaching and learning (Maharey 2006). It is a teaching-learning practice that is culturally specific and appropriate to Māori immersion programmes (Bishop et al. 2003). Ako as a principle in education recognises the importance of supporting te reo as a fundamental aspect of Māori identity. Furthermore, it looks into building productive partnerships with Māori in order to keep the language use and language corpus relevant to Māori cultural and societal developments and practices. Non-Māori students and community members have also been invited to participate in order to establish an

${ }^{21}$ Te Aho Matua literally translates to chief, important, primary line of descent, genealogy.

${ }^{22}$ Ako: to learn, study, instruct, teach, advise. 
inclusive cooperative working relationship that benefits Aotearoa New Zealand's bicultural principles (New Zealand Ministry of Education 2002).

\subsection{Obstacles and incentives along the way}

As a result of the lack of te reo educators due to the neglect of the language in previous years, the Ministry of Education dictated that immersion programmes be excluded from the requirement to employ only teachers who hold a practicing certificate and are officially registered with the Aotearoa New Zealand Teachers Council (ERO 2003). That does not mean that it is easier to become an educator of an immersion programmes. Quite the contrary: not only do immersion programme require educators to have certain degree of fluency in te reo, but educators are also expected to understand the appropriate techniques for teaching te reo to students with different cultural backgrounds who have different levels of exposure to te reo outside school grounds (ERO 2003). Yet despite the Ministry of Education's efforts to increase availability of material in te reo, there are still fewer curriculum resources available in te reo than those available for English medium teaching.

In an effort to increase assistance for professional development to educators of Māori medium schools, the Ministry of Education established the Resource Teachers of Māori (RTM) service. The RTM is a team of registered teachers who support immersion programmes by delivering and providing resources and professional assistance to Māori medium educators (Southland Resource Teachers of Māori 2004). The mission statement of RTM is to "Paddle forth the canoe of knowledge so that the indigenous language and customs of old continue forever." 23

In order to meet the high demand for Māori medium schools, a series of financial incentives were also made available by the Ministry of Education. These incentives aimed to increase the supply of teachers of te reo and support educators who are already part of Māori medium schools (New Zealand Ministry of Education 2007). These include the availability of scholarships to cover the fees of those wishing to become Māori medium teachers, as well as loan support to assist educators who have taught from two to four years in a Māori medium programme to repay their student loans. Another incentive

23 "Hoea te waka o te mātauranga kia pūmau tonu Te Reo Māori me ōna Tikanga mō ake tonu atu." 
is that of allowances: the Māori immersion teaching allowance (MITA) is an allowance paid by the government which is made available to educators who teach in Māori medium schools (New Zealand Ministry of Education 2007).

Funding strategies designed for immersion programmes were also made available by the Ministry of Education, and in 1996, the Māori Language Programme funding (MLPF) was established with the purpose of reviving te reo and increasing the educational achievement of Māori students (New Zealand Ministry of Education 2007). MLPF gives extra funding for every student enrolled in one of the four immersion levels of Māori language programmes. Prior to 2006, only Māori students were eligible to receive MLPF. In 2006, however, MLPF was extended to all students enrolled in any of the four immersion levels. The objective of expanding the funding levels to non-Māori students was to "demonstrate [Aotearoa New Zealand's] commitment to resourcing students on the basis of need, rather than ethnicity" (New Zealand Ministry of Education 2007). The Ministry of Education provides MLPF to Māori medium schools depending on the standing of the four levels of immersion. Level 1 programmes equating 'full immersion' methods, while Level 2- 4 programmes mainly relate to bilingual units within mainstream schools (New Zealand Ministry of Education 2007; see Figure 7.1).

Table 7. 1 Funding allocated per student according levels of immersion

\begin{tabular}{|c|c|c|c|}
\hline $\begin{array}{c}\text { Immersion } \\
\text { level }\end{array}$ & $\begin{array}{c}\text { Percentage of time allocated to } \\
\text { immersion teaching }\end{array}$ & $\begin{array}{c}\text { 2005 funding } \\
\text { per student }\end{array}$ & $\begin{array}{c}\text { 2006 funding } \\
\text { per student }\end{array}$ \\
\hline Level 1 & $(81 \%-100 \%$ immersion) $20 \mathrm{hrs}+$ & $\$ 902.65$ & $\$ 881.50$ \\
\hline Level 2 & $\begin{array}{c}(51 \%-80 \% \text { immersion }) 12.5- \\
20 \mathrm{hrs}\end{array}$ & $\$ 451.32$ & $\$ 430.20$ \\
\hline Level 3 & $(30 \%-50 \%$ immersion $) 7.5-$ & $\$ 231.87$ & $\$ 231.87$ \\
\hline Level 4 & $\begin{array}{c}12.5 \mathrm{hrs} \\
(\text { less than } 30 \% \text { immersion but at } \\
\text { least three hours per week })\end{array}$ & $\$ 56.29$ & $\$ 56.29$ \\
\hline
\end{tabular}

Source: Adapted from New Zealand Ministry of Education 2007. 


\subsection{Case study one - Petone Central School}

In order to understand the principles and structure of immersion programmes in Aotearoa New Zealand, I undertook a series of direct observations to use Petone Central School as a case study. Petone Central, a kura kaupapa which has had an established bicultural provision of education for more than fifteen years, is a state-funded primary school with years 1-8, located in Petone, Hutt City. According to the ERO Report of 2006, the school roll is of 221 students, of whom 53 percent are considered of Māori ethnicity, 29 percent Pākehā, 11 percent Samoan, and 5 percent Asian. The school has a ranking of 4 in Aotearoa New Zealand's decile system of 1- 10; decile 1 schools have the largest percentage of students from areas of greatest socio-economic disadvantage, while the largest percentage of students in decile 10 schools are from areas of least socio-economic disadvantage (Education Review Office [ERO] 1999; ERO 2002; ERO 2006).

The school has established two divisions with the purpose of creating bilingual and bicultural provisions for education in Māori immersion and English medium classes. Each classroom—or whānau ${ }^{24}$ — has been given a name: Ngā Rito ${ }^{25}$ and Ngā Māhuri. ${ }^{26}$ Ngā Rito provides a full Māori immersion curricula, while Ngā Māhuri provides English medium classes. The lessons observed were in Ngā Rito, the Māori immersion whānau, and the teachers who were interviewed are part of Ngā Rito's programme.

\subsection{Ngā Rito}

Ngā Rito's immersion programme is part of the MLPF and the programme is consistent with the Level 1 language funding it receives (ERO 2002). Therefore, in compliance with its Level 1 immersion ranking, Petone Central concerns itself with te reo revitalisation, but with teaching children how to naturally assume Māori knowledge, culture and values. Petone Central School's Ngā Rito abides by the philosophy of Te Aho Matua, establishing its framework and teaching guidelines based on tikanga Māori.

\footnotetext{
${ }^{24}$ Whānau refers to the basic social structure within Māori society and has traditionally been used to refer to family networks. Most recently, however, a whānau can denote a group of ongoing individuals who are not necessarily related yet gather to interact on a regular basis for the purpose of a specific kaupapa/ agenda (Metge 1995).

${ }^{25}$ Rito: centre shoot, undeveloped leaves of flax.

${ }^{26}$ Māhuri: young tree, sapling.
} 
I was welcomed by Petone Central School's tumuaki, ${ }^{27}$ Iosua Esera, to observe the children interact in a diversity of settings: during Ngā Rito's regular classroom activities; during karakia, ${ }^{28}$ the usual morning briefing between teachers and children; and during a one-hour long weekly assembly that included children from both whānau. During the course of the research, four teachers and over fifty children were observed in Ngā Rito, all between Levels 1 and 4. I focused on observing teaching methods and techniques, and participation of students in the classroom. Another important focal point of my observations was to learn if teachers abided to guidelines established by Te Aho Matua philosophy of providing children with te reo Māori as a medium of communication, as well as with the necessary confidence and knowledge for them to confidently be Māori and practice Māori customs. Most importantly, I focused on children's attitudes toward the use of te reo Māori amongst themselves and toward their teachers by observing their language use during class time, in karakia, and during their weekly assembly. These events were chosen in order to provide my observations with a scope of different circumstances under which I could observe different attitudes of children toward the use of te reo.

Not all children who are part of Petone Central's Ngā Rito are Māori. Out of the 53 percent of Māori students in Petone Central, 55 percent are part of Ngā Rito, with the remaining attending Ngā Mahuri. The rest of the children have a variety of ethnicities: some are Pākehā, European, Samoan or Fijian, among others. Not all of the parents of the children in Ngā Rito are fluent in te reo. All, however, according to Esera, acknowledge the value of maintaining te reo alive, which is why they choose to have their children learn it from an early age. Esera, who is Samoan, holds a passion of his own in the issue of language revitalisation efforts: he completed a postgraduate dissertation on critical practices to acquisition of a second language while maintaining a child's first language.

\footnotetext{
${ }^{27}$ Tumuaki: Principal.

${ }^{28}$ Karakia: incantation, prayer, grace, blessing, service, church service, that enable people to carry out their daily activities in union with the ancestors and the spiritual powers.
} 


\subsubsection{Class-time}

Due to my lack of knowledge of te reo Māori, I was unable to discern the quality and fluency of te reo of teachers and students. Nevertheless, there presided an evidently positive attitudes of both, children and teachers, toward the use of te reo, which was observed in the extensive use of te reo by children, their willingness to participate during class discussions, and their responsiveness to teachers.

Ngā Rito observes Māori traditions and principles in the classrooms; in accordance with Māori custom, students, visitors and teachers are asked to take off their shoes before stepping into the classrooms. Te Mako Orzecki, a teacher from Māori and Polish descent and the only male teacher at Ngā Rito, explained how carrying out small traditions like this help the programme provide "a meaningful context to provide examples of Māori cultural values surrounding te reo" (personal communication, 20 February 2007). Frances Barnsley, another teacher in Ngā Rito who is of Māori descent, added: "The purpose is not for children to see these actions as a set of rules, but for them to eventually embrace and adopt these activities as part of their identity, as a natural part of themselves" (personal communication, 20 February 2007). Both Orzecki and Barnsley agreed that the aim of upholding such traditions is to have children adopt Māori customs and values into their lives outside school, and not restrict the practice of Māori traditions to school grounds (personal communication, 20 February 2007).

Once students became aware that I had no knowledge of te reo, but was fluent in Spanish - a language foreign to them - many proudly offered their knowledge of certain words in te reo in exchange of me providing them with a Spanish translation (personal communication, 20 February 2007). "How do you say 'hello' in your language?" asked a girl from Level 3. "If you teach me how to say thank you in your language, I'll teach you two words in te reo," another girl from Level 3 offered. I showed her that in Spanish, thank you translated to 'thank you' and she fulfilled her part of the deal by offering me 'haere mai.' When I asked her what that meant, she replied "It means 'welcome."'

Children's appreciation of language was surprising and in all four levels observed, and during my time of observation, students seemed to feel privileged at the opportunity of 
showing their fluency in te reo. They expressed this pride by openly communicating to me their knowledge of not only words, but of their understanding of Māori concepts and traditions, such as the importance of the marae, ${ }^{29}$ the significance of haka ${ }^{30}$ and pōwhiri. ${ }^{31}$ Students from Level 2 showed no inhibitions and were proud to follow their teacher Lee Flutey's instruction to perform a pōwhiri to welcome me to their classroom.

\subsubsection{Assembly for all}

I was also able to observe the relationship between students from Ngā Rito and from the Ngā Mahuri whānau during their routine Friday morning assembly (personal observations, 30 March 2007). Before the assembly began, Flutey explained that the objective of holding the assembly once a week with both whānau is to "encourage teamwork across whānau. We want to share our activities and have the other whannau update us with what they are doing. It is also a great opportunity for children from both whānau to share and celebrate the week's success with each other" (personal communication, 30 March 2007).

All of the school's students gathered at the school's auditorium/gymnasium and each whānau sat on either side of the room. The use of te reo Māori was given clear priority, with teachers and students from Ngā Rito speaking in te reo to the entirety of the room first, followed in some, but not all instances, by an English translation. Students from Ngā Rito made announcements in te reo, and students from Ngā Mahuri made theirs in English. Overall, the assembly exemplified Petone Central School's success in establishing a bilingual and bicultural environment in which both Pākehā and Māori can prosper side by side. At the end of the assembly, Flutey pointed out to me that regardless of their whānau, all children at Petone Central School are provided with a general understanding of Māori cultural values and practices. "They all know their $m i h i^{32}$ and can present it to audiences when it is called for," Flutey said with pride (personal communication, 30 March 2007).

\footnotetext{
${ }^{29}$ Marae: refers to the common area of the wharenui (Māori meeting house) where formal greetings to visitors take place. Marae also means to be generous and hospitable.

${ }^{30} \mathrm{Haka}$ : a general term used to refer to vigorous dances with actions and rhythmically shouted words. Haka pōhiri refers to a ceremonial dance used to welcome visitors.

${ }^{31}$ Pōwhiri: A traditional Māori welcome on to a marae is called a pōwhiri (or pōhiri). Marae are not the only places where pōwhiri take place; pōwhiri can happen anywhere that hosts need to formally greet a group of visitors.

${ }_{32}^{32}$ Mihi: the Māori traditional greeting exchanged between host and visitor.
} 


\subsubsection{Karakia: daily ritual}

Karakia time, the morning briefing that takes place on a daily basis from 9:00 a.m. until 9:15 a.m. between Ngā Mahuri students and teachers, is carried out in te reo. Students from all levels gathered in a classroom, listening to announcements made by teachers and fellow students. Once again, despite my lack of understanding of te reo, I observed and attempted to perceive as well as possible the comfort levels of students when using te reo (personal observations, 14 June 2007). Very much like my observations in individual classrooms, the only inhibitions I became aware of were those of younger children whose te reo wasn't as fluent as that of older children, which meant their participation during the briefing was limited.

\subsection{Teaching principles}

Esera explained that Petone Central School uses the principle of Ako as basis for its approach in immersion education (I. Esera, personal interview, 9 February 2007). He defined Ako, which is an integral part of Te Aho Matua philosophy, as "the reciprocal relationship between teaching and learning used in classrooms in which knowledge is shared to produce better outcomes" (I. Esera, personal interview, 9 February 2007). Ako also ensures that Petone Central can cater to the needs of non-Māori students by learning from their needs.

Knowledge is also shared at professional experience levels with educators learning from the experience of other educators. A resource teacher of Māori (RTM) has supported the immersion whanau with professional advice and development with the objective of sharing expertise in order to enrich teaching schemes as well as the learning experience of children (ERO 1999).

\subsection{Teaching methods}

Ngā Rito applies a language maintenance model as a teaching strategy (I. Esera, personal interview, 9 February 2007). This means that the oral use of language takes precedence over any other form of language usage - including its written form - with the objective of maintaining the use of language active. Esera supports the language maintenance model, stating: "It is important for children to know how to write and spell, yet in the context of 
language revitalisation, we need to show children they can use the language in their daily activities" (personal interview, 9 February 2007).

Teachers use a variety of media to support the language maintenance model and promote the use of te reo, ranging from visual material to music. During the Level 2 class time, Flutey used music and audio cassettes in her classroom as a means of instruction (personal observations, 20 February 2007). She played the guitar as children sang along in te reo and used audio cassettes in te reo for children to listen. The cassette played during my visit was titled "I te marae" and explained in te reo how to behave and act when visiting a marae, emphasising on the importance of using te reo while in a marae.

Posters and visual material in the classroom were all in te reo, including Biblical passages in one classroom. Children were allowed to speak in English only when they were wearing their 'English hats,' which are imaginary hats they are asked to put on in order to address each other or the teacher in English (personal observations, 20 February 2007). If necessary, a teacher will explain an activity in English, which is followed by a repetition of the same set of instructions in te reo.

The relationship between teachers and students seemed to be positive, with children seeking help when required in a confident, respectable manner. Students in all levels observed engaged confidently in Māori conversations with their teachers, although the predominant language when establishing conversations amongst themselves, was English. The exception was perhaps in Level 4, where children seemed to address each other more frequently in te reo without prompting from the teacher to do so (personal observations, 20 February 2007; 30 March 2007; 14 June 2007; 19 September 2007).

\subsection{The voice of educators}

Teachers differed on their views of the level of endangerment of te reo. I asked four educators at Ngā Rito to answer three questions I provided them with for the purpose of this research (see Table 7.2 below). Two of the questions invited educators to give their personal insights on the advantages and disadvantages of immersion programmes, such as the one of Petone Central School. The remaining question was whether or not the educator considered te reo to be an endangered language. 
Table 7. 2 Questions provided to teachers in Petone Central School

Do you consider te reo to be a language that risks becoming extinct?

Please give some insights on the advantages of Petone Central School's immersion programme.

What are some challenges of teaching a minority language?

Puhi-Carlotta Campbell, a Māori teacher, did not consider te reo to be any longer on the verge of extinction; quite the contrary, she noted that "national statistics show that the language is becoming stronger because more people speak it than 10 years back" (personal communication, 20 February 2007). And she is right: a 2001 census indicated that 42 percent of Māori spoke and understood te reo, an impressive improvement from a 1996 census by Statistics New Zealand, which showed that only 26 percent of Māori spoke te reo (Statistics New Zealand 1996; Statistics New Zealand 2001). What is more, a 2006 language survey shows the greatest increases recorded in proficiency levels of te reo, with speaking proficiency having increased by 9 percent, listening by 8 percent, reading by 10 percent, and writing by 11 percent (Te Puni Kōkiri 2006).

Campbell pointed out that advances in the restoration of te reo are due, in great part, to the establishment of immersion programmes in Aotearoa New Zealand, and noted that the programmes are "a necessary tool for indigenous languages to be preserved" (personal communication, 20 February 2006). Likewise, Paea Rangi, who is the school's sole native speaker of te reo, believes "te reo's condition is not as bad as it used to be" (personal communication, 20 February 2007). She recalls how children were once prohibited to use te reo even in their homes, whereas presently, there are established official means (such as the kura kaupapa) that support and encourage the use of te reo in schools, at home, and elsewhere (personal communication, 20 February 2007). Orzecki reflected how "immersion programmes such as the one in Ngā Rito succeed in promoting te reo Māori as a viable alternative to the educational experience of our tamariki ${ }^{33}$ and their families" (personal communication, 20 February 2007).

${ }^{33}$ Tamariki: Children. 
Campbell also highlighted how the success of immersion programmes depend "one hundred percent on Māori participation and on Māori interest of keeping their culture alive" (personal communication, 20 February 2007). In order to secure the success and future of immersion programmes and to have successful language revitalisation efforts, active Māori educators, academics and professionals are required. Campbell noted that "Māori need to take pride in their culture and promote the use of te reo in places other than just classrooms" (personal communication, 20 February 2007).

Overall, teachers in Ngā Rito acknowledged that advances have been made in restoring te reo Māori. They all agreed that the role of immersion programmes such as the one in Petone Central are crucial for the ongoing development of te reo's status and usage in Aotearoa New Zealand. Nevertheless, teachers did voice concerns over the long-term success of te reo's revitalisation movement. As summarised by Esera, "te reo Māori is in a delicate and initiative stage of the restorative process," and although battles have been won to revitalise the interest of the public in the language, the war to effectively revitalise te reo is far from over (personal interview, 9 February 2007). Esera emphasised how it is still too early to take for granted the success of the complete restoration of te reo, which is why it is crucial, in his point of view, to involve families and academia in order to have te reo spill over from being used just in school grounds: "Language needs to be used in order to be learned" (personal interview, 19 September 2007). Promoting the use of te reo in homes and in public spaces is fundamental to achieve successful language revitalisation.

\subsection{Immersion programmes: some of its challenges}

There were other concerns expressed as well: Orzecki emphasised on "the risk of [te reo] being de-contextualised and losing its quality for the sake of quantity" (personal communication, 20 February 2007). Campbell stressed the lack of emphasis on the study of the importance of each child's genealogy, $i w i^{34}$ and marae, all which are intrinsic Māori values (personal communication, 20 February 2007).

\footnotetext{
${ }^{34}$ Iwi: tribe, nation, people, race.
} 
There exists a gap of lack of knowledge and appreciation for te reo and Māori between generations due to the previously mentioned efforts made in Aotearoa New Zealand prior to the 1980 s to assimilate Māori by excluding te reo from school curricula (I. Esera, personal interview, 9 February 2007; Bishop et al. 2003). This resulted in a gap of knowledge or interest for te reo between generations and created a vacuum in the amount of academics trained and specialised in the study of te reo Māori. Even though Aotearoa New Zealand's adoption and national recognition of immersion educational programmes is currently helping close this gap, there are still not enough certified professional teachers to source the demand of teaching te reo. This lack of Māori personnel has implications on the ability of schools to provide adequate and consistent quality of te reo in immersion programmes. Further to lack of human resources there is a need for didactic material: all teachers interviewed at Petone Central School expressed their concern regarding the lack of resources available, such as updated books, reading material, and even the lack of use of te reo in the Internet. Ngā Rito has received support from RTM, which has provided professional advice and resources in the past (ERO 1999).

Perhaps ironically, one of the greatest challenges teachers in Ngā Rito face is similar to the challenge that Henry Williams encountered in 1840 when translating the Treaty of Waitangi from English to Māori (see chapter 6): the lack of terminology in te reo Māori to represent concepts (such as technological advances) or objects (such as computers) that already have words in English. Orzecki explained how the combination of existing words in te reo to denominate new objects may result in the erosion of the spiritual significance of words in te reo (personal communication, 20 February 2007). He used the example of the word microwave, ngaru iti:

Ngaru is the word used in te reo to refer to an ocean wave, while iti is the word used to describe something small. For Māori, the ocean has high spiritual value, and the literal translation of ngaru iti would be 'small wave.' This presents a risk for te reo to becoming de-contextualised and losing its quality for the sake of quantity (T. Orzecki, personal communication, 20 February 2007).

Orzecki expressed concern that using words in te reo that have high spiritual value to address objects, such as a microwave, erodes both te reo and Māori cultural values. This creates a conflict of interests for educators in immersion programmes, as they struggle to 
maintain a healthy language corpus by increasing the rate of development of words in te reo Māori in order for the language to keep up with technological developments. Such conflicts could be avoided, according to Orzecki, if there were more resources or technology available for the development of the language corpus of te reo. "There needs to be an increase in the government's incentives for people to develop appropriate words that do not compromise Māori values or our cultural integrity," said Orzecki (personal communication, 20 February 2007).

During my last visit to Petone Central School on 19 September 2007, I was told Orzecki was no longer working with the school. He had accepted a position with Te Kete Ipurangi (TKI), an overarching website for teachers and a key online resource for te reo, which was established and is funded by the Ministry of Education. Organisations like TKI scope schools for talented educators for recruitment, which although it results in a loss for the school, it is a gain for the educator: providing professional development opportunities promotes interest in the field of language revitalisation. Providing teachers like Orzecki with such opportunities increases the number of Māori professionals and academics, which will consequently improve the status of te reo and hence, facilitate the process of language revitalisation (I. Esera, personal interview, 19 September 2007).

\subsection{Treaty of Waitangi and immersion programmes}

Esera acknowledged the importance of not only teaching children a language, but teaching them how to use it, referring to the cultural context and values surrounding a language, particularly in the context of indigenous languages. Esera referred to how crucial the Treaty of Waitangi has been for the revitalisation movement of te reo to effectuate, noting that "the existence of immersion programmes is possible due to the Treaty of Waitangi. Without it, te reo would just be another Pacific minority language on the verge of extinction" (personal interview, 9 February 2007). Both Rangi and Campbell referred the importance of the Treaty of Waitangi in consolidating the efforts behind te reo's revitalisation (personal communication, 20 February 2007). Rangi observed how "Before the settlements began, people used to hate the Treaty because it took Aotearoa New Zealand from Māori. But now, people realise that the Treaty can actually give Māori back the taonga what we had was lost, and te reo is part of what has been returned to us" (personal communication, 20 February 2007). 
Esera emphasised the need to have strong Māori participation in the development of adequate language planning methods (personal interview, 19 September 2007). "Language revitalisation can only work if a language is socially accepted and is of practical use in a community. Children are meant to take te reo home with them, to speak it with their parents and family members, to actively engage the use of language in their everyday life" (I. Esera, personal interview, 19 September 2007). Without users, languages die. Creating a demand for the language, therefore is fundamental. Once this demand has been established, it is therefore necessary to provide adequate supply. The privileged language status of te reo Māori is due to what Esera called during an interview the "on-ground support it receives," referring to the Treaty of Waitangi's recognition of te reo as a Māori taonga (personal interview, 9 February 2007).

Immersion programmes such as those of Ngā Rito supply the demand for te reo. Māori mainstream immersion programmes promote the development of Māori academics who will subsequently support the interest of maintaining te reo a functional and healthy language, increasing levels of language acquisition and improving the language corpus. Esera notes how the lack of Māori academics weakens the development not only of te reo, but of Māori as a fundamental part of Aotearoa New Zealand's identity, and asserts that this is why the recognition of te reo as an inherent Māori taonga by the Treaty of Waitangi is vital (personal interview, 9 February 2007). The official recognition of te reo at a national level allows for the creation of network organisations that safeguard and provide support for the ongoing development of te reo. These organisations include the Māori Language Commission, which, along with the implementation of immersion programmes, help foster and promote the importance of te reo in keeping alive tikanga Māori.

\subsection{Equation for success: use, status, acquisition, and functionality of language}

When language usage declines or is restricted to particular events or even restricted to school grounds, then there is a drop in the language status. If people don't feel there is an advantage in learning te reo, then they will lose interest in creating a dynamic bilingual, bicultural society. Esera points out that the lack of language usage can jeopardise the 
interest of Māori to use te reo in everyday settings (personal interview, 9 February 2007). He adds how this was once the case, recalling when during the early 1900s up until the 1970s, social discrimination against te reo users led Māori elders to prohibit their children the use of te reo in settings apart from religious ceremonies or traditional celebrations taking place in private, familiar situations. History therefore provides evidence that if te reo is not functional in a society and its use becomes restricted or confined, its development will stagnate. Stagnation in the process of language revitalisation will eventually lead to a decrease of interest in societies to fostering a language's revitalisation.

Classrooms in Ngā Rito promote language usage by including it the school's general assembly, promoting it in the playground during the children's breaks, and by addressing children in te reo at all times - even when outside of the classrooms. Esera also notes that “the school strongly encourages the use of te reo Māori in children's homes and promotes the involvement of family members whenever possible in school activities that involve the use of te reo" (personal interview, 9 February 2007).

Ngā Rito reflects how positive social attitudes toward te reo encourage the self-esteem of children in immersion programmes and promote their interest in learning how to write and speak te reo Māori, and, most importantly, learning how to use it accordingly with Māori customs and values. This allows immersion programmes, like those in Petone Central School, to endorse language acquisition. All of the teachers interviewed in Ngā Rito agreed that it is much easier to learn a language during the early stages of childhood. Shannon Dryden, who taught the youngest children in Ngā Rito, spoke from her own personal experience, as she is still working to perfect her own use and knowledge of te reo (personal communication, 30 March 2007). And although her efforts are praised by her fellow teachers in Ngā Rito-Orzecki, for example, acknowledged the improvement in Dryden's quality and fluency of te reo Māori since she began working as part of the Ngā Rito team-her te reo is still not flawless (T. Orzecki, personal communication, 30 March 2007). Dryden mentioned how she learns not only from the other teachers, but from children as well, which falls in line with the school's Ako principle (S. Dryden, personal communication, 30 March 2007). Esera also emphasised how recruiting nonnative speakers of te reo is part of the learning experience: "We need to learn how to 
teach those that are learning te reo, not only those who are already familiar with it" (I. Esera, personal interview, 19 September 2007).

Language acquisition will determine the different levels of proficiency among speakers, and develop methods of teaching children how to communicate depending on their level of fluency. If, as stated earlier, we apply Lennenberg's (1967) theory that the crucial period of language acquisition ends around the age of 12 years, then the responsibility of teachers in Ngā Rito is extraordinary in the revitalisation efforts of te reo Māori. Nevertheless and regardless of whether or not we abide by Lenneberg's theory, it is common knowledge or perhaps just popular belief that the sooner we start learning a language, the less trouble we'll have acquiring fluency in it. Esera emphasised that it is the school's responsibility to create a learning environment that will promote the levels of language acquisition and will consequently strengthen the self-esteem of children and encourage them to use te reo outside school grounds. By normalising the use of te reo Māori within school grounds, and in outside social events involving family members or the general community, "language acquisition by future generations will become an accepted feature of everyday life and this will see the language flourish" (Grin \& Vaillancourt 1998).

\subsection{Conclusion}

Kura kaupapa and immersion programmes flourished due to Māori interest in keeping their culture alive and promoting their values in their own language; the success of immersion programmes lies in that have been designed and shaped by Māori, by their needs and their demands. With the increase of te reo usage in homes and in spaces outside school grounds, there is a greater acceptance of te reo in social settings, which gives te reo Māori a higher language status. Once again, it is important to note that achievement of a higher language status in Aotearoa New Zealand has been possible due to the joint effort between Aotearoa New Zealand's official recognition of te reo as a national language and the contribution of immersion programmes, such as the one observed in Petone Central School, to supply the demand of te reo. 


\section{Chapter 8 - Mapuche: Right to Mapudungun won by the sword}

"Fewla kalewetuy mongen; tüfachi weche mütewe wingkatuingün; allwe ngoymarpuingün tain küpal ñi ngülam ka ñi dungu; kalli rupape kiñe mufü tripantu, feymew epe kimwerpulayay ñi Mapudungun engün."

"These days, our lives are changing; the new generations of Mapuche have chileanised themselves too much; slowly, they are forgetting about the purpose and nature of our race, and in a few years time and they will surely have forgotten about their true language, their indigenous language."

Pascual Coña, 2002

\subsection{Introduction}

Chile's language revitalisation efforts are an ongoing yet far from completed process. Mapudungun is a dying language, and unless Chile's government implements effective processes of language revitalisation, the language faces extinction, threatening Mapuche cultural practices and traditions.

In order to understand the obstacles for developing successful language revitalisation programmes in Chile, it is necessary to understand the relationship between Mapuche and Chile. The following will examine the uniqueness of Mapuche process of colonisation, first by Spain and then by Chile, and how the processes of cultural assimilation thereafter have impacted current language revitalisation schemes. Geographic isolation has played a critical role in the preservation of Mapudungun, yet it has also signified the ostracising of Mapuche from Chile's economic and social development. This chapter will outline Mapuche historical evolution in Chile and how a series of events, which will be briefly discussed, have directly influenced the lack of coordination by Chile's government and Mapuche to establish successful language revitalisation programmes. Finally, the chapter will emphasise the importance of the international community's role in fostering the protection of Mapudungun during the Pinochet regime. Without the support of the international community, Mapuche would have more than likely been absorbed by the regime's efforts of cultural assimilation. 


\subsection{The changing demographics in Chile}

In 1840, while the Māori were beginning to establish a relationship with Europeans in Aotearoa New Zealand, the Mapuche in Chile were marking 200 years of a bloodshedding resistance against Spain and then against the newly-founded republic of Chile .

Like the Māori, the Mapuche did not have a centralised system power that united them under one government. Instead, the Mapuche had developed regional cultural diversity, sharing customs, and heritage. Most important was the fact that Mapuche shared a language which allowed them to identify and distinguish themselves from other indigenous groups and despite their regional differences, Mapudungun allowed the Mapuche to create a strong sense of unity and nationhood. Although there are no formal census available concerning the amount of Mapuche in Chile, historians estimate that before the Spanish arrived in 1541, there were around one and a half million to two million Mapuche inhabiting the region that extended from the Bio-Bio River to the island of Chiloe in the south (Bengoa 1985).

While tribal wars amongst Māori were commonplace, the Mapuche found themselves waging wars not against each other, but against the neighbouring Incas long before the arrival of Europeans to their territory in 1541. Warfare with the Inca Empire had not only made the Mapuche ruthless and experienced warriors, but more importantly, the ongoing combat helped establish a strong sense of unity among Mapuche. Mapuche were-as they still are - determined to fight for their self-determination and freedom.

\subsection{From battlefields to a Treaty: Spain in the Americas}

The Mapuche's relationship with the Spanish Crown was always one of resistance. Ruthless, yet skilful war techniques allowed the Mapuche to successfully resist Spain's continuous attempts of conquest. After 100 years of continuous military defeats against the Mapuche of the area, the Spanish Crown finally decided to recognise the Mapuche as a political and territorial autonomy. On 6 January 1641, Spain signed the Treaty of Quillin, acknowledging, very much to their dismay, their failure to defeat the Mapuche. The treaty recognised Mapuche as a nation, and the Mapuche became the only indigenous group in the Americas to gain independence from Spain. The document established territorial rights and limitations, enabling Mapuche to retain control over 10 
million hectares of land south of the river, approximately one fourth of what is Chile's present territory (Haughney 2006).

For the most part, despite the intermittent attacks of the Spanish to pillage Mapuche communities and kidnap people to sell as slaves, the Treaty of Quillin kept the Mapuche people insulated from Spanish conquest for the next 177 years. This geographical isolation meant that Mapuche were able to maintain their linguistic autonomy; the territory signified a physical space in which Mapuche were able to freely speak Mapudungun, allowing them to carry on with their cultural practices.

By the early 1800s, Spain's power in the Americas was weakening, and when the Chilean republic was established in 1818, diplomatic relations with the Mapuche were terminated (Haughney 2006). The Treaty of Quillin was dismissed by Chile under the pretext that it was an agreement made between the Mapuche and Spain, and Spain was no longer in command.

\subsection{A new beginning for Chile, an end for Mapudungun}

In 1817, Bernardo O'Higgins became the Supreme Director of Chile and his interest in the Mapuche was made clear from the start: he wanted Mapuche territory annexed to Chile, and would not even consider negotiating with Mapuche for their autonomy.

The new Chilean government made it clear that it had "no intention of allowing the Mapuche to hold all the land they claimed as their own" (Faron 1986, p.11). An aggressive method of internal colonisation was launched by the Chilean state in order to consolidate its control over Mapuche territory. The method for Chilean colonisation followed previous models for conquest in the Americas, which sought to install a system of domination by implementing structures of political, economic, social, and cultural subordination and dependence (Stavenhagen 1989).

\subsubsection{Chile: A new republic of unequal equals}

O'Higgins' declared that "all indigenous persons were free Chilean citizens, and as such, would have equal voice and representation, just as any other citizen, and be free to enter into contracts, defend their interests, and select their profession according to their wishes 
and abilities" (Bengoa 1985). The statement appeared to be a move by the Chilean state toward a more humanitarian approach to colonisation. The reality, however, was that recognising the Mapuche as Chileans, and not as Mapuche, was a strategy to weaken the foundations of their indigeneity that would lead to assimilation. Being Chilean meant Mapuche would not be able to use Mapudungun, but would be forced to learn Spanish, which meant giving up their heritage and the practices they had traditionally carried out in their language. Being Chilean meant renouncing to Mapuche identity, to the practice of Mapuche culture, and to the use of their indigenous knowledge. The Chilean state attempted to disguise its interests by offering the Mapuche new rights and privileges; the Mapuche did not see this offer as advantageous, but as a threat to their language, identity, cultural and social freedoms.

O'Higgins' wish however, took some time before it materialised: it took another 65 years before his decree could be applied to the Mapuche, for it was not until 1883 that the Chilean army was able to defeat the Mapuche, conquer its territory, and forcefully apply Chilean law. Chilean history denominates the period of military struggle that occurred between 1818 and 1883 as the "pacification" of the Mapuche, a term that hardly conveys Chile's brutal policy that sought to "systematically deprive indigenous peoples of their ancestral lands" (Faron 1986; Human Rights Documentation Centre [HRDC] 2002, para. 9). The Mapuche prefer to refer to this period of "pacification" as the "penultimate struggle" (Anaquod \& Taylor 1987).

It has been estimated that after Chile's government incorporated the Araucanian territories in Chile, the Mapuche population dropped from a total of one-half million to 25,000 within a generation (Churchill 1998). The causes for the decline, very much like in Aotearoa New Zealand, included a myriad of diseases introduced by the new settlers. Yet unlike the case of Aotearoa New Zealand, reasons for the decrease of population included enslavement of Mapuche on estates and in mines, famine, and a series of other abuses in attempts for Mapuche assimilation. As the number of Mapuche plummeted, so did the number of speakers of Mapudungun. 


\subsection{The role of missionaries}

Because the Mapuche had to resist both, Spanish and later on Chilean colonisation, it is important to look at the role two different groups of missionaries had on Mapudungun during both periods of time. Developments made by missionaries in Mapudungun resulted in the establishment of grammatical and linguistic structures for Mapudungun. Conversely, the chronological disarray under which these linguistic structures were created resulted in a series of grammatical differences that make Mapudungun a complex language to teach and learn.

During the late sixteenth century the first group of missionaries, who were Jesuits, made contact with the Mapuche. By 1606, the first grammatical book on Mapudungun was published by the Jesuit Luis de Valdivia (Kramer \& Arellano 2006; Zúñiga 2006). Like in Aotearoa New Zealand, efforts to evangelise the Mapuche, resulted in the creation of the first texts of Mapudungun, establishing foundations for future generations to develop a written form of Mapudungun, as well as to track down the history of their language and people.

Largely outnumbered by the Mapuche, the Jesuits found themselves learning Mapudungun; the Mapuche, however, had little interest and need in learning the missionaries' language, which was Spanish. Constant warfare and geographic isolation of Mapuche communities made it difficult for the Jesuit to establish constant and continuous contact with Mapuche and eventually, contact between both groups terminated.

It was not until 1895 that the following group of missionaries entered Mapuche territory. Despite having been forced into annexation by Chile twelve years earlier, when the first group of Capuchin monks arrived in Mapuche territory, they found the Mapuche to be a monolingual society.

A research anthology of the influence of missionaries on the preservation of Mapudungun was presented in Temuco on 18 October 2006 by Rosenda Kramer and Carmen Arellano during the First International Congress on Indigenous Language and the XII Conference on Mapuche Literature and Language. The study attributes the arrival in 1895 of 
Capuchin monks from Baviera to the IX Region as a crucial event which contributed largely to the preservation of Mapudungun (Kramer \& Arellano 2006). Kramer explained how the Capuchin monks found themselves facing the same situation that missionaries had faced three centuries earlier: in order to effectively initiate the process of evangelisation, they would have to learn Mapudungun. In order to facilitate the learning of the vernacular, they began producing texts in Mapudungun that would serve as resources to teach fellow monks the language (Kramer \& Arellano 2006). These texts also included explanations of the meaning of words and concepts which did not have a Spanish equivalent. By the early 1900, there was an extensive array of bilingual grammatical texts (Kramer \& Arellano 2006).

Like in the case of initial British missionaries settling in Aotearoa New Zealand in the $1800 \mathrm{~s}$, the use of Mapudungun, first by the Jesuit missionaries and later on by the Capuchin monks in attempts made to convert Mapuche to Christianity, proved effective in safeguarding the indigenous language. The missionaries provided the necessary resources to establish a sustainable system for future generations to learn and teach Mapudungun. Interests on the study of Mapudungun, however, differed in terms of how to approach the development of a writing system for the language. Linguistic methodologies used by missionaries and linguists from each time period varied immensely. Furthermore, the Capuchin monks were for the most part unaware of texts developed by the Jesuits. This resulted in eight different graphemes for Mapudungun, four which are still presently used (Zúñiga 2006). Therefore, although the creation of texts by missionaries throughout time has secured the existence of Mapudungun, the variations in orthography have been challenging in both, the teaching and learning of the language.

\subsection{Reducing Mapuche}

Chile's 'pacificaction' of the Mapuche in 1883 marked the beginning of a century-long policy that sought to systematically deprive indigenous people of their ancestral lands by creating and institutionalising a system of reserves known as 'reducciones' (Haughney 2006; Stuchlik 1976; J. Pinto Rodríguez, personal interview, 23 October 2006). Reducciones essentially meant the expropriation of Mapuche from their land and forced them to establish in small plots of land. Unlike Spain's approach of designating a 
territory to allocate Mapuche, an area which Mapuche could essentially 'own,' the Chilean state opted to separate the reducciones with areas settled by Chileans and European immigrants. Reducciones changed Mapuche lifestyle, not only by impacting their economy and social structures, but by jeopardising the use and vitality of Mapudungun.

Dividing the Mapuche land into reducciones was considered by the Chilean government "a transitory step which should lead ultimately to the division of the whole Mapuche territory into small family farms" (Stuchlik 1976, p. 16). The government hoped that by separating the reducciones from areas that were being occupied by white settlers, the identity and collective strength of the Mapuche would weaken, vanishing altogether with the passing of time (Haughney 2006). Furthermore, reducciones were permanent and unchangeable holdings, (Stuchlik 1976, p. 17) which basically prevented the Mapuche from acquiring more land or moving from one location to another in search of better, more fertile soils. This reality was a metaphorical translation for Mapuche culture: being physically and geographically separated, Mapuche would encounter greater challenges in congregating as a community in order to continue exercising their traditional practices and customs, which were all carried out in Mapudungun. More obvious was the fact that having smaller quantities of Mapuche surrounded by increasing number of Chileans would inevitably force Mapuche to learn and communicate in Spanish, consequently breaking the transfer of indigenous knowledge and weakening Mapuche social and cultural structures.

\subsection{Paving the way for a monolingual society}

Jorge Pinto Rodríguez, Doctor in History and Professor at the Universidad de La Frontera in Temuco, explained first during a presentation in Temuco and later on during an interview, that after the period of 'pacification' the Chilean state viewed the Mapuche as obstacles for social and economic development (personal interview, 23 October 2006). Unless Mapuche could work farmlands and perform menial jobs, the Chilean state showed no interest of establishing foundations for Mapuche social inclusion and for the existence of a bicultural society. 
In order to effectively eradicate Mapuche, the government used the reducciones to carry out what Pinto refers to as ethnocide - the destruction of the culture of Mapuche as a distinct group of people (Haughney 2006; J. Pinto Rodríguez, personal interview, 23 October 2006). The division of Mapuche among the reducciones established the necessary conditions to carry out ethnocide of Mapuche.

The system of reducciones had a twofold effect on Mapuche and on Mapudungun: as it had been anticipated by the Chilean state, geographic isolation of reductions led to economic and social segregation, but this remoteness also acted as a shield for Mapuche practices, including their use of Mapudungun.

On one hand, such isolation inhibited Mapuche from being active participants of Chilean society, economic activities and politics. Like in the case of Aotearoa New Zealand, language became a crucial and fundamental mechanism for social and economic participation of indigenous people in mainstream society.

On the other hand, the insulation of Mapuche communities, albeit forced, meant they were not compelled to learn Spanish and were able to use solely Mapudungun to communicate amongst themselves. Mapudungun is not only the root of important Mapuche customs, but it is the source of Mapuche indigenous knowledge: free use of Mapudungun meant Mapuche were able to fully engage in traditional activities and practices. Thus, without "intending to, the State created the appropriate conditions for the reproduction of a specifically Mapuche culture: concentration of the population and cultural isolation" (Cantoni 1986). The use of Mapudungun was maintained within the reducciones, yet the preservation of language came at the expense of economic deprivation and social marginalisation, for the isolation also meant that Mapuche communities were unable to access formal schooling or receive any kind of training that would effectively allow them to become part of Chile's higher economic and social status.

The second outcome of the reducciones was that the high concentration of Mapuche in small parcels of land led to an increase in Mapuche population: it is estimated that between 1927 and 1961, the Mapuche population tripled (HRDC 2002). More Mapuche, 
meant more speakers of Mapudungun. Nevertheless, an increase in the number of Mapuche did not mean an increase in the amount of land available. The lack of space and land availability of the reducciones, meant that communities were unable to support the number of Mapuche, forcing a rural exodus to cities (Valdés 2006). So while Mapuche living in rural areas were able to prevent cultural assimilation by remaining insulated, they were forced to live at the fringes of Chile's economy and society, hindering their social integration and advancement in both urban and rural settings.

\subsubsection{Neither here nor there}

Under neither circumstances was it possible for Mapuche to focus or establish methods of recovering their cultural traditions or setting forth a system of teaching Mapudungun in schools. Like in Aotearoa New Zealand, the language survived due to linguistic diglossia: Mapuche used Mapudungun to communicate with family members or during cultural affairs and celebrations, but found little use for it outside the rural or communal areas. Eventually, however, increased discrimination inhibited the use of Mapudungun in public, and as the Chilean society denied and rejected the use of Mapudungun, the linguistic diglossia soon developed into disglossia. Disglossia, the linguistic condition in which a society denies a language, consigning it to the status of non-tongues, triggers the death of a language, in this case, it being Mapudungun. Many, if not most, Mapuche in rural areas did not have access to education, and depended on their skills and fluency on Spanish in order to be able to effectively communicate with and find work within Chilean society (A. Hernández, personal interview, 25 October 2006).

Those Mapuche who were able to attend schools in the city were not taught Mapudungun, since the language was not part of Chile's education curriculum. Furthermore, Mapuche who attended schools in the city had no interest in learning Mapudungun, since speaking Mapudungun in public made Mapuche targets for further discrimination. Mapudungun did not have a place within Chilean urban society that granted it a high value through official recognition and respect (Cañualef n.d.).This place was found only in the rural setting in Mapuche communes, and even there the maintenance of the language was threatened. Parents realised that their children would be socially and economically alienated by Chileans when using Mapudungun in public urban settings (Marimán 1990; A. Hernández, personal interview, 25 October 2006; A. 
Herrera, personal interview, 26 October 2006). Use of Mapudungun in cities became "an easily identified and stigmatised cultural trait which only increased discrimination" (Valdés 2006). Consequently, many families and communities prohibited their children from speaking or even learning Mapudungun (Trañi-Trañi community members, personal communication, 25 October 2006). Like in Aotearoa New Zealand, this led to a gap of knowledge and expertise on Mapudungun and halted the development and transmission of Mapuche indigenous knowledge from one generation to another. Without a functioning place in society, without users or speakers, extinction threatened Mapudungun, jeopardising Mapuche cultural identity and existence.

\subsection{The Mapuche since the 1970s}

Discrimination against Mapuche did not subside, increasing the erosion of Mapudungun as the use of the language became more and more limited. It was not until 1970 that hope was restored to the Mapuche community, with the election of Salvador Allende as Chile's president.

On September 1972, the Popular Unity government of Allende implemented Law 17,729, the first legislation in favour of the Mapuche (Herrera 2005). The process of creating the legislation actually included the participation of Mapuche leaders and community members, and the final draft of the Law provided for the Mapuche to recover more than 700,000 hectares of ancestral land (Herrera 2005). For Mapuche, land meant the ability to re-establish their cultural identity, which consequently meant reinstating Mapudungun (A. Hernández, personal interview, 25 October 2006; J. Pinto Rodríguez, personal interview, 23 October 2006). Law 17,729 also granted Mapuche communities technical and financial resources in the form of government subsidies, which facilitated their economic burden, allowing for emphasis on education and development of their cultural heritage. Additionally, the creation of a Directorate of Indigenous Affairs promoted social development of the Mapuche by creating health centres and education policies that favoured the integration of Mapudungun and Mapuche cultural values into Chile's national education curricula (Amnesty International 1992).

Communities went from one extreme to the other, as their indigenity was not only legally recognised, but the existence of their people was asserted with the implementation of 
decrees that would fulfil their basic needs. Hope, however, was short-lived as the military coup of September 11, 1973 reversed the implications of Law 17,729 (Haughney 2006).

\subsubsection{Backlash: a new political reality sinks in}

Advances made for and by Mapuche during Allende's presidency were invalidated with the arrival of General Augusto Pinochet to power in 1973. Pinochet's arrival resulted in a new wave of repression and abuses committed against the Mapuche. The military regime claimed that "national security and the nation's prosperity required an unregulated free market that was oriented to the world economy, a regime of private property, and a homogeneous national society" (Haughney 2006, p. 51). The ideologies were used to justify the series of injustices committed against the Mapuche and, in 1978, served for the implementation of Decree Law 2,568, which legally denied the existence of the Mapuche by declaring that there were "no indigenous people in Chile, only Chileans" (Haughney, p. 53).

Decree Law 2,568, officially titled For the Indian, Indian lands, the Division of the Reducciones and the Liquidation of the Indian Communities, called for the subdivision and privatisation of the reducciones, which were seen as an obstruction to Chile's economic development. By 1985, out of 2,066 registered Mapuche communities, only 655 remained in existence (Nesti 1999; Comité Exterior Mapuche [CEM] 1985). The numbers show that Pinochet's regime was in fact successful in dismantling what was left of the Mapuche community. The use of Mapudungun plummeted drastically (Zúñiga 2006).

The framework of Law 2,568 called for equality among Chileans, rejecting any kind of differential treatment the Mapuche asked for. The assimilation of the Mapuche into Chilean traditional social order would create a homogenous society, enabling the country to function more efficiently, according to neo-liberal standards (Haughney 2006). The Law's emphasis on the Mapuche as a minority who sought preferential treatment was a very convenient argument that facilitated the alienation of the Chilean community against the indigenous. As Mapuche protested the law, Pinochet branded them as revolutionary leftists who represented a threat to national security and stability by refusing to abide by the laws established for all Chileans to follow (Bengoa 1985; Saavedra 1971). 
Official government reports estimate that at least 300 Mapuche were reported missing or murdered under the Pinochet regime (HRDC 2002). Political persecution and the escalating abuses had a dual effect on Mapuche communities: on one hand, fear was successfully instigated among many Mapuche, forcing them to reject their culture, language, and heritage, and consequently face assimilation. On the other hand, Mapuche leaders summoned communities to adhere to their indigenous identity through the creation and support of existing organisations that would represent them internationally.

\subsubsection{In the face of extinction}

With the military coup came an exodus of Mapuche and left-wing activists, many who were imprisoned and released on the condition of exile (Christian 1986). The lack of Mapuche activists deflated attempts to revitalise Mapuche cultural values and practices, including the use of Mapudungun.

Aware that the Mapuche faced extinction in the wake of Pinochet's regime, and deemed with the lack of empowerment and organisational structure at a national level, leaders sought to create an international body that they could effectively use to their advantage. Politically-exiled Mapuche allocated in France and England organised the Exterior Mapuche Committee (Comité Exterior Mapuche [CEM]) seminar in 1978, which played a critical role in the revitalisation of Mapuche as indigenous people of Chile and in subsequent efforts to revitalise Mapudungun (Mapuche International Link 2002). ${ }^{35}$

CEM's mission was to appeal to the international community and publicise the abuses being committed against Mapuche as well as raise global awareness on the issues concerning Mapuche as indigenous peoples (CEM 1978). The headquarters of the CEM were established in Bristol, England, where the organisation began by launching the Ka Mapu Mapuche Traum-Mapuche Declaration of London (CEM 1978). In it, they stated the need for Mapuche and indigenous peoples to unite "in order to achieve higher levels of autonomy as part of the process of their development" (CEM 1978). Mapuche indigenous development included the right to maintain and make free, indiscriminate use of Mapudungun. Without Mapudungun, they argued, they would not be able to extend or transmit Mapuche indigenous knowledge, the essence of what being indigenous was all

${ }^{35}$ On May 1996 the CEM changed its name to Mapuche International Link (MIL). 
about. Furthermore, the same document condemned Chile's military regime and called for the elaboration of a programme to recognise "the exact needs of the Mapuche" (CEM 1978). Again, it became fundamental for this needs to include language revitalisation efforts.

On April 1979, CEM in France launched a second document denouncing the abuses being committed against the Mapuche (CEM 1979). The document condemned the implementation of Law 2,568 as a clear indication of the government's intentions to legally obliterate the existence of the Mapuche in Chile. This time, the CEM addressed the global community and petitioned for the urgent need to support the fundamental human rights being denied to the indigenous, including their inherent right to make active use of their language, as the Chilean state had officially prohibited the use of Mapudungun in schools and public spaces (CEM 1979). The need for the international community to intervene became a critical issue. Without any high-level coordination, projects proposed by the CEM became unsustainable and basically, unachievable.

The CEM, however, helped create and establish a link between Mapuche and the rest of the world's indigenous communities, enabling them to share the problems of Mapuche in Chile and learn from similar problems encountered by groups elsewhere. More importantly was the fact that CEM drew the attention and interest of the international community's organisations, and broke the isolation of the Mapuche by exposing their needs. Such attention has brought funding and programmes from a variety of institutions and organisations interested in the implementation of language revitalisation strategies.

\subsection{Conclusion}

Mapuche resistance to cultural assimilation during colonial and post-colonial history provided the foundations for the a relationship of opposition and resentment with the Chilean state. Despite numerous attempts for cultural assimilation, Mapuche have succeeded in maintaining their indigeneity, seeking mechanisms that protect their language, culture, values and practices. Upholding their identity by safeguarding Mapudungun has come at a high cost of alienating Mapuche from Chilean social and economic structures. Nevertheless, Mapudungun has secured Mapuche indigeneity by allowing them to transmit their indigenous knowledge, practices, and cultural values. 


\section{Chapter 9-A new beginning, yet a long road ahead}

\subsection{Introduction}

The Mapuche renaissance movement was initiated in the late 1980s, towards the end of the Pinochet regime. Since 1990, Chile's government has since established legislations and mechanisms that promote the protection of Mapuche as a unique group of people. Nevertheless, there still exists discord between demands made by Mapuche, including the official recognition of Mapudungun as a national language, and the willingness (or lack of willingness) on behalf of the Chilean government to acknowledge a due and adequate language revitalisation scheme that promotes Mapudungun at a national level.

The following will emphasise some of the education programmes and legislations created by the Chilean government and analyse why these have yet not succeeded in reaching many Mapuche living in Chile's rural areas. This chapter will show my own observations of language revitalisation efforts by describing three different case studies, each of which reflects the different levels of interest of Mapuche of engaging in existing language revitalisation methods as well as the levels of participation Mapuche have in owning the process of language revitalisation.

\subsection{Mapuche: a renaissance of sorts}

The democratic election of Patricio Aylwin in December 1989 marked a new era for the Mapuche and for indigenous language revitalisation efforts (Zúñiga 2006; Foerster \& Vergara 2000). Aylwin was committed to the Mapuche cause, promising to return to them as much territory as possible, to recognise their rights and indigenity, and to create a public institution that would concern itself solely with Mapuche affairs (Foerster \& Vergara 2000). Aylwin's concern with Chile's indigenous issues was a product of the persistence of the Mapuche movement that, due in great part to the continuous efforts of the CEM, had gained international attention.

On 17 May 1990, President Aylwin created the Special Commission of Indigenous Peoples (Comisión Especial para los Pueblos Indígenas [CEPI]) in order to establish communication between Chile's government and civil society, and Mapuche (as well as Chile's other indigenous groups). The CEPI's objective was to development institutional 
and legislative mechanisms that would recognise Chile's Mapuche as a distinct group of people with unique cultural values and needs (Sznadjer 1994). CEPI proposed a series of seminars, assemblies and meeting with indigenous leaders aimed to foster Chile's indigenous participation on the drafting of a law that would be of relevance to their needs and requests.

\subsubsection{Hatching of small language nests}

Important advances in language planning of Mapudungun were taken as a result of the meetings and seminars initiated by CEPI. Mapuche were able to convene and gain momentum and confidence in the reestablishment of their cultural values, heritage and hence, in the use of their language. In 1992, a project that had been launched one year earlier by Chile's National Nursery Schools Board (Junta Nacional de Jardines Infantiles [JUNJI]) was extended to the Mapuche community (Organización de Estados Iberoamericanos [OEI] 2006; JUNJI 2006). JUNJI was established in 1970 under Chile's Minister of Education, setting up nursery schools in all of Chile's thirteen regions. Until 1991, however, its programmes did not include educational provisions tailored for children in indigenous communities. A pilot project designed for two small indigenous communities $^{36}$ led to the development of a larger initiative: the establishment of nursery schools designed specifically for indigenous children throughout Chile.

The Programme of Attention for Infants of Indigenous Communities aimed to create the appropriate cultural learning environments for indigenous children living in rural areas (JUNJI 2006). The programme's objective was to secure the active participation of Mapuche in developing appropriate qualitative curricula for children of 2 to 5 years of age (OEI 2006). Capacity-building activities became an integral component of the programme; JUNJI provided support and training seminars to local Mapuche and provided them with resources and didactic material designed to meet the needs of each community (OEI 2006; JUNJI 2006).

JUNJI's indigenous programmes are limited only to rural areas with high percentages of indigenous populations. Mapuche who live in urban settings do not have access to the programmes. Children are part of JUNJI's programmes for a short period of time-four

\footnotetext{
${ }^{36}$ Yámana and Kawashkar both located in Chile’s southern XII Region.
} 
years at the most. Once they complete the programme, most children do not have access to intercultural or immersion programmes of any sort that further enable them to practice and develop the knowledge they have acquired during the time spent at the nursery.

JUNJI's programme was perhaps the most important success in the area of language revitalisation resulting from CEPI's meeting with Mapuche communities and leaders. Nevertheless, the programmes' isolation from Chile's urban centres has made the programmes virtually non-existent for the majority of Chile's population. A more drastic approach was required in order to effectively raise awareness on the importance of revitalising Mapuche cultural values and in creating a context for the widespread use of Mapudungun in Chile's society. It was necessary for Chile's government to act as unifying force in order to effectively close the gap between Chile's indigenous communities and the country's civil society.

\subsection{Law 19,253}

Aywlin's presidency materialised the government's efforts to act as a unifying force between Mapuche and Chile's civil society with the implementation of the Indigenous Act on 5th October 1993, otherwise known as Law 19,253.

For the first time since the fall of Allende, the Chilean state offered to establish structures and mechanisms that would guarantee the participation of Chile's indigenous peoples. Law 19,253 provided "the protection, promotion and development of the indigenous groups in Chile [by addressing] the political participation, education, land rights, cultural rights and development rights" of the Mapuche (Human Rights Resource Centre [HRRC] 2005). The Law recognises Chile's eight indigenous groups, of which the largest is the Mapuche. ${ }^{37}$

At the same time however, the solution presented by the State to the indigenous problems, became the problem: Law 19,253, and the series of organisational structures stemming from it, were created and designed to function as entities owned by the State, not by Mapuche. Mapuche were invited by CEPI to participate in the preliminary stages of drafting the law, CEPI effectuated the proposed series of meetings and assemblies with

\footnotetext{
${ }^{37}$ Aymara, Rapa Nui or Pascuense, Likay Antai, Quechua, Colla, Kawashkar or Alacalufe, and Yámana or Yagán.
} 
Mapuche community members and leaders in order to inform and discuss the basis of Law 19,253 prior to it being officially instituted. Ultimately, however, it was the Chilean State that devised the framework for the promotion of Chile's indigenous peoples' culture and knowledge, and proceeded to set an agenda that defined the limits of indigenous people's participation (Cayul 1990). Furthermore, while Law 19,253 aimed to increase social, cultural and economic participation of Mapuche, it excluded Mapuche from political and legislative participation, which had fundamental implications on the strategies for revitalisation of Mapudungun at a national level.

Even though Law 19,253 was, and still is, the most favourable legislation Chile has established in terms of promoting and protecting indigenous rights, it has not been entirely successful in adequately representing the needs and interests of the Mapuche, including the commitment that Mapuche expect from the government in recognising the need to address revitalisation of Mapudungun. Furthermore, Chile's constitution does not specify any mechanisms for indigenous participation in the legislative power, which results in Mapuche having little participation on the design and control over the development policies that directly affect them (Gasitúa-Marió 2001).

\subsubsection{Complexities within: Articles 22-33}

Law 19,253 is an extensive and complex document. Unlike the Treaty of Waitangi, which is made up of three articles, Law 19,253 is comprised by a total of 80 articles. It is, by no means, a 'user-friendly' document that can be readily understood by the general public. These 80 articles are divided by nine numbered sections, each labelled with a title that reflects the area of interest it addresses. Each Title is divided into numbered and individually headed subsections.

In looking at indigenous language revitalisation in Chile-most specifically at revitalisation of Mapudungun - the most relevant section is Title IV, under About Indigenous Culture and Education.

Mapudungun is an integral part of Mapuche cultural development, which must, according to stipulation made under Title I, be respected, protected and promoted by the State. Title 
I introduces the general principles of Law 19,253 under the heading "Of Indigenous Peoples, Their Cultures and Their Communities," stating that:

it is the duty of society as a whole and the State in particular, through its institutions to respect, protect and promote the development of indigenous peoples, their cultures, families and communities, adopting the necessary adequate measures to achieve this end" (Law 19,253 1993).

Of particular relevance to the revitalisation of Mapudungun is Article 28, which states that the "recognition, respect and protection of indigenous cultures and languages will contemplate the use and conservation of indigenous languages, alongside Spanish in areas of high indigenous density" (Law 19,253 1993). The continuing section of Article 28 calls for "the establishment within the national education system of a unit programmed to enable students with access to adequate knowledge of indigenous cultures and languages and that qualifies them to positively value it." Likewise, relevant to the revitalisation of Mapudungun is Article 32, which stipulates that:

in areas of high indigenous density and in coordination with corresponding the State's services or organisations, the National Corporation for Indigenous Development [Corporación Nacional de Desarrollo Indígena (CONADI)] will develop a system of bilingual intercultural education with the objective of preparing indigenous students to adequately engage in their society of origin as well as in the global society (Law 19,253 1993).

The specification of enforcing indigenous languages only in "areas of high indigenous density" provides to be problematic for Mapuche living in urban areas, where concentrations of Mapuche are scattered throughout the city (Law 19,253 1993). These pocket communities of Mapuche are not given the opportunity to equally benefit from Article 32 and still find themselves alienated from education centres and institutions, which are not required to provide intercultural education.

Furthermore, the limitation of the Article 32 also proves problematic for Mapuche in rural communities who are encouraging the revitalisation of Mapudungun among younger generations. Families still believe that if their children eventually want to pursue a life in the urban area, they will have no use for Mapudungun, which causes a conflict of 
interests among community members: should they enforce the use of Mapudungun at the expense of having their children eventually ostracised in urban settings for retaining their indigenous identity (Trañi-Trañi community members, personal communication, 25 October 2006; Marimán 1990)? In urban settings, Mapuche who are fluent in Mapudungun still, in many instances, address each other in Spanish for fear of being discriminated against (Trañi-Trañi community members, personal communication, 25 October 2006).

Articles 22-33 demonstrate that Law 19,253 provides the necessary legal mechanisms required to declare Mapudungun, on par with Spanish, an official national language in Chile. Yet without the ground support from Chilean society, without the social acceptance of Mapudungun, it still is not possible to achieve successful results in language revitalisation.

\subsubsection{CONADI}

Perhaps the most important provision made by Law 19,253 relating to language revitalisation has been the creation of the CONADI. As part of Law 19,253, CONADI was established the same day the law was ratified. CONADI was to fulfil a series of objectives, the main being that of "controlling that the cultural development of indigenous peoples is protected, provided for and respected" (CONADI 2006). CONADI functions as a government agency under Chile's Minister of Planning and Cooperation (Ministerio de Planificación y Cooperación [MIDEPLAN]). The agency is responsible for coordinating the State's role in relation to Chile's indigenous peoples and communities, with the objective of promoting indigenous participation in Chile's economic and social development (CONADI 2006). It implements Law 19,253 through specific programmes, which includes one focused on the establishment of intercultural bilingual education.

Requests and petitions of having Mapudungun officially recognised as a national language on par with Spanish were first discussed with members of CONADI's council in the late 1990's (A. Hernández, personal interview, 25 October 2006). CONADI's decision-making process is conducted by a council, which is composed of a governmentappointed director, eight representatives of different government agencies, and eight 
indigenous representatives, who are elected by indigenous peoples registered to vote. The purpose of having a culturally diverse council has been to ensure indigenous participation in decision-making processes. The arrangement, however, has proved to be flawed: votes by indigenous council members can be overruled and disregarded by government appointed members and the council's director. This offsets the CONADI's efforts of creating a participatory arrangement and instead, demonstrates the limitations indigenous peoples still have on being able to fully engage in decision-making processes that have a direct impact on them and the development of their interests. Such has been the case so far with requests made by Mapuche regarding language revitalisation efforts (Zúñiga 2006). Recommendations of introducing Mapudungun as an official language in Chile have been overruled by government members of the council.

Although the organisation has been criticised by indigenous leaders as well as by legal experts, neither its structure nor its regulations have changed (Gasitúa-Marió 2000). The council is essentially owned by the Chilean state. CONADI is still not held accountable for enforcing indigenous rights and it does not function as a channel of political participation for the Mapuche (Haughney 2006). This reflects that although Law 19,253 stipulates that the positions and opinions of indigenous peoples will be considered in decisions affecting them, CONADI is not held accountable when such considerations do not take place (Marimán 1990).

CONADI's role as an intermediary has proved to be ineffective in terms of language revitalisation efforts. Unlike the Waitangi Tribunal, which has so par proved to be an effective mediator between Māori and Aotearoa New Zealand's government, CONADI does not effectively mediate the interests and concerns of Mapuche with the Chilean government; instead Mapuche have so far been expected to settle with legislations, which in many cases act as a blanket solution to what are intricate and complex cultural and political problems that require specific attention.

\subsubsection{National Education and Cultural Fund}

In 1995, under the supervision of CONADI and as a response to the demands being made by Mapuche to increase efforts of language and culture revitalisation, the National Education and Cultural Fund was established. Among the responsibilities assigned to the 
Fund was the development of system of Bilingual Intercultural Education Programmes (Programa de Educación Intercultural Bilingüe [PEIB]). During an interview with the Fund's National Director, Eliana Huitraqueo Mena, she explained that the PEIB was just a fraction of a much larger set of responsibilities assigned to the Fund. The budget assigned to complete the objectives of PEIB at a national level is not enough to cover the costs of developing new projects in new areas or to support ongoing programmes that address intercultural and bilingual issues (Gasitúa-Marió 2000). This limits the scope and effectiveness of PEIB. Huitraqueo stated that:

CONADI's financing is quite low, and most of the money distributed by CONADI goes to settlement of indigenous land, as opposed to programmes concerned with cultural and language revitalisation. This is not only the government's prerogative - it is what Mapuche demand (E. Huitraqueo, personal interview, 27 October 2006).

Mapuche demand Mapudungun and indigenous knowledge to be appreciated at a national level, and not only in Chile's rural, poverty-stricken areas (R. Huisca, personal communication, 18 October 2006). They want to have Mapudungun recognised equally alongside Spanish. Huisca explained how:

the implementation of language recovery programmes should be the responsibility of Chile's government. Mapuche should not be pinned against the wall in choosing language over compensation of lands: the state owes Mapuche both. Where it gets its money from should not concern Mapuche (R. Huisca, personal communication, 18 October 2006).

Furthermore, Huitraqueo said that due to the lack of budget available to develop language revitalisation initiatives in rural areas, Mapuche opt to work with independent national and international independent agencies, institutions and organisations that offer them increased levels of funding (personal interview, 27 October 2006). While such approaches by external actors other than CONADI to work with Mapuche result in the development of effective methodologies and projects for language revitalisation, they also lead to inconsistencies in schemes for language revitalisation. By focusing solely on rural areas and neglecting to incorporate urban settings, many independent projects and programmes strengthen Chile's flawed approach of neglecting to increase indigenous 
participation in Chilean society by creating initiatives that apply only the isolated, rural communities.

\subsection{Bilingual Intercultural Education Programme}

Just like JUNJI's programmes may be compared to Māori kura kaupapa, the PEIB is Chile's approximation to Aotearoa New Zealand's Te Kohanga Reo movement.

The PEIB initiated as a pilot experience in 1996 as a response to the demands of Chilean indigenous people to have Mapudungun and indigenous knowledge integrated into school curricula, as Mapuche claimed that the provisions stipulated in Articles 28-33 of Law 19,253 were not being met. CONADI and Chile's Ministry of Education (Ministerio de Educación [MINEDUC]) agreed to support PEIB, which began as a collaboration of efforts between civil society members, non-government organisations and university research teams that had experience with Chile's indigenous issues. PEIB were officially adopted by Chile's government in 1998, after the pilot projects proved to be successful in a handful of indigenous communities.

The objective of developing PEIB was to promote the development of indigenous cultures by fostering and revitalising indigenous languages in schools with high attendance of indigenous children, providing continuation to JUNJI's indigenous nursery schools (C. Millacura, personal interview, 6 November 2006). PEIB was designed under the stipulations of Law 19,253, and the programmes are therefore not exclusive to the Mapuche, but include Chile's other 7 ethnicities. The observations and research carried out in this dissertation however, are based solely on Mapuche communities and the impact PEIB have on the revitalisation of Mapudungun.

The framework of PEIB was to promote indigenous knowledge at a national level by integrating indigenous values, language and culture into Chile's curriculum for basic education (Cañulef n.d.; Organization of American States 1998). The programmes were directed at schools in indigenous communities in order to stimulate the retention of Mapudungun, hence indigenous traditions and values. The greatest challenge PEIB face in Chile is to reflect the importance of incorporating intercultural and bilingual factors into the national curriculum, and not limit the existence of programmes just to indigenous 
communities (M. Sánchez, personal interview, 17 October 2006). Such partition of giving only Mapuche children the opportunity to be educated in a bilingual environment, furthers the historical divisiveness between Mapuche and Chilean society. It is fundamental to have PEIB function as part of Chile's national education system, and not as isolated experiences in rural indigenous communities (M. Sánchez 2006, personal interview, 17 October 2006).

Like in the case of te reo Māori and many indigenous languages, relying on the use of grammatical texts has not proved to be a successful norm in teaching and learning Mapudungun. Furthermore, Mapudungun is still notoriously difficult to teach, and currently still uses four different graphemes. Therefore, Mapudungun relies heavily on its social context, on reflecting Mapuche values and traditions, in order to make sense and be effectively taught and learned. Trying to fit Mapudungun into traditional teaching modalities used to teach Spanish would has not proved to be effective (C. Millacura, personal interview, 6 November 2006). The PEIB has therefore been designed as a platform to advance the disposition of the government and civil society to have social coexistence between Mapuche and Chileans in schools.

The objective of PEIB to develop a participatory approach epistemology, which means that Mapuche would be invited to design the framework and establish education curriculum for their children, was not entirely successful (M. Sánchez, personal interview, 17 October 2006). Even though PEIB were established with the participation of Mapuche community members, the core of the programmes was developed by nonindigenous external actors. This was due, in great part, to the lack of Mapuche professionals and academics that had the required proficiency and experience to develop plans of action in language revitalisation. Interested community members were also invited to participate, yet most were unable to spare enough time to be fully involved in the design of PEIB of their area. This does not mean that Mapuche were excluded from the development of PEIB; nevertheless, the lack of authority the Mapuche had throughout the process placed them once again at a considerable disadvantage. Consequently, nongovernment organisations and university researchers took the role of conducting the pilot programmes, without active participation from Chile's government and with limited consultation from Mapuche community members (Organization of American States 
1998). Mapuche were able to communicate their needs and preoccupations with the erosion of Mapudungun, yet they were unable to own the process of language revitalisation and depended on external actors for the development of methodologies that would ultimately, apply to them.

A new insight on the reason for developing PEIB is offered by Claudio Millacura, the Ministry of Education's National Coordinator of the PEIB, during an interview (personal interview, 6 November 2006). Millacura explained that the aim of PEIB is not to have Chile's indigenous people design the methodology, curricula, or teaching schemes that will be implemented in schools in their communities, but instead, the objective of PEIB is to give them an already developed methodology and plan that they can use in their communities (personal interview, 6 November 2006). This will potentially allow MINEDUC to systematically keep track of education advances achieved in rural areas of Chile and therefore create set standards that will allow to effectively measure Chile's national levels of education.

\subsubsection{Numbers speak for themselves}

Having language revitalisation programmes recognised by the government is a sign of progress: historically, the Chilean government had not only neglected the use of Mapudungun, but prohibited its use. Although there are still considerable advances to be made in consolidating language revitalisation initiatives at a national level, some progress has been made.

In a series of statistics carried out by Chile's National Statistic Institute since the year 2000, it was shown that the use of Mapudungun has increased considerably in rural settings. This increased may be attributed to JUNJI's nursery school initiatives as well as to the establishment of PEIB. In 2000, 27.8 percent of Chile's indigenous population declared it understood and/or was fluent in Mapudungun (Chile Instituto Nacional de Estadística 2000). The percentage increased in 2003, to 35.7 percent. More than 40 percent of Mapuche living in rural areas have at least a basic understanding of Mapudungun (Nuevo Trato 2006, p. 36). The numbers change drastically for Mapuche living in urban settings: census show that less than 10 percent of Mapuche in urban 
centres speak and understand Mapudungun, and only one third of that 10 percent understands Mapudungun (MIDEPLAN 2006).

\subsection{Real life examples: Case studies in Chile}

Mapuche perceive language to be a tool that has been used for colonisation and discrimination (J. Pinto Rodríguez, personal interview, 23 October 2006; M. Sánchez, personal interview, 17 October 2006). Consequently, there exists continuous resistance on behalf of the Mapuche to allow huincas ${ }^{38}$ to into their communities to act as teachers of Mapudungun (J. Pinto Rodríguez, personal interview, 23 October 2006). Nevertheless, the lack of funds and the lack of Mapuche trained educators, does not leave much option for Mapuche but to accept external actors who offer their expertise for the development of language revitalisation initiatives and intercultural education methodologies. The belief that Mapudungun should be learnt and taught within a context relevant to indigenous knowledge, has meant that language revitalisation efforts have been limited to rural, impoverished areas of Chile, where there is a high concentration of Mapuche.

Carrying out research and fieldwork in Chile, I became aware of the discrepancy between official government documents claiming successful promotion of Mapuche valuesincluding revitalisation of Mapudungun — and societal realities of Mapuche in living in rural areas of Chile's IX Region. Interviews with government officials, educators and researchers, members of NGOs working with Mapuche, and Mapuche community members all presented mixed opinions on the success of Mapudungun revitalisation programmes. Groups and individuals do not seem to agree on the reasons for the lack of success so far of Mapudungun revitalisation in Chile: whereas some blame the CONADI for not giving them enough resources to develop language revitalisation schemes, others blame the lack of interest on the Mapuche community to prioritise language and cultural values over their interest on regaining territorial land rights. The following three case studies are examples of the limited coverage of PEIB and of JUNJI's nursery schools designed to meet the needs of indigenous communities. Furthermore, these three case studies demonstrate the discrepancy between levels of language revitalisation efforts in the rural areas of IX Region, where the majority of Mapuche in Chile live. Visits made to

\footnotetext{
${ }^{38}$ Huincas, or Wincas: term used by Mapuche to refer to white, non-indigenous Chileans.
} 
the Mapuche commune of Juan Puña located in Galvarino, the bilingual intercultural school in Trañi-Trañi, and the Intercultural Technical Secondary School Guacolda located in Chol Chol, all show different aspects of what has been achieved by PEIB in terms of language revitalisation; none of the three communities had access to JUNJI's nursery schools. In fact, with the exception of educators, members I spoke with from these three communities were not aware that JUNJI had developed nursery schools designed to meet the particular needs of Chile's indigenous communities, despite the fact that JUNJI established its programme 12 years ago.

\subsection{Case study one - Galvarino: Land, not language}

I attended a meeting between Alejandro Herrera, director of the Instituto de Estudios Indígenas (Institute of Indigenous Studies) of the Universidad de la Frontera in Temuco, and community members of Juan Puña, a community located in the Galvarino area in the province of Cautín in Chile's IX Region, about 60 kilometres south of Temuco. Juan Puña is located in an extremely rural area where Mapuche cultural values and practices are still in place. Twenty-two families live in the community of Juan Puña (a total of 70 people), most of which were present during the meeting arranged with Herrera. The community's entire population is Mapuche and all of them speak and understand Mapudungun.

The opportunity to visit the commune of Juan Puña represented speaking and listening to the ongoing concerns of Mapuche living in rural areas and how they perceived the threat of language death as a factor that would (or perhaps would not) affect them. The language usage given to Mapudungun at ground levels, outside schools, can not be appreciated in the urban settings of Temuco and Santiago, where I carried out a great deal of my research.

The community of Juan Puña requested to meet with Herrera to seek his "guidance, advice, and counselling on how to advance the education and economic situation of the community" (A. Herrera, personal interview, 26 October 2006). Herrera asserted how one leads to the other: if community members don't have access to schools, they won't be able to better their economy (personal interview, 26 October 2006). 
Yet access to education is limited and sending children to school is in many cases not even an option: It takes approximately 40 minutes, on a broken dirt road, to reach the nearest school. Additionally, transport to and from the school is not always available. During the rainy season, it becomes almost impossible to drive on the muddy roads, and children are forced to miss school until the rain subsides (A. Herrera, personal interview, 26 October 2006).

Juan Puña's community members are concerned mostly with poverty, economic development and their need for land. These needs far outweigh their concern with language revitalisation. When addressing the subject of education, however, many said they see schools as a threat: "our children go to school, learn Spanish, learn the ways of the huinca, and then they leave to the city and forget all about us," said Alberto, one of the community's leader. "We want our children to learn the importance of our culture and language, and they don't learn that in school." Nevertheless, the community's youth would like to further their education. Currently, there are fourteen youths under the age of 18 who would like to attend university but are unable to because they don't fulfil the basic requirement of having completed their secondary level studies. "I would like to go to university and learn how to develop the land and bring tourism into our community," said a 16-year-old male attending the meeting. I asked him if he thought that his understanding and use of Mapudungun would help him in any way to achieve his dream, to which he replied: "Understanding the language of the land will help me bring back to Juan Puña what I have learned in the city and at school. Also, I think tourists like it when we talk in Mapudungun, so maybe that will attract tourists as well" (personal communication, 26 October 2006). Using Mapudungun solely for purposes of economic gain and to attract tourists would prove to be an unsustainable method for language revitalisation that would risk tokenism (Crystal 2000).

I asked members present during the meeting what their thoughts were on educational initiatives that sought to implement intercultural modes of education, and used JUNJI's nursery schools and the development of PEIB as examples. None of the community members attending the meeting, however, were aware of either programme. Nevertheless, most expressed distrust when referring to CONADI: "We can't understand how it works and they never answer our letters or pay attention to our requests," said a young woman. 
"When CONADI representatives finally visit our community, they say that we shouldn't complain about how we live. They expect us to live in rucas" (personal communication, 26 October 2006). ${ }^{39}$ Herrera's reasoned on language revitalisation efforts in Chile by explaining that:

The need of the Mapuche to have economic sustainable livelihoods takes precedence over their need to focus their energies on language revitalisation. Most of Chile's Mapuche live in poverty. Their preoccupations therefore usually lie on how to cope with their economic hardships (A. Herrera, personal interview, 26 October 2006).

\subsection{Nurturing language nests: New beginnings and lessons learned}

In order to have a clear understanding of PEIB, I visited two schools in Chile, both which offer PEIB programmes: the Communitarian Intercultural School of Trañi-Trañi and the Intercultural Technical Secondary School Guacolda in Chol Chol.

I visited both schools with Arturo Hernández, sociolinguist and Secretary General of the Universidad Católica de Temuco, who had been invited to give a seminar on revitalisation of Mapudungun in Chile in both schools.

Although the underlying theme of Hernández's two presentations was the same- the importance of revitalising Mapudungun - the audience attending each presentation was different. In the case of Communitarian Intercultural School of Trañi-Trañi, Hernández addressed parents and guardians of students attending the school; in the case of the Intercultural Technical Secondary School Guacolda in Chol Chol, Hernández addressed the school's educators and staff members (personal observations, 25 October 2006). The objective of both presentations was to raise awareness on the critical state of Mapudungun and prevent further language loss by addressing the issue in both, schools and households.

\subsubsection{Case study two - Bilingual Intercultural School Trañi-Trañi}

Trañi-Trañi is a rural area located about 10 kilometres from Temuco. Despite its geographic proximity to the city centre of Temuco, Trañi-Trañi appears remote, with dirt

${ }^{39}$ A ruca is a traditional Mapuche house usually made of adobe and covered with hay. 
roads dividing small farming communities in the area. The community's seclusion is evident not only in terms of the neglect and state of abandonment of its roads; the car's radio signal falters as we approach our destination: Trañi-Trañi's Communitarian Intercultural School.

Trañi-Trañi population is mostly made up of Mapuche. Juan Cayupán is a small community of 39 Mapuche families who live in the area. In the late 1990s, the community of Juan Cayupán, began mobilising to rescue their Mapuche heritage and to uphold their indigenous knowledge. Foundation for Peasant Development (Fundación de Desarrollo Campesino [FUNDECAM]) works with Mapuche communities in Region IX, with the objective of promoting Mapuche cultural identity through workshops and dialogue with Mapuche community members (R. Mansilla, personal interview, 25 October 2006). It is important to note that FUNDECAM is an independent and private organisation which is part of the Compas group, which is an international programme made up of 22 development organisations in 10 different countries, which supports the development of rural indigenous communities (Compas Organization 2006).

FUNDECAM approached the community of Trañi-Trañi and offered to support the preservation and revitalisation of Mapuche cultural values in the area by establishing an intercultural education centre for children in the region to have access to (R. Mansilla, personal interview, 25 October 2006). The proposal included teaching children Mapudungun in order to develop language revitalisation schemes in Trañi-Trañi.

The large majority of Juan Cayupán's community members work by farming small plots of land, and selling whatever produce is available to local markets. Before 2002, the area did not have a school. Having an education centre was critical but the community did not have the resources nor the trained personnel or teachers in order to effectively establish a sustainable learning centre (R. Mansilla, personal interview, 25 October 2006). The poor conditions of roads that link Juan Cayupán's community with neighbouring Mapuche communities and the lack of transportation available, made it almost impossible for community members to work in unison with fellow Mapuche. Hernández explained:

Ultimately, Mapuche communities living in remote rural areas, which are culturally and economically isolated, rely on external actors for the mobilisation 
of their cause. While isolation has worked in favour of the Mapuche by allowing them to retain much of their identity, it has also proved disadvantageous when it comes to their efforts of organising as a unity (A. Hernández, personal interview, 25 October 2006).

In a joint effort between members from the Mapuche community of Juan Cayupán and FUNDECAM, the Communitarian Intercultural School of Trañi-Trañi was established. CONADI has limited resources, limited personnel, and limited capacity; reaching communities like that of Juan Cayupán is not always possible for the organisation. Therefore, communities in rural areas usually eager to work with independent organisations like FUNDECAM.

"We seek to incorporate and promote Mapuche participation in our workshops. We want to achieve regional development by implementing participatory research and actions," said Roberto Mansilla, director of FUNDECAM. Mansilla organised and invited Hernández, along with a representative of the CONADI, to address parents and guardians of students at Tañi-Trañi's with the objective of effectuating a socio-linguistic study of the status of Mapudungun in the area of Trañi-Trañi. The aim of the study is to be able to design a language revitalisation strategy in accordance with the actual condition of Mapudungun. Recognising the level of vitality of Mapudungun outside the school grounds will allow for the development of adequate language resources for children in school. In order to complete the study, socio-linguists like Hernández will be asked to visit children's houses and interview household members. Mansilla explained:

So long as there are children who speak and understand Mapudungun, the language will stay alive. But we can not take it for granted that children will intuitively learn Mapudungun It is necessary to incorporate language revitalisation efforts into school curriculum (R. Mansilla, personal interview, 25 October 2006).

The school is equipped with the most basic infrastructure: concrete walls, wooden desks, toilets, and a green area for the children's recreation. Additional desks were added to the school's largest classroom and approximately 40 people attended Hernández's presentation (personal observations, 25 October 2006). Hernández began the presentation 
by addressing those present in Mapudungun, yet when he posed a question to a young man who is part of the audience, the young man instinctively responded in Spanish. "Why do you answer in Spanish if I am addressing you in Mapudungun?" asked Hernández. "Because you are a huinca," replied the young man. "But I can speak Mapudungun," replied Hernández, whose credentials include the publication in 2005 of the first illustrated dictionary in Mapudungun (personal observations, 25 October 2006). The young man did not reply and Hernández began his presentation (in Spanish) and explained to those present the importance of maintaining Mapudungun healthy, of teaching children how to use the language outside school grounds and homes, in public settings. In order to determine a methodology for language revitalisation, Hernández explained that it is necessary to first examine the condition of Mapudungun in the area (personal observations, 25 October 2006). Do children speak Mapudungun in their house? Do family members speak amongst themselves in Mapudungun? When do they use Spanish and how often?

Perhaps the most important segment of his presentation, however, was during his concluding remarks, when he directly addressed the audience and asked them whether they would like their children to learn Mapudungun: people shifted uncomfortably in their seats, many lowering their gaze, and all remained silent. Hernández prompted them for feedback and it took some time before community members began sharing their thoughts (personal observations, 25 October 2006).

Some said that they send their children to school hoping their children eventually move to urban settings. "We want our children to learn the way of the Mapuche, but we also want our children to have opportunities in places like Santiago," said a woman who is breastfeeding her newborn. An elderly man responded to Hernández in Mapudungun (Hernández later translated his answer for me): "If our children learn Mapudungun, we want them to be able to use the language without shame when they visit the urban centres. We don't want them to go the cities and be discriminated against" (personal observations, 25 October 2006).

Others, however, expressed a desire for their children to stay in the area and help farm and develop the land. "I want my son to deal with the huincas, to be respected by them, to show them his education. But I want him to be Mapuche and teach his children-my 
grandchildren-Mapudungun." Another man quipped in: "We were not allowed to speak Mapudungun in public, and our teachers were our grandmothers. Our fathers and mothers were not allowed to speak Mapudungun while they were growing up. But I want my children to learn the language of their people" (personal observations, 25 October 2006).

All of those present during the meeting acknowledged that they had agreed and supported the idea of having an intercultural school in the area; however, they also acknowledged the fact that they didn't have much choice and were not sure what was meant by 'intercultural school.' The community of Trañi-Trañi wanted to have a school in the area and FUNDECAM was the only orgranisation offering to support their cause. "We do as they say, as long as they fulfil their promise of educating our children," a woman told me after the meeting had concluded (personal communication, 25 October 2006).

\subsubsection{Case study three - Intercultural Technical Secondary School Guacolda}

Hernández made a second presentation on the importance of language revitalisation in Chile to educators at the Intercultural Technical Secondary School Guacolda in Chol Chol, located 28 kilometres northeast of Temuco. Hernández was invited by the institution's principal, Hernán Gutiérrez, to promote the importance of the principles of PEIB, with the objective of subsequently introducing an effective language revitalisation methodology. Hernández was asked to address educators first and then carry out a study that would determine the status of Mapudungun and its levels of usage within the school (A. Hernández, personal interview, 25 October 2006; H. Gutiérrez, personal interview, 25 October 2006).

The Intercultural Technical Secondary School Guacolda is free of charge and was established more than 20 years ago by the Foundation Indigenous Institute (Fundación Instituto Indígena [FII]), a private organisation sponsored and created by the Catholic Clergy of Villarica and Temuco. ${ }^{40}$ The school presently has 390 students, of which 87 percent are Mapuche (H. Gutiérrez, personal interview, 25 October 2006). The school is the only education centre of the area of Chol Chol that has an established intercultural curriculum, placing particular emphasis on the development and revitalisation of Mapudungun. The case of the Intercultural Technical Secondary School Guacolda, is

\footnotetext{
${ }^{40}$ Villarica and Temuco are both part of the IX Region.
} 
similar to that of Trañi-Trañi in that it was not established by Mapuche, but is administered and funded by the FII.

FII states it has worked for more than 45 years "alongside Mapuche [and presently] supports processes of participatory approach that seek to include Mapuche in decisionmaking processes" (FII 2007). Despite FII's disclaimer on its website and other documentation that it does not carry out proselytisms of any kind, nor that it questions the political or religious affiliation of its participants, Guacolda is a Catholic school. It requires its students to attend mass, and commemorates Catholic as well as Mapuche celebrations. Mapuche must comply to the standards set by FII in order to attend Guacolda; they are not empowered to decide whether or not to partake in FII's religious activities and ceremonies.

In 2005, the school developed an independent language revitalisation scheme which was approved by MINEDUC. The scheme's proposal included the latest advances in technology available for language acquisition, resulting in the creation of a room fully equipped with computers that made the latest software for teaching and learning Mapudungun available to all students. Unfortunately, the computers are barely used nowadays. Students prefer to practice mathematics or focus on other areas rather than just practicing Mapudungun. Results of elevating the language status by promoting new methods of language acquisition were not successful.

A lack of interest on promoting Mapudungun on behalf of educators has seen a slow deterioration in the school's language revitalisation efforts. Around 35 educators attended Hernández's presentation, including Hernán Gutiérrez, the school's principal (personal observations, 25 October 2006). Unlike his presentation at Communitarian Intercultural School in Trañi-Trañi, Hernández began his presentation distinguishing between intercultural education and the "tokenism" of Mapudungun. He acknowledged Mapudungun to be the nucleus of Mapuche traditions and practices, yet went on to warn that the language must not be turned into a museum object, but should instead be taught as a functional tool to be utilised outside school grounds (personal observations, 25 October 2006). "Mapudungun needs to be taught not only for the sake of teaching it, but for the sake of using it" (A. Hernández, personal interview, 25 October 2006). He urged educators to seek ways to promote and motivate students to actively engage in language 
usage, and they can do so by raising levels of language awareness, and by facilitating methods of language acquisition (personal observations, 25 October 2006).

One of the educators referred to the social disconnection between life outside school and life inside school as an enormous challenge in order to achieve language usage: Unless confined to rural areas, Mapuche find little use for Mapudungun (Herrera 2006). "Children will not be using Mapudungun in city centres, so why should we focus on teaching them something they won't be able to use?" Furthermore, many of the educators expressed concern on dedicating their careers to teaching Mapudungun and hence, confining themselves to Guacolda. Several pointed to the fact that schools in Santiago are not seeking educators of Mapudungun, and when they, the educators at the Intercultural Technical Secondary School Guacolda, reach high levels of proficiency in Mapudungun and seek to further develop their careers as academics, they find that schools in urban centres are not interested in hiring them. Therefore, they have no incentives to further advance their studies on a language that will likewise be neglected in areas where Mapuche are not the majority (Guacolda 2006).

Others acknowledged the difficulty of teaching Mapudungun. The challenge lies not only in the complexity of the language itself, but in dealing with the radically different levels of fluency that students attending Guacolda have in Mapudungun (H. Gutiérrez, personal interview, 25 October 2006). Guacolda acts as a boarding school for children living in rural areas who can not afford the cost or do not have access to daily transportation. Because Mapudungun is still widely used in the area's households, children who are able to return to their homes at the end of a school day are able to use Mapudungun with family members and develop their language skills. Children who stay in Guacolda for the week, however, find themselves using Spanish more often than Mapudungun $(\mathrm{H}$. Gutiérrez, personal interview, 25 October 2006).

Furthermore, teachers said that they don't receive appropriate resources in order to develop enough or appropriate didactic materials to use during class time. "The young men and women attending this school, they want to feel inspired by new texts, new media - music, poems, even movies in Mapudungun. If they can't, they why would they want to learn the language?" asks a young professor, who goes on to ask me: "In New Zealand, you have the All Blacks, the greatest rugby team in the world. They do this 
Māori dance that I bet inspires people to learn how to speak te reo. New Zealand feels proud of your indigenous population. We, on the other hand, as Mapuche, have nothing to teach or show to the world that is as empowering as the All Blacks" (personal communication, 25 October 2006).

When Hernández asked if there was any interest on behalf of educators to take advantage of the technology available to them, referring to the space with computers and software on learning acquisition, one young male teacher replied:

No one consulted the Mapuche living in the ruca if they wanted computers to use their language. These people don't even know what a computer is - they don't want people learning how to say translate words from Spanish to Mapudungun. They want people in cities - and not computers - to understand what being Mapuche means (personal observations, 25 October 2006).

Despite an overall negative attitude during the presentation on behalf of educators, the Intercultural School of Chol Chol continues to incorporate Mapudungun as a mandatory subject all children are required to take.

\subsection{Conclusion}

Education has the potential to play an instrumental role in implementing effective strategies for revitalisation of Mapudungun, yet the muddled organisation and strained relationship between Mapuche and Chile's government have so far hindered the successful materialisation of what these legislations prescribe. Furthermore, in many cases, Mapuche preoccupations with economic development and overcoming poverty surpasses their interest in language revitalisation.

Due to the lack of financial support available from CONADI to develop language revitalisation schemes, Mapuche rely heavily on the financial support of external organisations to materialise many of their goals, including building and maintaining schools where children can learn Mapudungun. Therefore, efforts carried out by external actors have not benefited Mapuche collectively; only a handful of Mapuche communities,

most of them in the rural areas, have benefited from the funds provided by private organisations to establish bilingual intercultural schools. 


\section{Chapter 10 - Drawing conclusions}

\subsection{Introduction}

Language revitalisation efforts rely on the interest indigenous peoples have in restoring and further developing their identity, and transmitting their indigenous knowledge not only to their kin, but as a contribution to society. Yet research, case studies and observations carried out for this dissertation show there exist a variety of factors which impact language revitalisation efforts.

The objectives for presenting key historical events and background information on previous chapters is to understand the influence these historical developments have on present relations between Māori and Pākehā, and in the case of Chile, between Mapuche and non-indigenous Chileans. These events established the foundations for race relations in each country, directly impacting language revitalisation efforts.

The following chapter provides a comparison of language revitalisation efforts experienced in Aotearoa New Zealand and Chile by revisiting the research objectives of this dissertation. The case studies presented in previous chapters will be used as examples that reflect the strengths as well as weaknesses of current language revitalisation schemes in each country.

\subsection{Contrast and compare contexts}

It may seem, at this stage, hard to emphasise the similarities between Aotearoa New Zealand and Chile. Yet they do exist and will be shortly discussed. The dissimilarities, on the other hand, appear to be obvious: the Māori and the Mapuche are in no way related one with the other; country's colonial ties trace back to different empires and nations; with 16 million people, Chile's population overshadows Aotearoa New Zealand's modest population of over 4 million; and finally, although Chile is credited to be a growing economy, it lags behind Aotearoa New Zealand in the Human Development Index ${ }^{41}$ and income disparity (see Table 10.1).

\footnotetext{
${ }^{41}$ Chile country a rank of $40^{\text {th }}$ out of 177 countries with data HDI for New Zealand is 0.943 , which gives the country a rank of $19^{\text {th }}$ out of 177 countries with available data.
} 
Table 10. 1 Human Development Index and GDP per capita of Aotearoa New Zealand and Chile

\begin{tabular}{|c|c|c|}
\hline Index & Aotearoa New Zealand & Chile \\
\hline Human Development Index & 0.943 & 0.867 \\
\hline GDP per capita (PPP US\$) & 24,996 & 12,027 \\
\hline
\end{tabular}

Source: United Nations Development Programme. (2007). Human Development Reports.

\subsection{Comparing processes of colonial legacy: national Māori, territorial}

\section{Mapuche}

Despite the above mentioned discrepancies, the most significant distinctions between Maori and Mapuche are the more subtle ones, and are based on the relation each group established with colonisers.

Understanding colonial legacies enable us to reconnect with the past in order to make sense out of the present. In order to understand the current state of Māori and Mapuche, it is important to acknowledge their history. The impact of colonial historical events on Māori and on Mapuche directly affected language revitalisation efforts in Aotearoa New Zealand and Chile respectively. It is therefore necessary to address these events in order to understand why language revitalisation has, so far, proven to be more successful in Aotearoa New Zealand than in Chile.

Māori saw Aotearoa New Zealand as their country. The Declaration of Independence, the selection of a flag to represent a Māori Aotearoa New Zealand, and even the Treaty of Waitangi were all processes which sought Māori consent in order to proceed. These events reinforced Māori sense of self-determination, and empowered them to build a strong sense of cultural identity. More importantly, these events demonstrated that Māori were able to partake in the decision-making processes of Aotearoa New Zealand.

Conversely, Chile's Declaration of Independence from Spain meant the end of Mapuche self-determination and territorial rights. Furthermore, the Mapuche sense of empowerment and self-determination was the product of winning wars against the Spanish and being able to isolate themselves from the dominance of external actors. Retaining a portion of their territory meant they were able to maintain their practices, 
their language and their identity, for the most part, intact. Pinto emphasised how "Mapuche never recovered their pride after Chile colonised their territory and subordinated the indigenous. The reducciones literally reduced Mapuche esteem and social status" (J. Pinto Rodríguez, personal interview, 23 October 2006). Although Mapuche resilience is rooted in their history - in fending off the Incas, in forcing Spain to yield them an autonomous territory, and even in the maintenance of their indigeneity throughout the Pinochet regime - their indigeneity is tied to their land. Mapuche have depended on exercising their territorial rights in order to maintain their indigeneity and hence, their language, alive.

Unlike the Māori, who saw Aotearoa New Zealand as their country, the Mapuche did not see Chile as theirs. The Māori developed a strong sense of national identity, whereas the Mapuche built upon a sense of territorial identity. Te reo belonged to Māori, therefore, it was part of their nation; Mapudungun was rooted to Mapuche territory. The reducciones

policy expropriated Mapuche not only from their land, but from their cultural identity, of which Mapudungun is integral. This may explain why indigenous language revitalisation strategies in Chile do not extend at a national level, but are instead restricted to areas of high Mapuche concentration. Nevertheless, the high mobilisation of Mapuche to urban centres has resulted in high concentrations of Mapuche in cities like Temuco and Santiago, where indigenous language revitalisation schemes in schools are less available.

\subsubsection{Drawing historical parallels}

Likewise, similarities between both groups date back to colonial times: Māori and Mapuche both underwent a period of colonisation which led to their social, economic and political marginalisation. Moreover, both periods of colonisation were followed by efforts for cultural assimilation and homogeneity (M. Durie 1998; Walker 1990; J. Aylwin, personal interview, 23 October 2006). Colonisation by the British Crown and the Chilean state happened correspondingly throughout the nineteenth century, making developments by Māori and Mapuche comparable in terms of time.

With reference to indigenous language, both Māori and Mapuche benefited from the linguistic developments missionaries did in recording and establishing grammatical structures for te reo and for Mapudungun. The early twentieth century saw te reo and 
Mapudungun banned from schools and both languages began to rapidly deteriorate with the mobilisation of each indigenous group to urban centres.

The twentieth century also saw both Māori and Mapuche comprise the lowest end of their countries' respective economic spectrum. The Mapuche people are among the poorest in Chile, with 32 percent of Chile's indigenous population living in poverty, compared to 20 percent of the non-indigenous population (Stavenhagen 2003). Region IX, which holds the majority of Mapuche population and where I carried out the three case studies for this dissertation, scores lowest of all of Chile's regions on the Human Development Index. Evidence available on the condition of urban Mapuche shows most live in margins of cities such as Temuco, lacking employment stability and unable to afford or access education (Aylwin 1998).

In Aotearoa New Zealand, it is challenging to accurately estimate percentages which relate Māori to poverty for according to Statistics New Zealand (1999), Aotearoa New Zealand does not have an official poverty line. Therefore, data around income distribution is used in Aotearoa New Zealand to determine economic and social wellbeing. Krishnan's (1995) analysis of income as poverty measure, shows Māori poverty incidence at 60 percent level, which is three times that of Pākehā. Studies by Statistics New Zealand (1999) also show Māori to be at the lowest levels of household income distribution.

The strongest similarity between Māori and Mapuche, however, is the underlying rationale behind my research: both groups share a common desire to transcend colonial mentalities, challenge injustices within systems of power, and restore indigenous knowledge in order to reinstate their indigeneity (Maaka \& Fleras 2005). Revitalisation of indigenous language in each country is a manifestation of this ongoing desire.

\subsubsection{Relations between indigenous and non-indigenous: From settlement to cohesion}

Concession of Māori indigenous rights initiated with the establishment of the Waitangi Tribunal and the recognition of the Treaty of Waitangi by the Crown. This enabled Māori 
to present claims regarding the Crown's actions or omission during the period since 1840 . In Chile, Mapuche are still struggling to understand the complexity of Law 19,253 and the CONADI has so far proved ineffective in representing the interests and needs of Mapuche to the Chilean state (J. Aylwin, personal interview, 23 October 2006).

Settlement relationships aim "to right a wrong" (M. Durie 2001). In the case of te reo, a settlement relationship was established by Māori demands of having the legal principle established in the Treaty of Waitangi recognised. A social policy relationship, on the other hand, "is about recognising and seeking to realise Māori aspiration within a framework that can be endorsed by the Crown" (M. Durie 2001). It is not a negotiation but an ongoing commitment which focuses on the future place of Māori in Aotearoa New Zealand's history, as opposed to focussing on Māori's place in past colonial events. Once compensation has been granted as a result of a settlement, then the social policy relationship sets in place mechanisms that, in the case of language revitalisation, will lead to Māori educational advancement. This mechanism is based on a model of participatory approach in which Māori and the Crown work together to advance the interests and wellbeing of both parties.

The reassertion of Māori culture and language is tied to the promises made in the Treaty of Waitangi. Recognising te reo as an intangible taonga, instituting it as one of Aotearoa New Zealand's three official languages, and embracing Māori medium education programmes, have all been part of the Māori-Crown settlement relationship. In terms of language revitalisation, the relationship between Māori and the Crown appears to be moving from one which solely seeks compensation and settlement, to a social policy relationship. The social policy relationship extends its model of participatory approach to immersion programmes.

Conversely, in Chile, Law 19,253 seeks to compensate Mapuche and act as settlement to Mapuche claims. Yet the complexity of the legislations, dissatisfaction with CONADI, the lack of accountability, and lack of resources, have hindered the goal of Law 19, 253 from righting a wrong and hence, establishing a settlement relationship. Mapudungun has only been partially included in the settlement process through the implementation of bilingual intercultural centres. Mapuche are still waiting for the Chilean state to reach a 
satisfying settlement with them that will compensate for what Mapuche feel they have lost so far in terms of land and culture, including the erosion of Mapudungun (J. Pinto Rodríguez, personal interview, 23 October 2006). Not being able to establish a satisfactory settlement relationship hinders the process of establishing a social policy relationship. Chile has not been able to thus far create a sustainable system of participatory development in which Mapuche and the Chilean state can share decisionmaking processes regarding language revitalisation strategies.

\subsection{Gaps and bridges between indigenous and non-indigenous}

The UNESCO constitution states that:

since wars begin in the minds of men, it is in the minds of men that the defences for peace must be constructed; that ignorance of each other's ways and lives has been a common cause, throughout the history of mankind, of that suspicion and mistrust between the peoples of the world through which their differences have all too often broken into war (UNESCO 1946).

Mapuche wage a war of resentment toward the Chilean state. The historical discrimination policies against Mapuche, including land displacement by reducciones, banning of Mapudungun in schools, and later on, the rejection of Mapuche as a distinct cultural identity by Pinochet's regime, have all fuelled Mapuche resentment toward the Chilean state, creating a culture of distrust and resistance (J. Pinto Rodríguez, personal interview, 23 October 2006; Faron 1968) . This resentment has been transmitted from generation to generation, worsening steadily throughout time, and has led to a silent war Mapuche wage against the Chilean state. This war has been fuelled by what Herrera as well as members from the community at Galvarino recognise as a lack of interest on behalf of the Chilean state on learning about Mapuche ways and values (personal interview and communication, 26 October 2006). The disconnection induces and prolongs this resentment on behalf of Mapuche. "We don't understand CONADI, but CONADI doesn't understand us either. They think all we want is land or money. But what we want is to be Mapuche and they don't understand what being Mapuche means" (Galvarino community member, personal communications, 26 October 2006). 
In Aotearoa New Zealand, education is used as a bridge that connects indigenous knowledge and practices with and to mainstream society. When an indigenous language is taught through immersion programmes, as observed in Petone Central School, a culture is taught with it. Immersion programmes provide that bridge of understanding in Aotearoa New Zealand. They create a link between indigenous and non-indigenous, and allow for the exchange of ideas, as well as the stabilisation of indigenous language and knowledge. Chile, on the other hand, is still experiencing a disconnection between the relation of Mapuche and non-indigenous society. This disengagement is being reinforced by not extending bilingual intercultural programmes into urban school settings. Moreover, teaching the language in isolation of its cultural context may lead to cultural tokenism. In the case study of Guacolda, Hernández emphasised his concern with tokenism by stating that if taken out of context, the purpose of revitalising Mapudungun in order to restore Mapuche indigenous knowledge, would be defeated (personal interview, 25 October 2006).

\subsection{Measuring levels of language health}

Colonisation and urbanisation of Māori in Aotearoa New Zealand left te reo on the brink of disglossia (see chapter 5), but recent efforts at a national level have successfully began the process of restoring linguistic attitudes, elevating the status of te reo beyond levels of language endangerment. Conversely, in Chile, disglossic attitudes toward indigenous languages currently threaten the existence of Mapudungun.

In order to implement a comparative understanding of the levels of language deterioration of te reo and Mapudungun, I referred to Fishman's (1991) eight-stages of language loss. In them, Fishman proposes a benchmark guideline to measure the levels of language loss, with the healthiest standards of language use in stage one, while languages on the verge of extinction are ranked in stage eight (see Table 10.2). Using Fishman's guidelines proved to be useful for me to give a rough approximation of the real situation of the conditions of te reo Māori and Mapudungun. 
Table 10. 2 Stages of Language Loss

\begin{tabular}{|c|l|}
\hline Stage 8 & $\begin{array}{l}\text { Language use is limited to elders who are usually isolated from each } \\
\text { other and are therefore unable to foster language use at a public levels } \\
\text { within a community. }\end{array}$ \\
\hline Stage 7 & $\begin{array}{l}\text { Language use is limited to adults beyond childbearing years. Children are } \\
\text { not encouraged to learn the language and may often even be reprimanded } \\
\text { for using it. }\end{array}$ \\
\hline Stage 6 & $\begin{array}{l}\text { Language use exists between community members of different } \\
\text { generations and ages and language use is encouraged by the } \\
\text { establishment of local neighbourhood institutions. }\end{array}$ \\
\hline Stage 5 & $\begin{array}{l}\text { Language is regularly and actively used within a community. } \\
\text { Programmes in schools may be established at an informal level to } \\
\text { promote the use of language. }\end{array}$ \\
\hline Stage 4 & $\begin{array}{l}\text { Language inclusion in school curricula is made compulsory and } \\
\text { bilingualism is strongly encouraged in education systems. }\end{array}$ \\
\hline Stage 3 & $\begin{array}{l}\text { Language use is encouraged in the workplace and used by employees in } \\
\text { lower work spheres. }\end{array}$ \\
\hline Stage 2 & $\begin{array}{l}\text { Language use is encouraged by higher levels of government and in high- } \\
\text { level education. }\end{array}$ \\
\hline
\end{tabular}

Source: Adapted from Fishman's Graded Intergenerational Disruption Scale for Threatened Languages (1991, pp. 88-109)

After my field observations and empirical research, I concluded te reo Māori to be part of stage one, in which language use is encouraged by higher levels of government and in high-level education. Conversely, after field observations and case studies, it is difficult to assert whether Mapudungun should be placed as part of stage six or stage seven. Data 
made available by MIDEPLAN that shows increased language usage among Mapuche as well as increased financial support for PEIB, may lead one to lean toward categorising Mapudungun at stage four. Nevertheless, there exists a considerable discrepancy between what documentation shows to the reality encountered on-ground in terms of the conditions of Mapudungun and stage four does not accurately reflect the current status of Chile's indigenous language.

Stage six is applicable when there is funding capacity available. Education centres promote and encourage the use of Mapudungun in Trañi-Trañi and Guacolda; however, in order for language revitalisation to be sustainable and successful, it depends on how functional it is within communities. Community members and educators in both communities expressed concern regarding the functionality of Mapudungun. In TrañiTrañi, many showed apprehension of the cultural implications of using Mapudungun in public, which has led to alienation of Mapuche in urban centres. Consequently, stage seven of language endangerment seems more appropriate in some rural settings in which families do not necessarily encourage the use of Mapudungun for fear of being discriminated against. Conversely, in Galvarino, Mapudungun depends solely on the community's support and usage. Although there is no financing available to establish institutions that support the teaching and learning of Mapudungun, community members provide the necessary demand of the language to keep its status and functionality relevant.

In all three case studies, however, it is important to note that the lack of prioritisation given to revitalisation of Mapudungun by Mapuche is due to the ongoing struggles these communities face on a daily basis. Their constant preoccupation with finding ways to subsist, for their economic well-being, defending or regaining their lands, and with fighting political discrimination, deters language revitalisation efforts to gain momentum. A language depends upon the context and conditions of its users in order to obtain a favourable status.

In the case study of Galvarino, the community of Juan Puña showed preoccupation with issues of poverty, land acquisition, and economic development. A national census by CEP in 2006 showed that 35 percent of Mapuche considered lack of land to be their 
major problem; 34 percent said poverty, and 30 percent said lack of education. Even though 52 percent of Mapuche said they believed that Mapudungun is the most important tool for keeping indigenous knowledge and culture alive, 56 percent said they neither speak or understand the language (CEP 2006). Referring to Wurm's levels of language endangerment (see chapter 5), my observations and research show Mapudungun to be a potentially endangered language due to its social disadvantage, whereas kōhanga reo, kura kaupapa and Māori language programmes in schools seemed to have effectively helped te reo surpass levels of endangerment.

\subsection{Revisiting language planning and language policy}

The success of language planning strategies depend on the usage, status, acquisition, structure and functionality of a language. The example of te reo in Aotearoa New Zealand shows that the relation between language planning strategies and language policy is sequential: ideally, a language planning trial is conducted in order to determine the demand for a particular language in a society. If results demonstrate that there exists a demand for the language, then a language policy is requested in order for governments to officially supply this demand by implementing effective language planning strategies at a national level. The initial language planning strategies used to research a language's usage and demand are then further developed.

Language policy and language planning strategies have officially established te reo as a national language in Aotearoa New Zealand, raising the language's status and functionality. The Māori Language Act 1987 provides a language policy that allows for the implementation of a language planning strategy. The purpose of developing and implementing a language planning strategy was, and is, to modify the linguistic behaviour of Aotearoa New Zealand's society as well as raise cultural awareness (Trudgill 1993; Bishop et al. 2003). The Act, a result of the settlement reached in compliance with the Treaty of Waitangi, is an umbrella regulator under which the Māori Language Commission, kōhanga reo and kura kaupapa are all incorporated (see Figure 10.1). 
Figure 10. 1 Organisational structure for language revitalisation in Aotearoa New Zealand

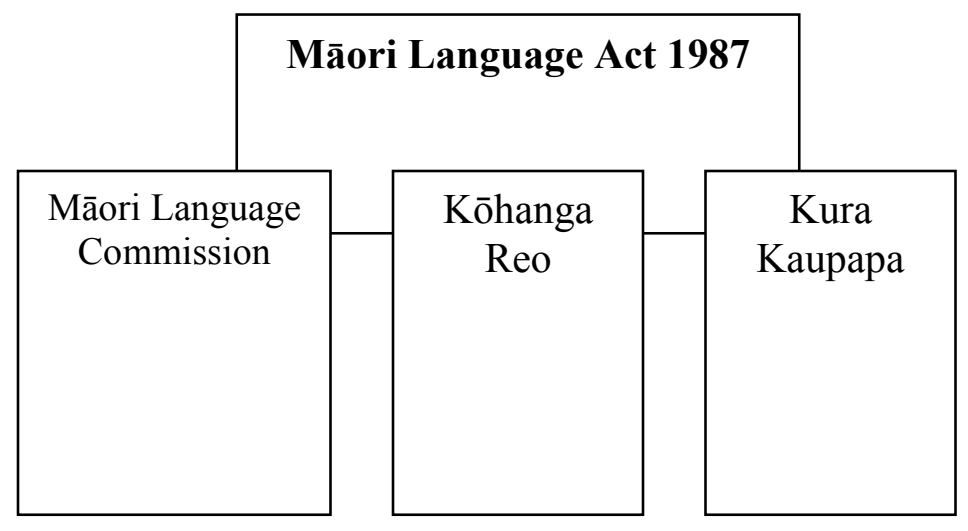

Source: Personal research conclusions.

Present language policies in Chile are segmented throughout various government organisations. Consequently, it is not possible to hold just one institution accountable for the implementation of a language planning strategy. While PEIB are managed by the Ministry of Education and by CONADI's National Education and Cultural Fund, JUNJI is a separate entity that works under separate guidelines (see Figure 10.2). Furthermore, MIDEPLAN, under which CONADI exists, has a separate language revitalisation scheme, not covered in this dissertation. This array of language planning options would be more efficient if they merged under one cohesive policy that would allow them to work together and avoid the present lack of coordination. Additionally, establishing language revitalisation efforts under one department would allow for organisational consistency in language planning strategies, overall understanding of what agency Mapuche can address regarding issues of language revitalisation, and would more than likely avoid overlap of funding for resources, activities or incentives. 
Figure 10. 2 Organisational structure for language revitalisation in Chile

\begin{tabular}{|c|c|c|c|}
\hline MINEDUC & CONADI & MIDEPLAN & JUNJI \\
\hline $\begin{array}{c}\text { PEIB } \\
\text { (Bilingual } \\
\text { Intercultural } \\
\text { Programme) }\end{array}$ & $\begin{array}{c}\text { National } \\
\text { Education } \\
\text { and Cultural } \\
\text { Fund } \\
\text { (PEIB) }\end{array}$ & $\begin{array}{l}\text { Programme } \\
\text { Orígenes for } \\
\text { Intercultural } \\
\text { Education }\end{array}$ & $\begin{array}{c}\text { Indigenous } \\
\text { nursery } \\
\text { schools } \\
\text { initiative }\end{array}$ \\
\hline
\end{tabular}

Source: Adapted from MIDEPLAN. (2006). La Memoria Nuevo Trato 2000- 2006. p.73.

\subsection{Comparing language revitalisation schemes}

Aotearoa New Zealand and Chile have both used education as a mechanism for developing language revitalisation schemes. Both countries have placed particular emphasis on the exposure of children to their native language during preschool years.

In the case of Māori and Mapuche, Lenneberg's theory (see chapter 5) may be applied when referring to the benefits of exposing children before the age of 12 years to their native language: exposure during these years leads to the development of linguistic capacity, acquisition, and functionality, as observed in Petone Central School. Educators at Guacolda stated that if their secondary-level students would have had exposure to Mapudungun before reaching the age of 12 years, levels of fluency wouldn't be so disparate and the language would be much easier to teach (personal communication and observations, 25 October 2006).

More importantly, however, as Esera pointed out during an interview, is that this period of time in children's lives represents exposure to how indigenous language is tied to indigenous culture and practices (personal interview, 9 February 2007). This understanding leads to the formation of indigenous identity in young children and allows non-indigenous children to accept and understand cultural diversity. 


\subsubsection{Comparing language revitalisation through education initiatives}

Both kura kaupapa in Aotearoa New Zealand and JUNJI's indigenous nursery schools in Chile aim to provide indigenous children with an appropriate cultural environment in which they can nurture and uphold their indigeneity. Teaching children their indigenous language during the early stages of their lives is a key component for both programmes.

The underlying objectives of the nurseries established by JUNJI's initiatives are the same as those of the kura kaupapa in Aotearoa New Zealand: the preservation of indigeneity by fostering the growth of their cultural values and heritage, and empowering indigenous children with the necessary tools in order to advance and reinstate indigenous knowledge. At the core of both approaches to education was the use of indigenous language in order to promote cultural renaissance. The rationale behind using nursery schools as language breeding centres was that for both, the Māori and the Mapuche language is the key mechanism that allows for the transmission of indigenous knowledge. Language was and is still indispensable in efforts to regenerate indigenous knowledge and heritage (Crystal 2000).

Perhaps the most significant difference between JUNJI's programme and kura kaupapa is that JUNJI was a state-owned and designed scheme, while kura kaupapa was an initiative owned and developed by Māori. Furthermore, JUNJI's indigenous programmes are limited only to rural areas with high percentages of indigenous populations. Mapuche who live in urban settings do not have access to the programmes. Finally, the biggest setback of JUNJI's programmes lies in the fact that children are part of the programme for a short period of time- four years at the most. Once they complete the programme, most children do not have access to intercultural or immersion programmes of any sort that further enable them to practice and develop the knowledge they have acquired during the time spent at the nursery. JUNJI's nursery schools do not have, as of yet, developed education programmes that extend the level of immersion experienced by Mapuche children during this period of their lives. The approximation Chile has so far to immersion programmes like that of Petone Central School, are the bilingual intercultural schools. Even though this is a promising step for revitalisation efforts of Mapudungun, 
access to most, if not all, bilingual intercultural schools is limited to rural areas, creating a dichotomy in Chilean society that relegates Mapuche who want to develop their cultural and indigenous identity to rural areas.

The problem seems to arise when children are exposed to external abusive environments that discriminate against them based on using their indigenous language in public, which seems to be the case in Chile. Based on primary source research as well as on my own personal observations in the field and interviews carried out for this dissertation, Mapuche appear to agree that using Mapudungun in public urban settings places them at a social disadvantage. A census carried out in 2006 by CEP indicates that 78 percent of Mapuche who participated in the study stated they feel discriminated against in urban settings due to their ethnicity and feel they are not integrated to Chilean society. In the same study, thirty percent of Mapuche stated they had experienced racial discrimination in school and, consequently, avoided using Mapudungun in public (CEP 2006 ). As a result, Mapudungun's destitute status confines its use to Chile's rural areas. Therefore, regardless of whether adult or children are exposed to Mapudungun in their communities, factors that threaten revitalisation efforts of Mapudungun are not only limited to having access to learning the language before the age of 12, but include the lack of language usage and its social disfavoured status. These, combined with consigning the language's functions to rural settings, all prove to be detrimental for the restoration of Mapudungun.

Conversely, in Aotearoa New Zealand, education developments have halted the process of language loss for Māori (May 1996). The support Te Kōhanga Reo movement received since its foundation in 1981 resulted in the successful emergence of Māoricontrolled, Māori-administered, and Māori-designed education schemes, all of which empowered Māori identity and self-determination (May 1996). The development of immersion programmes as an extension of kura kaupapa reasserted the importance of Māori cultural values to the development of Aotearoa New Zealand's society and identity as a bicultural nation. Immersion programmes, like the one observed in Petone Central School, provide a sustainable environment to foster and promote the development of te reo into primary and secondary education. Immersion programmes create educational 
environments which nurture and foment children's indigenous identity beyond preschool years. In Aotearoa New Zealand, immersion programmes support the notion of recognising Māori as a distinct group of people whose values and practices have an equally important place in society (see Figure 10.3).

Figure 10. 3 Support for Māori Language Revitalisation Initiatives

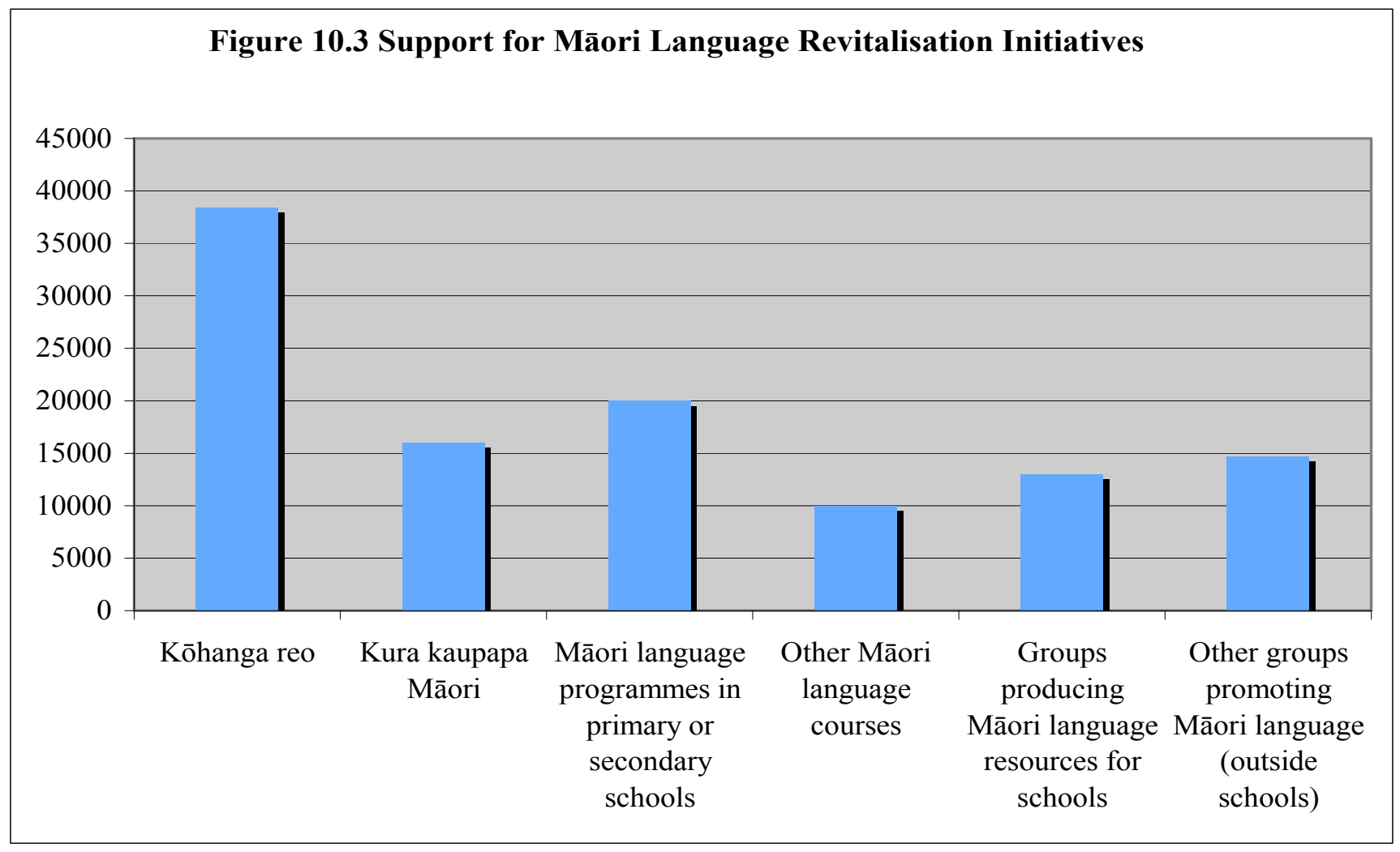

Adapted from: Survey on the health of te reo. (2001) Social and Population Group of Statistics New Zealand.

\subsubsection{Comparing funding schemes for language revitalisation}

In Aotearoa New Zealand, the initiative of stabilising te reo began without government support; but unlike in Chile, the process was never owned by external actors but by Māori themselves. Language revitalisation initiated as a process run by Māori for Māori, in which Māori supplied the demand of te reo by establishing kura kaupapa as Māori medium education centres. Since 1990, due to the success of kōhanga reo and kura kaupapa Māori, the programmes have been "incorporated into the state's educational system as recognised (and state-funded) alternative education options" (May 1996, p. 164). A series of incentives were introduced by the Ministry of Education, which have been helpful in increasing the interest in revitalisation of te reo. Māori language 
revitalisation however, has not depended entirely on government initiatives, but is a result of Māori efforts and interest in stabilising te reo in order to restore Māori culture. The success of the programmes lies in that they were designed by Māori to meet and uphold Māori tikanga. ${ }^{42}$

In Chile, the curricula of bicultural education programmes is administered by the Ministry of Education; funding for the establishing and developing of PEIB, however, are managed by CONADI (C. Millacura, personal interview, 6 November 2006). Yet CONADI appears to be overestimated in its financial capacity to effectively manage all of Chile's indigenous issues. In an attempt to comply with the regulations stipulated in Law 19,532, CONADI has sought to micro-manage the interests of Mapuche, and due to its limited funds and resource-capacity, it is unable to effectively promote or successfully implement bilingual intercultural schools in rural areas, let alone branch out the programmes into urban setting. This leads to Mapuche having to rely on external actors to support the development of PEIB. Mapuche do not own the initiative of PEIB: they do not develop or administer its curriculum, they do not participate enough in the design of the programmes' structures, and depend on CONADI or other external actors for the implementation of PEIB to take place, including providing Mapuche with adequate training skills.

Due to factors such as geographic isolation and lack of resources, Mapuche are not able to work collectively nor have they been able to organise as a single unit in order to establish a set of agreed stipulations or requirements for external actors to abide by. Localities are approached independently, and programmes for language revitalisation are designed separately according, in most cases, to premeditated standards that fulfil each external organisation's goals or principles, instead of focussing on assessing the needs of each community. FUNDECAM and FII are two examples of how Mapuche depend on funds of private independent organisations in order to advance language revitalisation efforts.

\footnotetext{
42 Tikanga: treasure
} 
This was observed in both, Guacolda and Trañi-Trañi, where education centres in each area were unable to rely on CONADI to receive the necessary resources to establish PEIB. Both education centres sought private, independent groups to fund and administer PEIB initiatives. What's more, the groups working with Guacolda and Trañi-Trañi centres are two separate and different organisations with different backgrounds, each with its own set of goals and objectives. This presents problems in the coordination and execution of PEIB.

Having external actors provide funds and language development schemes for Mapuche is advantageous in that it at least maintains language revitalisation efforts alive. Nevertheless, this also negatively impacts Mapuche on two levels: first, it hinders Mapuche to own their own processes of development and well-being, creating and increasing the already existing dependence on external actors for funding and capacitybuilding schemes on language revitalisation. Second, external actors work with independent groups of Mapuche, usually confined to rural areas. This creates a disparity

in approaches to language stabilisation: each area applies different language planning methods, which leads to a lack of collaboration and cohesiveness between Mapuche communities in how to approach language revitalisation. Interviews and research carried out for this dissertation show that there is an enormous need for Mapuche to consolidate their efforts in order to create and establish a consistent method of language revitalisation at a national level.

\subsection{Disparities in processes of indigenous language participatory approach}

In Chile, the lack of a satisfactory settlement relationship between the state and Mapuche has led to uneven developments of indigenous participation in language revitalisation schemes. In the case of Trañi-Trañi, FUNDECAM established a process of consultative participation in order to assess levels of language deterioration in the area. Consultative participation, according to S. Bigg's typology of participation and as defined in chapter 4 of this dissertation, is that in which "most of the key decisions are kept with one stakeholder group [in this case FUNDECAM], but emphasis is put on consultation and 
gathering information from others, especially for the identification of constraints and opportunities, priority-setting and or/evaluation” (S. Biggs 1989).

Consultative participation with Mapuche led FUNDECAM to establish the area's education centre, since community members expressed their need for a school. Nevertheless, establishing a bilingual intercultural school that sought to promote the use of Mapudungun without first evaluating the levels of language use in the area is counterproductive. Information gathered from Mapuche in the census carried out by Hernández will hopefully result in the development of a language revitalisation scheme appropriate for the region; yet the process of developing this scheme is not developed, designed or owned by Mapuche, despite the fact that the results will directly impact them. FUNDECAM decided to move forward with language revitalisation in the area without establishing a fully informed language planning methodology first. Allegorically, this is comparable to seeking evidence in a trial after the verdict has been established.

The socio-linguistic studies, according to Mansilla and Hernández, will be carried out in order to assess the usage and status of Mapudungun in the area. The study's results, which will be based on interviewing family members of children attending Trañi-Trañi's bicultural intercultural school, will then be used to design a language revitalisation scheme that suits the area (R. Mansilla, personal interview, 25 October 2006; A. Hernández, personal interview, 25 October 2006). Results will also be used in the development of appropriate education resources. Yet the decision-making authorities who will design this language revitalisation scheme and who will design the resources will not be Mapuche, but members of FUNDECAM and the external consultants they will work with in order to complete the project (Hernández being one of them).

An additional element that proves to be advantageous in Aotearoa New Zealand and that is lacking in Chile are incentives for educators to engage in language revitalisation schemes. Even though CONADI's programmes for the promotion of intercultural bilingual education offer scholarships to Mapuche children and youth to attend school, there is a lack of incentives available for Mapuche educators (C. Millacura, personal 
interview, 6 November 2006). The shortage of educators of Mapudungun combined with the lack of incentives for professional development in Mapudungun results in a setting like the one observed in Guacolda: the risk of tokenism of Mapudungun and unenthusiastic educators.

In Aotearoa New Zealand, immersion Māori education initiatives, like the one observed in Petone Central School, have grown from Māori effort. The success of these programmes can be measured in their increasing number: as of 1991, 1 percent of Māori primary school students were enrolled in kura kaupapa Māori; as of 1993, 49.2 percent of Māori children enrolled in pre-school were at a kōhanga reo (Ministry of Education 2004). As a result of the demand, the number of immersion schools has more than doubled between 1999 and 2003 (Ministry of Education 2004).

The success of the programmes created an appropriate environments for contractual participatory methods of development in which Māori hold decision-making power in designing appropriate language revitalisation strategies. This was part of the settlement policy which allowed Māori to own the process of language revitalisation despite incentives and funding introduced by the Ministry of Education. Currently, however, collaboration between Māori and the Ministry of Education has resulted in a social policy relationship, which advocates for the establishment of a collaborative participatory approach model in which Māori and non-Māori can work together in the process of research and implementation of language revitalisation. This collaborative participatory approach is exemplified in Petone Central School's immersion programme and its underlying philosophy of Ako (see chapter 7).

\subsection{Conclusion}

Attempts for indigenous language revitalisation are being carried out in the educational systems of both Aotearoa New Zealand and Chile. Nevertheless, while te reo has seen improvement in its restoration, Mapudungun is still a highly endangered language. The use of language throughout this dissertation shows the active use of te reo in Aotearoa New Zealand (hence, the need to provide the reader with a glossary of words in te reo) as opposed to the lack of Mapudungun actively used in Chilean society. 
A key component that determines the success of processes of language revitalisation of each country is the level of indigenous participation in designing language planning strategies, as well as the importance of implementing effective language policies at a national level. The following chapter will draw some conclusions on the process of indigenous language revitalisation and on whether or not it is viable for Chile to adopt some of Aotearoa New Zealand's language revitalisation schemes. 


\section{Chapter 11 - The formula}

\subsection{Conclusions}

After carrying out a series of interviews and a total of four case studies, I hoped to find a suitable answer to present as a conclusion to the questions behind my research. In indigenous language revitalisation schemes, why can language be revitalised in one place, yet not in another? What works? What doesn't? The answer, in the words of Fishman (1995) is because "as in most complex societal areas, [...] 'It all depends."”

Fishman compares language endangerment to a "cluster of diseases: [it is] what cardiovascular medicine is to a heart murmur, or rehabilitation medicine is to a fractured pelvis" (Fishman 1995). An appropriate solution to a medical condition depends on the symptoms as well as on the patient: whereas a medication or treatment may suit one patient, it may not suit another. The problem will more than likely be examined, but not limited, to a group of people under certain departments of a particular unit: cardiologists will examine heart problems, yet require the assistance of an anaesthesiologist if they plan on operating. Experts and specialists convene to make a diagnosis; yet regardless of the recommendations made by specialists and so long as the patient is conscious, the ultimate decision of whether to undergo operation or not should be taken by the patient, and not by the doctor.

In establishing an analogy relevant to language revitalisation, the patient is the group of indigenous people; the disease is language erosion; the solution (or cure) is language revitalisation. A series of opinions need to be taken into consideration before reaching a consensus on what is the best approach for carrying the operation of language stabilisation. Input from linguists, anthropologists, policy-makers and government officials, all play an important role in diagnosing the degree of language erosion. Each group of specialists may choose to recommend different possible approaches (or treatments) for achieving language revitalisation. Yet ultimately, the decision as to which approach to use must be taken by the group of indigenous people. Whether or not they use the recommendations or alternatives presented to them, is up to them; the choice 
should remain in the control of the indigenous group, in this case the group being either Māori or Mapuche.

\subsection{Limitations and results of this research}

Thus, language revitalisation is not a mechanical formula. Although language planning studies may be used to measure a language's wellness or health, they do not guarantee answers to how to establish effective methods for language stabilisation.

In Aotearoa New Zealand and Chile, the implementation of a scheme or strategy for language stabilisation depends on a series of factors in order for it to be effective: "the solution of what works varies with the problem" (Fishman 1995). Areas of concern for the success of indigenous language revitalisation range from availability of resources, to attitudes toward the culture of the target language (Bishop et al. 2001). Obstacles in language revitalisation efforts may include the cost of resources involved in promoting a minority language, in training and capacitating personnel and teachers, and in accommodating and modifying school curricula (Mule 1999).

In Aotearoa New Zealand, the main concerns on the grounds of language revitalisation appear to be providing adequate supply for the demand of te reo, both in terms of quality and quantity of professionals fluent in te reo. Language policies recognise the demand of te reo; consequently, language planning strategies attempt to provide the supply for this demand. Conversely, Chile lacks a comprehensive, all-encompassing language policy, which hinders the success of its present language planning strategies. Concerns for the lack of success of language revitalisation schemes in Chile include the lack of supply to the language demand as well as lack of participation of Mapuche in the design of language planning strategies. Mapuche are unable to evenly benefit from present language revitalisation schemes due to a series of factors ranging from geographic isolation, to the lack of funds available to implement intercultural bilingual programmes at a national level. Furthermore, lack of cohesion at institutional levels proves to be prejudicial to the development of uniform bilingual education programmes available for language revitalisation. 
Although it would be ideal to prescribe the language planning and revitalisation schemes used for te reo in Aotearoa New Zealand to restore Mapudungun in Chile, each country's unique circumstances and historical developments surrounding race relations creates a much more complex process for recommendations to effectuate. Historical trajectories of each country's indigenous peoples have yielded different contextual circumstances in terms of how indigenous people and their language is perceived by the mainstream, nonindigenous population. My research and experiences have led me to believe, however, that Aotearoa New Zealand's successful language revitalisation efforts may offer valuable models of language revitalisation that may potentially influence restoration of Mapudungun in Chile. However, further research needs to be carried out to reflect on how children who complete immersion programmes in Aotearoa New Zealand choose to utilise their knowledge on te reo in their personal and/or professional development. Research based on indigenous language revitalisation as a needs-based, rather than a rights-based movement, might yield more quantitative results in terms of how or if language revitalisation contributes to economic development.

\subsection{The recommendations}

Since the enactment of the Māori Language Act 1987, acquisition, use and status of te reo has increased considerably (Keating 1995). The Act supports Māori medium programmes, which have effectively established conditions to advance promotion of Māori cultural values, an integral part of Aotearoa New Zealand's identity as a bicultural nation. Having Mapudungun recognised as an official language on par with Spanish in Chile has the potential to raise the language's status and hence, create higher demand for its use. A national language policy in Chile would create the necessary support networks at an institutional level that could restore Mapuche confidence in Chile's interest in reaching a settlement relationship.

The present language status of te reo is a product of the policy dialogue, partnership and participation of Māori in the process of language revitalisation, and was reached as a result of Māori demand and mobilisation. Mapuche have been unable to develop the 
necessary mechanisms to mobilise as a single unit for reasons ranging from persecution during the Pinochet regime to geographic isolation amongst themselves. Nevertheless, reaching a settlement with the Chilean state which recognises Mapudungun as a key component of Mapuche identity would establish the grounds for policy dialogue to initiate between Mapuche and the state.

\subsection{From local to global in Aotearoa New Zealand; from global to local in Chile}

International recognition of indigenous rights, more particularly the right to use indigenous language, has led Māori and Mapuche to contest histories and trends of colonisation, economic marginalisation, and most importantly, cultural assimilation. Both, Māori and Mapuche have been empowered by the international movement on indigenous rights and on indigenous language revitalisation, with the difference that schemes for revitalisation of te reo have been so far considerably more success than efforts for restoring Mapudungun (Skutnabb-Kangas 2000; May 1996).

Aotearoa New Zealand has been regarded as an exemplary case study by world standards in fostering positive race relations with Māori and establishing a bicultural nation (Maaka \& Fleras 2005). In terms of language revitalisation, extending te reo to education systems and supporting Māori medium programmes at a national level reflect Aotearoa New Zealand's position regarding the progress made in developing their own incentives without depending on the international community.

Bishop (2005) uses Eleanor Roosevelt's words to reflect on Aotearoa New Zealand's position regarding advancing intercultural education: earlier in the $20^{\text {th }}$ century, Roosevelt stated that peace begins at home, in the local rather than the global situation. Immersion programmes encourage social tolerance and understanding of Māori culture on a local scale, setting an example to the global community that in order to achieve international reconciliation with indigenous peoples, the conditions must first be created and implemented at a local and regional scale, on younger generations, regardless of their ethnic or racial background (Bishop 2005). 
Language revitalisation through immersion programmes give Māori choices regarding the use of their indigenous language to advance their knowledge. Stabilisation of indigenous language is a key component in the process of development as understood and defined by Sen (1990), Cowen and Shenton (1991). Language revitalisation expands opportunities for people to realise the kind of life they wish to live by providing them with the possibility to restore indigenous knowledge, and to secure their cultural identity as well as their freedom of cultural expression (Wereta \& Bishop 2004). Presenting indigenous peoples with the opportunity to exercise their right to their indigeneity increases indigenous participation in larger economic, social and political processes. Realising the potential of Māori and Mapuche indigenous knowledge by providing them with appropriate education schemes allows them to contribute to the societal and economic development of their respective countries. 


\section{Glossary}

\section{Words in te reo Māori}

Ako: to learn, study, instruct, teach, advise.

Karakia: incantation, prayer, grace, blessing, service, church service, that enable people to carry out their daily activities in union with the ancestors and the spiritual powers.

Kāwana: governor.

Kāwanatanga: government

Kōhanga reo: Māori language preschool.

Kura: school.

Kura kaupapa: school operating under Māori custom and using Māori as the medium of instruction.

Māhuri: young tree, sapling.

Mana: prestige, authority, control, power, influence, status, spiritual power, charisma mana is a supernatural force in a person, place or object.

Mana whenua: territorial rights, power from the land - power associated with possession and occupation of tribal land.

Marae: refers to the common area of the wharenui (Māori meeting house) where formal greetings to visitors take place. Marae also means to be generous and hospitable.

Mihi: the Māori traditional greeting exchanged between host and visitor.

Pākehā was established for the recognition of foreigners. Far from derogatory, the term is derived from pakepakeha, which is defined as "imaginary beings resembling men, with fair skins" (Walker 1990).

Tamariki: children.

Taonga: treasures, valued customs, or valued possessions.

Taonga katoa: all other treasured possessions.

Te Aho Matua: literally translates to chief, important, primary line of descent, genealogy.

Te reo: Māori language. 
Te tino rangatiratanga: unqualified chieftainship.

Tikanga: treasure.

Tumuaki: Principal.

Haka: a general term used to refer to vigorous dances with actions and rhythmically shouted words. Haka pōhiri refers to a ceremonial dance used to welcome visitors.

Pōwhiri: a traditional Māori welcome on to a marae is called a pōwhiri (or pōhiri). Marae are not the only places where pōwhiri take place; pōwhiri can happen anywhere that hosts need to formally greet a group of visitors.

Rangatiratanga: sovereignty, chieftainship, right to exercise authority, selfdetermination, self-management, ownership, leadership of a social group.

Rito: centre shoot, undeveloped leaves of flax.

Tino rangatiratanga: self-determination.

Whānau: refers to the basic social structure within Māori society and has traditionally been used to refer to family networks. Most recently, however, a whānau can denote a group of ongoing individuals who are not necessarily related yet gather to interact on a regular basis for the purpose of a specific kaupapa/ agenda (Metge 1995).

\section{Words in Mapudungun}

Che: people

Dungun: speech

Mapu: land

Mapuche: literally translates to "people of the land."

Mapudungun: literally translates to "language of the land."

Mapudungun: (also referred to as Mapunzungun or Mapuzungun) official language of Mapuche.

Huincas, or Wincas: term used by Mapuche to refer to white, non-indigenous Chileans.

Reducciones: refers to the expropriation of Mapuche from their land, forcing them to establish in assigned smaller plots of land.

Ruca: a traditional Mapuche house usually made of adobe and covered with hay 


\section{References}

Adams, P. (1977). Fatal Necessity: British Intervention in New Zealand, 1830-47. Auckland: New Zealand.

Aitchison, J. (1991). Language change: progress or decay? ( $2^{\text {nd }}$ ed.). Cambridge: Cambridge University Press.

Amery, R. (2001). Language Planning and Language Revival. Language Planning, 2(2 \& 3). Retrieved 25 June 2007, from http://www.multilingualmatters.net/cilp/002/0141/cilp0020141.pdf

Amnesty International. (1992, October). Human Rights Violations against Indigenous Peoples. London: Amnesty International.

Anaquod, M. T., \& Taylor, K. I. (1984, July 27). Report on the present situation of the Mapuche in Chile. Retrieved from the Working Group on Indigenous Populations of the United Nations on 5 November 2006, from http://www.cwis.org/fwdp/Americas/mapuche.txt

Andersson, T., \& Boyer, M. (1970). Bilingual schooling in the United States (Vol. 1). Austin: Southwest Educational Development Laboratory.

Aywlin, J. (1998). Indigenous Peoples Rights in Chile: Progress and contradictions in a context of economic globalisation. Paper presented at the Canadian Association for Latin American and Caribbean Studies (CALACS) XXVIII Congress March 19-21, 1998. Vancouver: Simon Fraser University.

Baker, C., \& Prys Jones, S. (Eds.) (1998). Encyclopedia of Bilingualism and Bilingual Education. Clevedon: Multilingual Matters.

Barrington, J.M., \& Beaglehole, T.H. (1974). Māori Schools in a Changing Society: A historical review. Wellington: NZCER.

Bengoa, J. (1985). Historia del Pueblo Mapuche. Santiago: Ediciones Sur.

Benton, R. A. (1986). Māori perceptions of school experiences and other influences on the maintenance and use of the Māori language. Wellington: NZCER.

Benton, R. A. (1991). The Māori language: Dying or reviving? Honolulu: East West Center.

Bernard, H. R. (1992). Preserving language diversity. Human Organization, 51(1), 82-89. 
Bhaskar, R. (1997). A Realist Theory of Science (2 ${ }^{\text {nd }}$ ed.). New York and London: Verso.

Biggs, S. D. (1989). Resource-poor farmer participation in research: a synthesis of experiences from nine national agricultural research systems. National Agricultural Research Systems, OFCOR Comparative Study Paper, 3, 3-37.

Biggs, B. (1968) The Maori Language Past and Present. In E. Schwimmer (Ed.) The Māori People in the Nineteen-sixties (pp. 65 -84). Auckland: Blackwood and Janet Paul.

Bishop, R. (2005). Addressing Education for International Understanding in New Zealand. Journal of Education for International Understanding, 1, 109-125.

Bishop, R., Berryman, M., \& Richardson, C. (2001). Te Toi Huarewa: Effective teaching and learning strategies, and effective teaching materials for improving the reading and writing in te reo Māori of students aged five to nine in Māori medium education. Final report to the Ministry of Education. Wellington: Ministry of Education.

Bishop, R., Berryman, M., Tiakiwai, S., \& Richardson, C. (2003). Te Kotahitanga: The experiences of Year 9 and 10 Māori students in mainstream classrooms. Report to the Ministry of Education. Wellington: Ministry of Education.

Black, T., Marshall, P. \& Irwin, K. (2003, May 20) Māori Language Nests in New Zealand: Te Kōhanga Reo, 1982-2003. The Revival of Indigenous Languages: New Zealand and Ecuador's Experience. In the United Nations Permanent Forum on Indigenous Issues. Retrieved 25 October 2007, from http://www.kohanga.ac.nz/docs/UNAddressMay21.pdf

Brockington, D., \& Sullivan, S. (2003). Qualitative research. In R. Scheyvens and D. Storey (Eds.) Development Fieldwork - A practical guide (pp. 57-74). London: Sage.

Cantoni, W. (1986). Legislación indígena y el pueblo Mapuche. Santiago: GIA.

Carleton, H. (1877). The Life of Henry Williams, Archdeacon of Waimate (Vol. II). Auckland: Wilsons and Horton.

Cayul, A. (1990, January). El indigenismo de la Concertación y la Ley 17.729: Una comparación. Revista Liwen, 1.

Chambers, R. (1997). Whose Reality Counts: Putting the First Last. London: Intermediate Technology Publications. 
Chomsky, N. (1975). Reflections of Language. New York: Pantheon Books.

Christian, S. (1986, May 4). Most Chile exiles still keeping their distance. The New York Times, p. A6. Retrieved from ProQuest database 8 June 2006, from http://helicon.vuw.ac.nz:2065/pqdweb?did=954695001\&sid=11\&Fmt=3\&clientId $=7511 \& \mathrm{RQT}=309 \& \mathrm{VName}=\mathrm{PQD}$

Churchill, W. (1998). A Little Matter Of Genocide: Holocaust And Denial In The Americas 1492 To The Present. San Francisco: City Lights Books.

Comité Exterior Mapuche (CEM). (1978, January). Ka Mapu Mapuche Traum: Declaración Mapuche de Londres. Mapuche International Link. Retrieved 10 June 2006, from http://www.mapuche-nation.org/espanol/html/documentos/doc$\underline{01 . h t m}$

CEM. (1985, July 29). Primer documento presentado al Grupo de Trabajo por los Mapuches del exterior. Mapuche International Link. Retrieved 10 June 2006, from http://www.mapuche-nation.org/espanol/html/documentos/doc$\underline{04 . h t m}$

CEM. (1979, April). Comité Exterior Mapuche a la opinion publica. Mapuche International Link. Retrieved 10 June 2006, from http://members.aol.com/MARIQUEO/archivo-e/doc-11.html

Consedine, B., \& Consedine, J. (2001). Healing our history: the challenge of the Treaty of Waitangi. Auckland: Penguin.

Constantino, R. (1978). Neocolonial Identity and Counter Consciousness. London: Merlin Press.

Conway, K. (2003). Case study: health, environment, and indigenous culture: revitalizing Chile's Mapuche community. In The International Development Research Centre, in focus collection. Retrieved 15 September 2006, from http://www.idrc.ca/in_focus/ev-29138-201-1-DO_TOPIC.html

Coña, P. (2002) Lonco Pascual Coñ ñi Tuculpazugun. Testimonio de un Cacique Mapuche ( $7^{\mathrm{a}}$ ed). Santiago: Pehuén.

Cooper, R.L. (1989). Language planning and social change. Cambridge: Cambridge University Press.

Corporación Nacional de Desarrollo Indígena (CONADI). (2006). Leyes y Normativas que rigen el Funcionamiento de la Institución. Retrieved 7 June 2006, from http://www.conadi.cl/mision.htm 
Cowen, M., \& Shenton, R. (1991). The invention of development. In J. Crush, The power of development (pp.28-29). Oxford: Routledge.

Crawford, J. (1996). Seven Hypotheses on Language Loss: Causes and Cures. In G. Cantoni (Ed.), Stabilizing Indigenous Languages (Electronic version). Retrieved September 15, 2006 from http://www.ncela.gwu.edu/pubs/stabilize/iipolicy/hypotheses.htm\#N 2

Creswell, J. (2003). Research Design: Qualitative, Quantitative, and Mixed Methods Approaches. California: Sage Publications.

Crystal, D. (2000). Language Death. Cambridge: University Press.

Cummins, J. (2002). Bilingual Education: Basic principles. In J. Dewaele, A. Housen and W. Li (Eds.), Bilingualism: Beyond basic principles. Clevedon: Multilingual Matters.

Cummins, J., \& Swain, M. (1986). Bilingualism in education: Aspects of theory, research, and practice. London, $\mathrm{NJ}$ : Longman.

De Freine, S. (1965). The Great Silence. Westport, Ireland: Foilseachain Nasisiunta Teoranta.

Dementi-Leonard, B., \& Gilmore, P. (1999). Language revitalization and identity in social context: A community-based Athabascan language preservation project in western interior Alaska. Anthropology \& Education Quarterly, 30(1), 37-55.

Denoon, D. (1983). Settler Capitalism: The Dynamics of Dependent Development in the Southern Hemisphere. Oxford: The Clarendon Press.

Dogan, M., \& Pelassy, D. (1990). How to Compare Nations: Strategies in Comparative Politics $\left(2^{\text {nd }}\right.$ ed). Chatham, New Jersey: House Publishers Inc.

Dorian, N. (1999). Linguistic and ethnographic fieldwork. In J. Fishman (Ed.), Handbook of language and ethnic identity (pp. 25-41). Oxford : Oxford University Press.

Drake, D. (1920). Essays in Critical Realism. New York: Macmillan, 1920.

Dussel, E. (1995). The invention of the Americas: eclipse of 'the other' and the myth of modernity ( $2^{\text {nd }}$ ed.). New York: Continuum International Publishing Group.

Durie, M. (1998). Te Mana Te Kawanatanga: the politics of Maori self-determination. Auckland: Oxford University Press.

Durie, M. (2001). A Framework for Considering Maori Educational Advancement. ' Opening Address. Hui Taumata Matauranga, Turangi. 
Durie, M. (2004). Progress and Platforms for Māori Educational Achievement. Ministry of Education: Hui Taumata Matauranga: Māori Education Summit. Retrieved 1 November 2007, from http://www.minedu.govt.nz/index.cfm?layout=document\&documentid=6491\&ind $\underline{\text { ex }=6606 \& \text { indexparentid }=8734 \text { \#DocTop }}$

Education Counts. (2006). Māori Medium Education: Ministry of Education. Retrieved 10 August 2007, from http://educationcounts.edcentre.govt.nz/datacube/qualityproviders/dsau29.html

Education Review Office (ERO). (2003). Māori students in mainstream schools. Wellington: Education Review Office.

ERO Report. (1999). Education Review Report: Petone Central School 1999. New Zealand.

ERO Report (2002, 10 December). Education Review Report: Petone Central School December 2002. Retrieved 20 November 2006, from http://www.ero.govt.nz/ero/reppub.nsf/0/B56C12AE8B8A6797CC256CAD00168 783/\$File/2955.htm?Open

ERO Report. (2006, 3 August). Education Review Report: Petone Central School August 2006. Retrieved 20 February 2007, from http://www.ero.govt.nz/ero/reppub.nsf/Institution/0821E4A2AA2FB19ACC2571 D20016A806/\$File/2955.htm?OpenElement

Eide, A. (1995). Cultural rights as individual human rights. In Eide et al. (Eds.) Economic, Social and Cultural Rights. A Textbook (pp. 229-240). Dordrecht/Boston/London: Martinus Nijhoff.

Escobar, A. (1994). Encountering Development. New Jersey: Princeton University Press.

Faron, L.C.(1986). The Mapuche Indians of Chile. Prospect Heights, Illinois: Waveland Press.

Feagin, J. R., Orum, A. M., \& Sjoberg, G. (eds.) (1991). A Case for the Case Study. Chapel Hill, NC: The University of North Carolina Press.

Fishman, J. A. (1991). Reversing language shift: Theoretical and empirical foundations of assistance to threatened languages. Clevedon, UK: Multilingual Matters.

Fishman, J. (1995). In G. Cantoni (Ed.) Stabilizing Indigenous Languages. Flagstaff: Center for Excellence in Education, Northern Arizona University 
Foerster, R., \& Vergara, J. (2000, March 13). Los mapuches y la lucha por el reconocimiento en la sociedad chilena. In XII Congreso Internacional. Derecho consuetudinario y pluralismo legal: desafios en el tercer milenio (pp. 191-206). Retrieved 2 June 2006, from http://www.xs4all.nl/ rehue/art/arica.html

Foucault, M. 1969, The archaeology of knowledge and the discourse on language. (A. M. Sheridan Smith, trans.). New York: Pantheon.

Freire, P. (1970). Pedagogy of the Oppressed. New York: Continuum International Publishing Group.

Freire, P. (1985). The politics of education, culture, power, and liberation. (D. Macedo, trans.). South Hadley, Mass.: Bergin and Garvey.

Gasitúa-Marió, E. (2000, August). Indigenous Peoples in Chile Current Situation and Policy Issues. In Poverty and Income Distribution in a High Growth Economy: The Case of Chile 1987-1998, (pp. 170-196). The World Bank. Retrieved 10 June 2007, from http://wbln0018.worldbank.org/LAC/lacinfoclient.nsf/d29684951174975c852567 35007fef12/88f6550e6207292785256af600780da5/\$FILE/BP-7.pdf

Giddens, A. (1989). Sociology. Polity Press, Cambridge: Polity Press.

Giddens, A. (1991). The Consequences of Modernity. Cambridge: Polity Press.

Grin, F., \& Vaillancourt, F. (1998). Language Revitalisation Policy: An Analytical Survey.Theoretical Framework, Policy Experience and Application to Te Reo Māori Report to the Treasury. Wellington, New Zealand.

Gorjestani, N. (2000, November 1). Indigenous Knowledge for Development: Opportunities and Challenges. In Indigenous Knowledge for Development Program from the World Bank. Retrieved 25 June 2007, from http://www.worldbank.org/afr/ik/ikpaper_0102.pdf

Grenier, L. (1998). Working with Indigenous Knowledge. A guide for researchers. International Development Research Centre.

Hairston, M., \& Ruszkiewicz, J.J. (1996). The Scott, Foresman Handbook for Writers (4th ed). New York : HarperCollins College Publishers.

Hamers, J. F., \& Blanc, M. H. A. (1989). Bilinguality and Bilingualism. Cambridge: Cambridge UP.

Harker, R.K, \& McConnochie, K.R. (1985). Education as a Cultural Artifact. Studies in Maori and Aboriginal Education. Palmerston North: Dunmore Press. 
Haugen, E. (1953). The Norwegian Language in American: A Study in Bilingual Behaviour (2 vols). Philadelphia: University of Pennsylvania Press.

Haughney, D. (2006). Neoliberal Economics, Democratic Transition and Mapuche Demands for Rights in Chile. Florida: University Press of Florida.

Havemann, P. (Ed.), (1999). Indigenous Peoples' Rights in Australia, Canada, and New Zealand, Auckland: Oxford University Press.

Held, D., McGrew, A.G., Goldblatt, D., \& Perraton, J. (1999). Global Transformations: Politics, Economics and Culture. Cambridge: Polity Press.

Henderson, J. \& Bellamy, P. (2002). Democracy in New Zealand. Christchurch: Macmillan Brown Centre for Pacific Studies.

Herrera, A. (2005). The Mapuche in Chile and their Struggle for Territorial Rights. Temuco: Universidad de La Frontera, Chile, Instituto de Estudios Indígenas. Retrieved 8 June 2006, from http://www.uwgb.edu/outreach/events/socialjustice/assets/pdfs/herreraMapuche.p $\underline{\mathrm{df}}$

Heylighen, F. (1993, September 1993). Epistemology, Introduction. In F. Heylighen, C. Joslyn and V. Turchin (Eds.) Principia Cybernetica Web. Brussels: Principia Cybernetica. Retrieved 15 November 2007, from http://pespmc1.vub.ac.be/EPISTEMI.html

Horkheimer, M. (1982). Critical Theory. New York: Seabury Press.

Human Rights Documentation Centre (HRDC). (2002, January-March). Pinochet's legacy still haunts Mapuche Chile's century-long policy of discrimination and dispossession endures. Human Rights Features, 2, Article 09. Retrieved 7 June 2006, from http://www.hrdc.net/sahrdc/hrfquarterly/Jan_march_2002/chile.htm

Human Rights Resource Centre (HRRC). (2005). The Mapuche People of South America. Retrieved 10 June 2006, from http://www.hrusa.org/indig/reports/mapuche.pdf

Instituto Nacional de Estadísticas (Chile National Institute of Statistics). (2002). Censo de Población y Vivienda 2002. Retrieved 30 January 2007, from www.ine.cl/23otras/xls/etnia2002.xls

Junta Nacional de Jardines Infantiles (JUNJI). (2006, June 2). Párvulos aprenden Mapudungun. Retrieved 29 September 2007, from http://www.utopia.cl/junji/?navid=m001\&id_mirada $=106$

Kaplan,R., \& Baldauf, R.B. Jr. (1997). Language Planning. From Practice to Theory. Clevedon: Multilingual Matters. 
Keating, C. (1995, April 7). Summary record of the 1394th meeting : New Zealand. United Nations Commission on Human Rights, Fifty-third session. (CCPR/C/SR.1394). Retrieved 1 July 2007, from http://www.unhchr.ch/tbs/doc.nsf/7cec89369c43a6dfc1256a2a0027ba2a/aea1179f 28764591802566510053e3f4?OpenDocument

Kincade, M. D. (1991). The decline of native languages in Canada. In R.H. Robins and E.M. Uhlenbeck (Eds.) Endangered Languages (pp. 157-176). Oxford: Berg Publisher Ltd.

King, M. (2003). The Penguin History of New Zealand. Auckland: Penguin Books.

Kitchin, R., \& Tate, N. (2000). Conducting Research in Human Geography: Theory Methodology and Practice. Harlow: Prentice Hall.

Kramer, R., \& Arellano, C. H. (2006). En la Araucanía. El Padre Sigifredo de Frauenhäusl y el parlamento mapuche de Coz Coz en 1907. Madrid: Iberoamericana; Frankfurt: Vervuert.

Krauss, M. (1992). The world's languages in crisis. Language, 68, 4-10.

Krishnan, V. (1995, July). Modest But Adequate: An Appraisal of Changing Household Income Circumstances in New Zealand. Social Policy Journal of New Zealand, 4.

Lennenberg, E.H. (1967). Biological Foundations of Language. New York: Wiley.

Maaka, R., \& Fleras, A. (2005). The politics of indigeneity: challenging the State in Canada and Aotearoa New Zealand. Dunedin: University of Otago Press.

Macedo, D. (1999). Decolonizing Indigenous Knowledge. In L.M. Semali and J. Kincheloe, J. (Eds.), What is indigenous knowledge? Voices from the Academy (pp. xi-3). USA: Garland Reference Library of Social Science.

Maharey, S. (2006, October 7). Speech to National Hui Taumata Mātauranga. Retrieved 5 July 2007, from http://www.beehive.govt.nz/speech/speech+national+hui+taumata+mtauranga

Māori Dictionary. (2007). Te Aka Māori-English, English-Māori Dictionary (Online Version). Retrieved 10 March 2007, from http://www.maoridictionary.co.nz/index.cfm

Archives New Zealand. (n.d.) Ākona te reo: Māori Language in State Education 1840 1990. Retrieved 1 November 2007 from http://www.archives.govt.nz/exhibitions/pastexhibitions/tereo/1970_eng.php 
Marimán, J. A. (1990, March). The Mapuche issue: State decentralization and regional autonomy. Temuco, Chile: Mapuche International Link. Retrieved 10 November 2006, from http://www.mapuche-nation.org/english/html/articles/art-04.htm\#5\#5

May, S. (1996). Indigenous language rights and education. In J. Lynch et al. (Eds.), Education and development: Tradition and innovation, 1, 149-71. London: Cassell.

McDougall, C. \& Braun, A. (2003). Navigating complexity, diversity and dynamism: reflections on research for natural resource management. In B. Pound, S. Snapp, C. McDougall, and A. Braun (Eds.), Managing natural resources for sustainable livelihoods, uniting science and participation (chap. 2). Retrieved 13 September 2006, from http://www.idrc.ca/ehip/ev-43432-201-1-DO TOPIC.html

McMichael, P. (1990). Incorporating comparison within a world-historical perspective: An alternative comparative method. American Sociological Review, 55, 385-397.

McMichael, P. (2000). Development and Social Change - A Global Perspective. USA, UK, India: Pine Forge Press.

Metge, J. (1995). New Growth from old. Whānau in the modern world. Wellington, University Press.

Ministerio de Planificación y Cooperación (MIDEPLAN). (2006). Memoria Nuevo Trato 2000-2006. Santiago: Subsecretaría de Planificación Coordinación de Políticas y Programas Indígenas.

Moon, P. (2002). Te Ara Ki Te Tiriti. The Path to the Treaty of Waitangi. Auckland: David Ling Publishers.

Mule, L. (1999). Indigenous Languages in the School Curriculum: What Happened to Kiswhahili in Kenya? In L.M. Semali and J.L. Kincheloe (Eds.), What is Indigenous Knowledge? New York and London: Falmer Press.

Murray, W. E. (2006). Geographies of Globalization. London and New York: Routledge.

Murray, W. E., \& Challies, E. R. T. (2004). New Zealand and Chile: Partnership for the Pacific century?. Australian Journal of International Affairs, 58 (1), 89103.

Murray, W. E., \& Overton, J. (2003). Designing development research. In R. Scheyvens and D. Storey (Eds.), Development Fieldwork - A practical guide (pp. 17-35). London: Sage. 
Narayan, D., Patel, R., Rademacher, A., Schafft, T. \& Koch-Schulte, S. (2001). Voices of the Poor: Can anyone hear us?. Oxford: Oxford University Press.

New Zealand Ministry for Culture and Heritage. (2007, 10 July). History of the Maori language: Te Wiki o Te Reo Māori. New Zealand History online. Retrieved 1 October 2007, from http://www.nzhistory.net.nz/culture/tereo-introduction

New Zealand Ministry of Education. (2002). Tertiary Education Strategy 2002/07 Consultation on the strategy two - Te Rautaki Mātauranga Māori. Wellington: Ministry of Education.

New Zealand Ministry of Education. (2007, September 26). Māori Language Programme Resourcing Changes. Retrieved 2 October 2007, from http://www.minedu.govt.nz/index.cfm?layout=document\&documentid=10757\&in $\underline{\text { dexid }=3963 \& \text { indexparentid }=3964}$

New Zealand Mission to the United Nations. (2006). Declaration of the rights of indigenous peoples, 17 May 2006. Retrieved 3 August 2006, from http://www.nzmissionny.org/humanrt.htm\#Indigenous17052006

Nesti, L. (1999, July 15). Indigenous peoples' right to land: international standards and possible developments. The cultural value of land and the link with the protection of the environment. The perspective in the case of Mapuche-Pehuenche.

Padua/Bilbao: University of Padua, Italy/ University of Deusto, Spain: School of Indigenous Studies and Human Rights. Retrieved 8 June 2006, from http://www.xs4all.nl/ rehue/art/nest1.html

Ngugi wa, T. (1986). Decolonizing the mind: The Politics of language in African literature. London: Heinemann.

Office of the United Nations High Commissioner for Human Rights (OHCRH). (2007, September 12). United Nations Declaration on the Rights of Indigenous Peoples. Retrieved 29 September 2007, from http://www.un.org/esa/socdev/unpfii/en/drip.html

Orange, C. (1987). The Treaty of Waitangi. Wellington: Bridget Williams Books.

Organización de Estados Iberoamericanos (OEI). (2006). Educación Inicial Experiencias no escolarizadas. Junta Nacional de Jardines Infantiles. Retrieved 29 September 2007, from http://www.oei.es/inicial/chilene.htm\#8

Organization of American States (OAS). (1998). Intercultural Bilingual Education Programme, Chile. Unit for Social Development, Education and Culture. Retrieved 5 November 2006, from http://www.oas.org/udse/observatorio/english/documentos/ChileProgramonInterc ulturalBilingualEducation.doc 
Pagel, M. (1995). Contribution to the Conservation of Endangered Languages seminar, University of Bristol, 21 April 1995. Iatiku 1.6.

Penelope, J. (1990). Unlearning the Lies of the Fathers' Tongues. New York: Pergamon Press.

Pool, I. (1991). Te iwi Māori: a New Zealand population, past, present \& projected. Auckland: University Press.

Pound, E. (1960). The ABC of reading. New York: Laughlin.

Probst, K., Hagmann, J., Becker, T., \& Fernandez, M. (2000). Developing a Framework for Participatory Research Approaches in Risk Prone Diverse Environments. Deutscher Tropentag, Berlin: University of Hohenheim. Retrieved 5 November 2006, from http://www.unihohenheim.de/atsaf/download/iaks/probst et al pr\%2Bnrm.pdf

Reyhner, J. (Ed.). (1997). Teaching indigenous languages. Flagstaff: Northern Arizona University.

Research New Zealand. (2007). 2006 Survey of the health of the Maori language: Final report. Wellington: Te Puni Kōkiri/Ministry of Māori Development.

Ross, R.M. (1972). Te Tiriti o Waitangi: texts and translations. New Zealand Journal of History, VI(2),129-157.

Ross, W.H. (1966). Te Kooti Rikirangi. Auckland: Collins.

Royal, Te Ahukaramū C. (2007, September 23). Māori urbanisation and Renaissance. In Te Ara, the Encyclopedia of New Zealand. Retrieved 15 October 2007, from http://www.TeAra.govt.nz/NewZealandInBrief/Maori/en

Saavedra, A. (1971). La cuestión Mapuche. Santiago: ICIRA.

Saunders, A. (1896). History of New Zealand 1642-1861 (Vols. 1\& 2). Wellington: Whitcombe \& Tombs Ltd.

Schaeffer, S. (2003). Language development and language revitalisation: An educational imperative in Asia. Retrieved 20 September 2007, from http://www.sil.org/asia/ldc/plenary papers/sheldon_shaeffer.pdf

Scheyvens, R., Nowak, B., \& Scheyvens, H. (2003). Ethical Issues. In R. Scheyvens \& D. Story (Eds.), Development Fieldwork. London: Sage Publications. 
Sen, A. (1990). Development as capability expansion. In Griffin, K. \& Knight, J (Eds.), Human Development and the International Strategy for the 1990s. London: Mcmillan.

Sen. A. (1999). Development as Freedom. Oxford: Oxford University Press.

Shelton H. D., \& Soeftestad, L.T. (1996). Participation and Indigenous People. The World Bank Participation Sourcebook. Retrieved 15 September 2006, from http://www.worldbank.org/wbi/sourcebook/sba212.htm

Simon, J. (Ed.). (1998). Nga kura Māori; the native school system 1867 - 1969. Auckland: Auckland University Press.

Skutnabb-Kangas, T. (1984). Bilingualism or Not-the education of minorities. Clevedon, UK: Multilingual Matters.

Skutnabb-Kangas, T. (2000) Linguistic Genocide in Education-or worldwide diversity and human rights? Manwah, NJ/ London: Lawrence Erlbaum Associates, Inc.

Sorrenson, M.P.K. (1991). Treaties in British Colonial Policy: Precedents for Waitangi. In W. Renwick (Ed.), Sovereignty and Indigenous Rights (pp. 15-29). Wellington: VUW Press.

Stake, R. E. (1995). The Art of Case Study Research. Thousand Oaks, CA: Sage.

Statistics New Zealand (1996). Use of te reo Māori. 1996 Census of Population and Dwellings. Retrieved 20 October 2007, from http://www.stats.govt.nz/analyticalreports/maori/te-reo-maori.htm

Statistics New Zealand. (1999, May). Income distribution in New Zealand. Key Statistics. Retrieved 10 November 2007, from http://www.stats.govt.nz/products-andservices/Articles/income-distrib-May99.htm

Statistics New Zealand (2001). Māori Language and Culture Statistics. 2001 Census of Population and Dwellings. Retrieved 20 October 2007, from http://www.tpk.govt.nz/maori/language/default.asp

Statistics New Zealand. (2007, 27 March). Māori Ethnic Population. 2006 Census of Population and Dwellings. Retrieved 20 October 2007, from http://www.stats.govt.nz/NR/rdonlyres/095030F8-BD62-4745-836D0EF185619C37/0/2006censusquickstatsaboutmaorirevised.pdf

Stavenhagen, R. (1989). Comunidades étnicas en Estados modernos. América Indigena, $X L I X(1), 18$. 
Stavenhagen, R. (1996). Indigenous rights: some conceptual problems. In E. Jelin and E. Hershberg (Eds.), Constructing democracy: human rights, citizenship, and society in Latin America (p. 148). Boulder: Westview Press.

Stavenhagen, R. (2003, November 17). Report of the Special Rapporteur on the situation of human rights and fundamental freedoms of indigenous people, Rodolfo Stavenhagen: Mission to Chile. United Nations Commission on Human Rights, Sixtieth session. (E/CN.4/2004/80/Add.3). Retrieved 15 July 2006, from http://www.iwgia.org/graphics/SynkronLibrary/Documents/InternationalProcesses/UNCHR/Specialrapporteur/Stavenhag enofficialreportChile2003.doc

Stavenhagen, R. (2005, 8 December). International Human Rights and Indigenous Peoples Today. Retrieved from Rothko Chapel collection 15 November 2007, from http://www.rothkochapel.org/Rudolfo\%20Stavenhagen.pdf

Stavenhagen, R. (2006, March 13). Report of the Special Rapporteur on the situation of human rights and fundamental freedoms of indigenous people, Rodolfo Stavenhagen: Mission to New Zealand. United Nations Commission on Human Rights, Sixty-second session (E/CN.4/2006/78/Add.3). Retrieved 15 July 2006, from http://www.iwgia.org/graphics/SynkronLibrary/Documents/InternationalProcesses/Special\%20Rapporteur/SRreportNew Zealand2005.pdf

Stavenhagen, R. (2007, November 15). Report of the Special Rapporteur on the Situation of Human Rights and Fundamental Freedoms of Indigenous People. United Nations Commission on Human Rights (A/HRC/6/15). Retrieved 30 November 2007, from http://www.unhcr.org/cgibin/texis/vtx/refworld/rwmain?docid=475fbd9f2

Stuchlik, M. (1976). Life on a Half Share: Mechanisms of Social Recruitment among the Mapuche of Southern Chile. London: C. Hurst and Co.

Sznadjer, M. (1994, July-December). El Problema Mapuche en Chile. Estudios Interdisciplinarios de América Latina y el Caribe, 5(2). Retrieved 5 October 2006, from http://www.tau.ac.il/eial/V 2/sznajder.htm\#foot4

Tapine, V., \& Waiti, D. (Eds.). (1997). Visions for Māori Education. Wellington: NZCER.

Te Kōhanga Reo. (2003). In the beginning. Te Kōhanga Reo National Trust. Retrieved 20 October 2007, from http://www.kohanga.ac.nz/beginning.html

Te Puni Kōkiri (Ministry of Māori Development. (2006). Fact sheet: Realising the potential. The Māori Language Survey. Wellington, Māori Monitoring Team, Te Puni Kōkiri. 
Toffleson, J.W. (1991). Planning language, planning inequality. London: Longman.

Trudgill, P. (1983). Sociolinguistics: An introduction to language and society (Rev. Ed.). Harmondsworth, Middlesex: Penguin.

Tuhiwai Smith, L. (2001). Decolonizing methodologies: research and indigenous peoples. Dunedin: University of Otago Press.

United Nations Development Programme (UNDP). (2007). Statistics of the Human Development Report. Retrieved 1 November 2007, from http://hdr.undp.org/en/statistics

United Nations Educational Scientific and Cultural Organisation (UNESCO). (1945, November 16). Constitution of the United Nations Educational, Scientific, and Cultural Organization. International Council of Monuments and Sites. Retrieved 2 June 2006, from http://www.icomos.org/unesco/unesco constitution.html

UNESCO. (2001, November 2). UNESCO Universal Declaration on Cultural Diversity. Retrieved 7 June 2006, from http://portal.unesco.org/en/ev.php$\underline{\text { URL_ID }=13179 \& U R L \_D O=D O \_ \text {TOPIC\&URL_SECTION }=201 . \mathrm{html}}$

United Nations Office of the High Commissioner for Human Rights (UNHCHR). (1993). The draft United Nations Declaration on the Rights of Indigenous Peoples. Retrieved 7 June 2006, from http://www.ohchr.org/english/about/publications/docs/indileaflet5.doc

UNHCHR. (1997). Fact Sheet No.9 (Rev.1), The Rights of Indigenous Peoples. Retrieved 2 June 2006, from http://www.unhchr.ch/html/menu6/2/fs $9 . h t m$

UNHCHR. (2006a). Indigenous Peoples and the United Nations System: An overview. Retrieved 7 June 2006, from http://www.ohchr.org/english/about/publications/docs/indileaflet1.doc

UNHCHR. (2006b). UN Charter-based Bodies and Indigenous Peoples. Retrieved 7 June 2006, from http://www.ohchr.org/english/about/publications/docs/indileaflet3.doc

UNHCHR. (2006c). Human Rights Treaty Bodies and Indigenous Peoples. Retrieved 7 June 2006, from http://www.ohchr.org/english/about/publications/docs/indileaflet4.doc

Valdés, M. R. (2006, May 16). Migración Mapuche y no Mapuche. Biodiversitas. Retrieved 1 October 2007, from http://www.prodiversitas.bioetica.org/nota28.htm 
Van Huyssteen, L. (2003). A practical approach to the standardisation and elaboration of Zulu as a technical language. Unpublished dissertation. Pretoria: University of South Africa.

Wai-11. (1986, April). Te reo Māori report: Wai 11 (2nd Ed.). Wellington, New Zealand: GP Publications.

Waitangi Tribunal. (2007, August). Waitangi Tribunal Practice Note: Guide to the practice and procedure of Waitangi Tribunal. Retrieved 15 October 2007, from http://www.waitangitribunal.govt.nz/doclibrary/public/practicenote/FINALGuidet oPractice10August2008.pdf

Walker, R. (1990). Struggle Without End. Ka Whawhai Tonu Matou. New Zealand: Penguin Books.

Walker, R. (1999). Māori Sovereignty, Colonial and Post-colonial Discourses. In P. Havemann (Ed.), Indigenous Peoples' Rights in Australia, Canada and New Zealand (pp. 108-122). Auckland: Oxford University Press.

Ward, A. (1999). An Unsettled History: Treaty Claims in New Zealand Today. Wellington: Bridget Williams Books.

Warren, D. M. (1991). Using indigenous knowledge in agricultural development. Washington D.C.: The World Bank.

Williams, M. (NA). Witi Ihimaera and Patricia Grace: The Maori Renaissance. International Literature. Retrieved 7 June 2007, from http://www.ucalgary.ca/UofC/eduweb/engl392/492/williams.html

Wurm, S. (1991). Language death and disappearance: Causes and circumstances. In Robins, R. H., \& Uhlenbeck, E. (Eds.), Endangered languages (pp. 1-18). Oxford: Berg.

Wurm, S. ( 1998). Methods of language maintenance and revival, with selected cases of language endangerment in the world. In K. Matsumura (Ed.), Studies in endangered languages (pp.191-211). Tokyo: Hituji Syobo.

Zúñiga, F. (2006). Mapudungun: El habla Mapuche.. Santiago: Centro de Estudios Públicos. 
Appendices 


\section{Appendix 1- Key interviews in Chile and Aotearoa New Zealand}

Members of Non-government organisations in Chile involved with indigenous rights and language revitalisation

Miguel Sánchez

Coordinator of Intercultural Bilingual Education of the Institute of Indigenous Studies of the Universidad de la Frontera

Alejandro Herrera

Director of the Institute of Indigenous Studies of the Universidad de la Frontera

Roberto Mansilla

Director of FUNDECAM

José Aylwin

Director of the Observatory of Rights of Indigenous Peoples

Government officials in Chile involved with indigenous language revitalisation schemes

Eliana Huitraqueo

Director of the National Education and Cultural Fund CONADI

Claudio Millacura Salas

MIDEPLAN Coordinator of bilingual intercultural education programmes (PEIB)

Academics and Educators in Chile involved in language revitalisation

Teresa Durán

Anthropologist and Professor at the Universidad Católica

Arturo Hernández

Sociolinguist and Secretary General of the Universidad Catolica

Jorge Pinto Rodríguez

Doctor in History and Professor at the Universidad de La Frontera

Hernán Gutiérrez

Principal Intercultural Technical Secondary School of Guacolda 


\section{Academics and Educators in Chile involved in language revitalisation}

Peter Adds

Head of Māori Studies at Victoria University

Iosua Esera

Principal of Petone Central School

Puhi-Carlotta Campbell

Educator at Petone Central School's Ngā Rito

Te Mako Orzecki

Educator at Petone Central School's Ngā Rito

Paea Rangi

Educator at Petone Central School's Ngā Rito

Lee Flutey

Educator at Petone Central School's Ngā Rito

Shannon Dryden

Educator at Petone Central School's Ngā Rito

Frances Barnsley

Educator at Petone Central School's Ngā Rito 


\section{Appendix 2 - Listing of case studies in Chile and Aotearoa New Zealand}

Immersion Programme Petone Central School

Direct observations during class-time, karakia and general school assembly.

16 Britannia St. Petone

Hutt Valley, New Zealand

Bilingual Intercultural School of Trañi-Trañi

Direct observations and interviews with community members

Attended presentation by Arturo Hernández on importance of revitalisation of Mapudungun to guardians and parents of students attending the school.

Trañi-Trañi, Chile

Intercultural Technical Secondary School Guacolda

Direct observations and interviews with community members

Attended presentation by Arturo Hernández on importance of revitalisation of Mapudungun to educators and staff members of the school.

Chol Chol, Chile

Mapuche community of Juan Puña

Direct observations and interviews with community members

Attended meeting between Mapuche commune of Juan Puña and Alejandro Herrera, Director of the Institute of Indigenous Studies of the Universidad de la Frontera

Galvarino, Chile 


\section{Appendix 3 - Listing of relevant workshops, seminars and conferences attended in Chile and Aotearoa New Zealand}

\section{Workshops attended}

Atribuir a los niños la capacidad de aprender: Cómo conocer y aprovechar el contexto cultural de la enseñanza y del aprendizaje? (Attributing children's learning capacities: How to understand and maximise the cultural context of teaching and learning) Facilitator: Dr. Robert M. Leavitt 16 - 20 October 2006

Universidad de la Frontera

Temuco, Chile

Tikanga Māori Workshop

Facilitator: Doris Kaua

Māori Development Family Planning New Zealand

9 June 2007

Family Planning New Zealand National Office

Wellington, New Zealand

\section{Seminars attended}

Debate: The Big Picture - Where is the Treaty?

Speakers: Hon Justice Edward Taihakurei Durie and Colin James

Panel: Claudia Orange and Richard Boast

8 February 2007

Te Papa Tongarewa, The Museum of New Zealand

Wellington, New Zealand

Event: First International Congress for Indo-American Language and Literature

XII Conference on Mapuche Language and Literature

16 - 20 October 2006

Temuco, Chile

\section{Lectures attended}

Language Death Writing the Obituary of Languages?

Presenter: David Crystal

21 September 2006

Victoria University of Wellington, New Zealand 
The future of language

Presenter: David Crystal

27 September 2006

Victoria University of Wellington, New Zealand

The Treaty of Waitangi

Presenter: Peter Adds

17 July 2006

Victoria University of Wellington, New Zealand

Year 514: Globalisation for whom?

Presenter: Noam Chomsky

Universidad de la Frontera

Temuco, Chile

16 October 2006

Cuál es el destino de las lenguas minoritarias en el mundo? El caso del Maori de Nueva Zelanda. (What is the fate of the world's minority languages? The case of the Mãori in New Zealand.)

Presenter: Lillian González

Universidad de la Frontera

Temuco, Chile

16 October 2006

P. Jerónimo de Amberga (1913): Estado moral, intelectual y económico del Mapuche.

(P. Jerónimo de Amberga (1913): Moral, intellectual and economic status of the

Mapuche).

Universidad de la Frontera

Temuco, Chile

Presenter: Roswitha Kramer

18 October 2006

Mapuche during the first post-occupational period, 1900-1940. (Los mapuches en la primera fase postocupacional 1900-1940).

Presenter: Jorge Pinto Rodríguez

Universidad de la Frontera

Temuco, Chile

19 October 2006

Derechos Humanos: Evolución Histórica y Desafios Actuales. (Human Rights: Historical Evolution and Present Challenges).

Presenter: José Zalaquett Daher

Universidad Católica

Temuco, Chile

20 October 2006 